\title{
The Expression of Periostin in Dental
}

\author{
Pulp Cells
}

By

\section{Robert M. Wiesen Jr. D.D.S}

Dissertation presented to the Endodontics/CRSE Faculty at the University of Michigan submitted in partial fulfillment of the requirements for the degree of Masters of Science in Endodontics Rackham Graduate School 2014

\section{Thesis Committee}

Hector F. Rios, Chair

Tatiana M. Botero

Daniel J. Chiego

Neville J. McDonald 


\title{
Acknowledgements
}

\author{
Thesis Committee
}

Hector F. Rios

Tatiana M. Botero

Daniel J. Chiego

Neville J. McDonald

Special Thanks

Miguel Padial-Molina

Sarah Volk

Marissa Wiesen

Arthur Lamia

$\underline{\text { Research Lab }}$

Miguel Padial-Molina

Sarah Volk

Funding

CRSE Graduate Master's Funding

Delta Dental Foundation 


\section{Table of Contents}

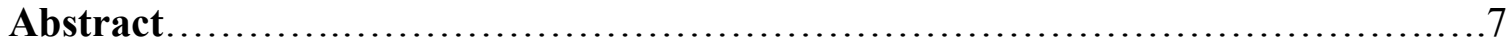

Chapter 1 - Introduction...............................................

Chapter 2 - Materials and Methods.......................................... 17

Chapter 3 - Results.......................................................28

Chapter 4 - Discussion .................................................. 37

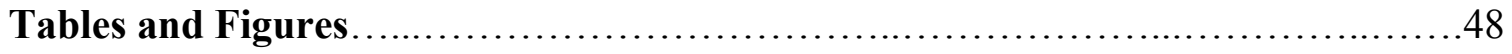




\section{List of Tables and Figures}

Figure 1: Phase contrast image of human dental pulp stem cells (DPSC) at 10x magnification

Figure 2: Phase contrast image of human dental pulp fibroblast cells (DPF) at 10x magnification

Figure 3: Phase contrast image of MDPC-23 odontoblast-like cells at 10x magnification.

Figure 4: TGF- $\beta 1$ Effect on Periostin mRNA in DPSC

Figure 5: Western Blot for Periostin Protein in DPSC

Figure 6: TGF- $\beta 1$ Effect on Periostin Protein in DPSC

Figure 7: TGF- $\beta 1$ Effect on Periostin mRNA in DPF

Figure 8: Western Blot for Periostin Protein in DPF

Figure 9: TGF- $\beta 1$ Effect on Periostin Protein in DPF

Figure 10: TGF- $\beta 1$ Effect on Periostin mRNA in MDPC-23

Figure 11: Western Blot for Periostin Protein in MDPC-23

Figure 12: TGF- $\beta 1$ Effect on Periostin Protein in MDPC-23

Figure 13: TGF- $\beta 1$ Effect on Periostin mRNA in DPSC, DPF, \& MDPC-23

Figure 14: TGF- $\beta 1$ Effect on Periostin Protein (ELISA) in DPSC, DPF, \& MDPC-23

Figure 15: Continuous Biomechanical Stimulation on Periostin mRNA in DPSC

Figure 16: Continuous Biomechanical Stimulation on Periostin Protein in DPSC (ELISA)

Figure 17: Intermittent Biomechanical Stimulation on Periostin mRNA in DPSC

Figure 18: Intermittent Biomechanical Stimulation on Periostin Protein in DPSC (ELISA)

Figure 19: Continuous Biomechanical Stimulation on Periostin mRNA in DPF

Figure 20: Continuous Biomechanical Stimulation on Periostin Protein in DPF (ELISA)

Figure 21: Intermittent Biomechanical Stimulation on Periostin mRNA in DPF

Figure 22: Intermittent Biomechanical Stimulation on Periostin Protein in DPF (ELISA)

Figure 23: Continuous Biomechanical Stimulation on Periostin mRNA in MDPC-23

Figure 24: Continuous Biomechanical Stimulation on Periostin Protein in MDPC-23 (ELISA)

Figure 25: Intermittent Biomechanical Stimulation on Periostin mRNA in MDPC-23

Figure 26: Intermittent Biomechanical Stimulation on Periostin Protein in MDPC-23 (ELISA) 
Figure 27: Continuous Biomechanical Stimulation Effect on Periostin mRNA in DPSC, DPF, \& MDPC-23

Figure 28: Intermittent Biomechanical Stimulation Effect on Periostin mRNA in DPSC, DPF, \& MDPC-23

Figure 29: Western Blot for DPSC, DPF, \& MDPC-23

Figure 30: Biomechanical Stimulation Effect on Periostin Protein in DPSC, DPF, and MDPC-23 (ELISA)

Figure 31: Exogenous Periostin Affect on Total Collagen in DPSC

Figure 32: TGF- $\beta 1$ Affect on Collagen I mRNA in DPSC

Figure 33: Continuous Biomechanical Stimulation Affect on Collagen I mRNA in DPSC

Figure 34: Intermittent Biomechanical Stimulation Affect on Collagen I mRNA in DPSC

Figure 35: Exogenous Periostin Affect on Total Collagen in DPF

Figure 36: TGF- $\beta 1$ Affect on Collagen I mRNA in DPF

Figure 37: Continuous Biomechanical Stimulation Affect on Collagen I mRNA in DPF

Figure 38: Intermittent Biomechanical Stimulation Affect on Collagen I mRNA in DPF

Figure 39: Exogenous Periostin Affect on Total Collagen in MDPC-23

Figure 40: TGF- $\beta 1$ Affect on Collagen I mRNA in MDPC-23

Figure 41: Continuous Biomechanical Stimulation Affect on Collagen I mRNA in MDPC-23

Figure 42: Intermittent Biomechanical Stimulation Affect on Collagen I mRNA in MDPC-23

Figure 43: TGF- $\beta 1$ Affect on Collagen I mRNA in DPSC, DPF \& MDPC-23

Figure 44: Continuous Biomechanical Stimulation Effect on Collagen I mRNA in DPSC, DPF, \& MDPC-23

Figure 45: Intermittent Biomechanical Stimulation Effect on Collagen I mRNA in DPSC, DPF, \& MDPC-23

Box 1: ELISA Mean Values - TGF- $\beta 1$ Effect on Periostin Protein

Box 2: ELISA Mean Values - Biomechanical Stimulation Effect on Periostin Protein

Box 3: Total Collagen Assay Mean Values - Periostin Affect on Total Collagen 


\begin{abstract}
Introduction: The proper regulation of the dentin-pulp complex is intimately related through crucial cell-matrix interactions and important bioactive proteins. The proteins modulating these interactions are highly expressed during development and implicated in tissue repair and regeneration. Within this context, periostin is essential for ECM stability, collagen fibrillogenesis, and tissue healing. Periostin is regulated by TGF- $\beta 1$ in response to biomechanical challenges in the PDL. In the scope of the dental pulp, periostin expression is reported during development and active dentinogenesis, but has yet to be evaluated in dental pulp cells specifically. We hypothesize that periostin is expressed by DPCs in response to TGF- $\beta 1$ and biomechanical stimulation, which has implications in dental pulp tissue healing and regeneration. Aims: 1) To determine if periostin is expressed by DPCs and to analyze the effect in response to TGF- $\beta 1$ 2) To analyze the influence of biomechanical stimulation on the expression of periostin in DPCs, 3) To analyze the influence of periostin on the expression of collagen in DPCs.
\end{abstract} Methods: Human dental pulp stem cells (DPSC), human dental pulp fibroblasts (DPF), and murine odontoblast-like cells (MDPC-23) were treated with different concentrations of TGF- $\beta 1$ or different regimens of biomechanical stimulation to evaluate periostin expression. Cells were also treated with periostin to evaluate the effect on collagen. Western blot and ELISA were used to evaluate protein expression. RNA analysis was performed by qRT-PCR and a Total Collagen Assay was utilized to evaluate collagen. Statistical analysis was performed by Student T-test and ANOVA with Fisher's LSD test. Results: Each cell line expressed periostin protein and mRNA. TGF- $\beta 1$ supplementation resulted in significant changes of periostin expression. Biomechanical stimulation acts to 
induce changes in periostin expression. No statistically significant differences were found in total collagen expression. Conclusions: Expression of periostin was identified in each of the dental pulp cell lines, which can be regulated by TGF- $\beta 1$. DPSC are the most responsive cells to stimulation. Continued research and evaluation is needed to determine the potential therapeutic ability of periostin within the dental pulp. 


\section{Chapter 1 - Introduction}

The term "Regenerative Endodontics" is defined as a "biologically-based procedure designed to physiologically replace damaged tooth structures, including dentin and root structures, as well as the dentin-pulp complex" (1). The success of this procedure varies,

and applying a clinical treatment protocol can be challenging (2). In most cases, this procedure is used to manage immature permanent teeth diagnosed with pulpal necrosis (2). However, current research is leading to a better understanding of the underlying mechanisms of pulpal regeneration and the potential exists to develop a reliable clinical protocol that may lead to a consistently successful outcome. Recently, it has been proposed that progenitor cell lines in combination with extracellular matrix (ECM) bioactive molecules (3), appropriate 3D scaffolds (4, $\underline{5}$ ), and biomaterials (6) can potentially achieve a state of pulpal regeneration $(\underline{1}, \underline{3}, \underline{7}, \underline{8})$.

The structure and properties of the dentin-pulp complex are intimately related through crucial cell-matrix interactions (9). The proper regulation of these interactions determines the adaptive dentin-pulp response by orchestrating the function of important bioactive proteins such as growth factors, cytokines, chemokines, and neuropeptides (9-15). The proteins modulating these interactions are collectively known as matricellular molecules. These molecules act during the repair process by providing a range of signals to the constituent cell populations and modulating their phenotype. These molecules are expressed at different stages of the healing process with chemo-attractive properties that may signal endogenous cells from the pulp proper into the healing zone with the expectation of generating tertiary dentin to seal the injury, allowing for soft tissue remodeling and repair, maintaining the pulp vitality, or promoting regeneration of pulplike tissue (16-20).

In this context, periostin, a matricellular protein has to be considered. Periostin is a 835amino acid secreted protein; located on chromosome 13 in humans at map position 13q13.3 (21). It is a disulfide linked 90-kDa heparin-binding $\mathrm{N}$ terminus-glycosylated protein (21). It was originally named osteoblast-specific factor-2 (OSF-2), because it was discovered in mouse osteoblasts (22), but recently it has been renamed 'periostin' due to 
its heavy localization to periodontal ligament (PDL) fibroblasts and the periosteum of mice during development (23). It has been reported in tissues throughout the human body which include bone, periosteum, skin and heart tissue; as well as being up-regulated in events needing repair, such as in vascular injury, myocardial infarction, muscle injury, epithelial ovarian cancer, colorectal cancer, and pulmonary vascular remodeling (21).

Within the oral cavity, periostin is implicated in the maintenance of proper periodontium function, integrity and tissue strength $(21,24)$. It regulates the structural and functional characteristics of the PDL $(\underline{21}, \underline{24})$ in order to withstand the forces of mastication (25) and is regulated by TGF- $\beta 1(22, \underline{26})$ in response to biomechanical challenges $(\underline{24}, \underline{27})$. Periostin is important for ECM homeostasis, remodeling and repair $(21,24)$ and plays a direct role in controlling tissue healing $(\underline{21}, \underline{24}, \underline{25}, \underline{27})$. It is considered to be an extracellular modulator of cell function via $\alpha_{v} \beta_{3}$ and $\alpha_{v} \beta_{5}$ integrin receptor interactions with growth factors and matrix components such as collagen type $1(\underline{26}, \underline{28})$. These matricellular interactions have been reported to influence cell behavior (28) as well as collagen fibrillogenesis $(\underline{26}, \underline{29}, \underline{30})$.

Although periostin has been identified in numerous tissues throughout the body and localized to the PDL, its identification in the dental pulp has been controversial. Early evidence, using immunohistochemistry sections of mandibles from mice show heavy localized expression of periostin in the PDL only $(\underline{23}, \underline{31})$. However, more recent studies using in situ hybridization of $4 \& 10$-week old mice mandibles show periostin expression throughout the dental pulp, specifically localized at the "pre-odontoblast layer" during tooth development (27). Additionally, periostin expression was recently observed throughout the pulp proper of fully developed molars in mice one day following cavity preparation without pulp exposure using immunohistochemistry sections (32). This experimental model suggests that the mechanical stress of drilling acts in the same way as mechanical stress of mastication in order to induce periostin expression. Interestingly, periostin was identified near the center of the coronal pulp, in proximity to the pulp chamber floor and as magnification was increased periostin localization was observed to be extracellular. Periostin expression peaked at 24 hours but was detected up to 7 days 
following the cavity preparation. However, periostin was not identified in the odontoblast layer, but there was heavy periostin expression throughout the PDL (32).

The dental pulp is an appropriate tissue to investigate periostin expression since it is a loose connective tissue that is highly cellular, vascular and innervated (8). It contains multiple cell populations including odontoblasts, fibroblasts and dental pulp stem cells, as well as immunocompetent cells including dendritic cells, macrophages, lymphocytes, and mast cells (8). The presence of multiple cell populations creates ambiguity as to which, if any of these cells express periostin. Odontoblasts are a specialized post-mitotic cell responsible for the secretion of dentin $(\underline{8}, \underline{9}, \underline{33})$. They line the inner wall of dentin around the periphery of the pulp proper. They have cell bodies that are highly polarized, with odontoblastic processes that extend into predentin and dentinal tubules and are able to secrete collagen, glycoproteins and calcium salts $(\underline{8}, \underline{9})$ prior to mineralization of dentin. Conversely, dental pulp fibroblasts are located throughout the pulp proper and are responsible for the formation and maintenance of the fibrous components and ground substances of the connective tissue (8). Fibroblasts synthesize and secrete elements of the ECM including collagen, elastin, proteoglycans, glycoproteins, cytokines, growth factors and proteinases (8). Fibroblasts are involved in remodeling the connective tissue through degradation of collagen and can synthesize molecules for its replacement ()ㅡ. The main difference in collagen between the cell types is the type of collagen secreted by odontoblasts normally becomes mineralized $(\underline{8}, 9)$. Dental pulp stem cells are adult stem cells localized to the perivascular region and the cell-rich zone near the odontoblastic layer in the pulp proper. These cells are unspecialized with the ability for self-renewal by mitosis while in an undifferentiated state. They are multipotent, have the capacity to continuously divide, and produce progeny cells that can migrate, differentiate and proliferate into a well-differentiated cell line (34). The pulp also contains an ECM, which is a structure-less mass that makes up the bulk of loose connective tissue. It is mainly composed of collagen I, and III, but contains small amounts of collagen V, VII and XII. It also contains other ground substances such as proteoglycan, glycosaminoglycan, noncollagenous protein, hyaluronic acid, chondroitin sulfate and elastic fibers $(\underline{8}, \underline{9})$. The ECM functions in cell-matrix adhesion and signaling, regulates nutrient diffusion, waste 
products, and soluble signaling in order to maintain pulpal homeostasis. The ECM also contains cytokines, growth factors and inflammatory mediators (ㅁ).

The characteristics of the pulp allow for a unique environment as it is enclosed entirely by dentin, which forms the dentin-pulp complex. Specifically, dentin is a calcified connective tissue that is made up of $10 \%$ water, $20 \%$ organic material and $70 \%$ inorganic material $(\underline{9}, \underline{33})$. The inorganic matrix is composed of hydroxyapatite ( 9 ), while the organic material consists of about $90 \%$ collagen, the majority of which is collagen type I, with small traces of collagen type $\mathrm{V}(\underline{9}, \underline{33})$. Collagen fibrils are important to dentinogenesis as they provide an organized scaffold for mineralization (33). The noncollagenous components include dentin phosphoproteins (DPP), dentin matrix protein (DMP1), dentin sialoprotein (DSP), Osteopontin (OPN), Osteocalcin, and bone sialoprotein (BSP), as well as other proteoglycans, Gla proteins, glycoproteins, growth factors and lipids (6). The growth factors included are bone morphogenetic proteins (BMP), insulin-like growth factors (IGF), and transforming growth factor beta (TGF- $\beta$ ). These non-collagenous components and growth factors play a crucial role in dentinogenesis as signaling molecules and regulators of mineralization ( $\underline{8})$.

The primary functions of the dentin-pulp complex are sensory, nutritional, and protective. The dentin-pulp complex is similar to other organs throughout the body, in that it possesses innate and adaptive immunity to defend against acute and/or chronic, physiologic or pathologic challenges. It responds as a defensive organ and is regulated by its ability for pulpal homeostasis and dentinogenesis (). Generally, any irritation or stimulation to the pulp that causes the local release of inflammatory mediators, may result in arteriolar vasodilation, increased capillary hydrostatic pressure, leading to increased tissue pressure and the potential for localized areas of inflammation (35). In a clinical scenario, this sequence of events could be triggered by restorative procedures, dental trauma, uncontrolled orthodontics, para-functional forces, abrasion, or dental caries ( $\underline{36})$. The dental pulp's ability to protect itself is based on the nature and degree of the stress, the severity and proximity to the pulp as well as the amount of force placed on the entire tooth (15). In general, the potential outcomes from such events include repair and 
healing, canal obliteration, or complete pulpal necrosis (36). In the event of repair and healing, the pathologic challenge must be removed and the neurovascular supply must remain intact. This allows for reactionary dentin, a sub-set of tertiary dentin, to be formed (9). It is characterized as a response by the original odontoblasts from a mild to moderate stress $(\underline{8}, \underline{9})$. Specifically, an up-regulation of molecular events, initiated by the stimulatory effects that release growth factors (TGF- $\beta 1, \mathrm{BMP}, \mathrm{FGF})$ from dentin $(20,37$, 38) leads to collagen secretion from existing post-mitotic odontoblasts and subsequent mineralization. Alternatively, reparative dentin may be formed when the pathological challenge to the pulp is harmful enough to cause cell death to the original odontoblasts (20). It is proposed that progenitor cells within the pulp are then signaled to migrate, proliferate and differentiate into odontoblast-like cells at the site of injury leading to reparative dentin formation (20). Lastly, when a pathological challenge is strong enough to cause all cells within the pulp to die, definitive root canal treatment must be performed. Necrosis occurs as a result of unmanageable inflammation leading to irreversible damage of the pulp.

Under normal conditions, the pulp and PDL are maintained by appropriate mechanical loading $(27, \underline{39}, \underline{40})$ regulated by TGF- $\beta 1(22-25,27)$. It is a regulator of cell growth and differentiation, matrix biosynthesis $(\underline{41}, \underline{42})$, acts as a chemo-attractant and promotes dentinogenesis (9). TGF- $\beta 1$ has been implicated in odontoblast differentiation and dentin formation, as well as in the initiation of collagen synthesis (41). TGF- $\beta 1$ is also known to regulate periostin expression and studies have shown there is a dose-dependent increase of periostin mRNA by recombinant TGF- $\beta 1$, in both PDL fibroblasts $(24,43)$ and preodontoblasts in vitro (27). In this context, there was a 3-fold increase of periostin mRNA levels in comparison to the age-matched control mice when stimulated with TGF- $\beta 1$. Furthermore, TGF- $\beta 1$-null mice displayed no apparent tooth phenotype during normal early tooth development. The periostin mRNA level in the TGF- $\beta 1$-null incisor was reduced to $75 \%$ of the age-matched control (27).

Application of biomechanical stimulation through cyclic strain has been used to evaluate dental pulp cells, and how it effects proliferation (44), production of inflammatory 
cytokines and collagen (45). It has also been shown to stimulate odontoblastic differentiation of dental pulp stem cells ( $\underline{40})$. The application of cyclic strain has also been shown to significantly increase periostin expression in PDL cells $(27, \underline{30})$. In PDL cells, periostin mRNA expression is increased by the application of uniaxial cyclic strain and the addition of exogenous TGF- $\beta 1(24,30)$. The effects of biomechanical stimulation on periostin have not been evaluated in dental pulp cells. In general, periostin-null dentin in knockout mice show increased mineralization and decreased pulp space under mechanical loading. Periostin-null dentin maintains integrity of pulp space under loadingfree conditions (27), but mechanical loading of teeth during mastication produce thick secondary dentin, whereas impacted teeth rarely produce secondary dentin (39). Additionally, during periostin-null mice knock out experiments the dentin in the incisor became thicker and the pulp space gradually became narrower under occlusal loading. There was approximately $80 \%$ reduction of pulp space compared with that of the agematched control. The contralateral loaded-free incisor maintained the integrity of the pulp tissue and space. Interestingly, deletion of periostin also lowers the overall non-collagen protein levels and affects the group of small integrin-binding ligand, N-linked glycoproteins (SIBLING) in dentin (27). NCP with the ECM are believed to be essential for initiation and control of mineralization $(\underline{9}, \underline{41}, \underline{46})$. In periostin-null mice, DSP levels were increased, while DMP-1 levels were decreased, suggesting that deletion of periostin leads to dramatic changes of SIBLING protein expression profiles, affecting the mineralization of dentin and further suggesting that periostin plays a role in regulating these proteins $(\underline{27}, \underline{41})$.

Recruitment of appropriate/adequate cells to the area, stabilization of the matrix, and cell proliferation are critical characteristics that influence tissue healing responses and homeostasis. An effect on collagen matrix content and quality translate into altered biomechanical properties and diminish its capacity to respond to stress. Periostin not only influences cell proliferation and migration but has a considerable effect on collagen fibrillogenesis during wound healing with a clear effect on tissue strength $(\underline{29}, \underline{30})$. The extracellular matrix, mainly composed of collagen, serves as a scaffold for cellular organization (29). The matricellular molecules, such as periostin, serve as mediators 
and/or signaling molecules to modulate cell activities. Furthermore, periostin's ability to bind collagen and interact with cell surface integrin receptors $\left(\alpha_{v} \beta_{3}\right.$ and $\left.\alpha_{v} \beta_{5}\right)$ highlights its potential role in different cell functions (29). These properties could enhance its potential role as a mediator of collagen metabolism by different DPC populations relevant in dental pulp homeostasis, repair and regenerative response.

Periostin expression has been reported within the dental pulp at different developmental stages (27) and in response to cavity preparation (32). In this system, it has been proposed to play a role in collagen synthesis, dentinogenesis and the overall integrity of the dental pulp. Collectively this evidence suggests a critical role of periostin, serving as a potential modulator of important tissue and cellular functions, regulated by TGF- $\beta 1$ in response to biomechanical challenges. However, it is currently unknown if periostin's role is exclusive to a specific cell type, its expression is induced as a reaction to biomechanical stimulation to the pulp and what affect this may have on collagen fibrillogenesis within the pulp.

\section{Therefore, our goal is to identify the expression of periostin in different dental pulp cell populations, evaluate its ability to be induced by TGF- $\beta 1$ and biomechanical stimulation and to investigate its effect on collagen synthesis.}

Hypothesis: Dental pulp cells express periostin, which can be induced by TGF- $\beta 1$ and biomechanical stimulation, leading to increased expression of periostin and changes in collagen expression.

Null Hypothesis: Dental pulp cells do not express periostin, nor can periostin expression be induced by TGF- $\beta 1$ or biomechanical stimulation, and does not effect collagen expression or dental pulp healing.

The following specific aims will address the hypothesis:

1) To determine if periostin is expressed by Dental Pulp Cells in vitro and the effect of TGF- $\beta 1$ on its expression 
2) To analyze the influence of biomechanical stimulation on the expression of periostin in different dental pulp cells in vitro

3) To analyze the effects of periostin on collagen expression by different dental pulp cell populations in vitro 


\section{Chapter 2 - Materials and Methods}

\section{General Cell Culture}

All cell types used in this experiment have been well characterized and were donated by Dr. Tatiana Botero (University of Michigan, Ann Arbor, MI, USA). All cell culture tasks were carried out under a laminar flow hood. Human dental pulp stem cells (DPSC, passage 2) as seen in Figure 1 (47); human dental pulp fibroblasts (DPF, passage 2) as seen in Figure 2 (47); and murine MDPC-23 odontoblast-like cells (passage 52) as seen in Figure 3 (48), were stored in recovery cell culture freezing medium (Gibco \#12648010) in liquid nitrogen cryosystem. Cells were thawed in $37^{\circ} \mathrm{C}$ warm water bath and the contents transferred to a T-75 flask (Corning Life Sciences) with $10 \mathrm{ml}$ of Dulbecco's Modified Eagle's (DMEM (High glucose 1x, Gibco \#11995-065)) medium supplemented with heat inactivated $10 \%$ fetal bovine serum (FBS, Gibco \#10082-147), 1\% penicillin/streptomycin $(100 \mathrm{IU} / \mathrm{ml}$ penicillin and $100 \mu \mathrm{g} / \mathrm{ml}$ streptomycin, Gibco \#15140122), and 1:1000 fungizone (Gibco \#15290-018). Cultures were maintained at $37^{\circ} \mathrm{C}$ in a humidified atmosphere of $5 \% \mathrm{CO}_{2}$ and $95 \%$ air. After 24 hours, the media was removed by vacuum pipetting and $10 \mathrm{ml}$ of fresh media was added. All cells were cultured to reach a minimum of $75 \%$ confluence. At which point the media was removed by vacuum pipetting, the cell layer was washed with $5 \mathrm{ml}$ of sterile PBS, and the cells were passed by adding $1 \mathrm{ml}$ of $0.25 \%$ trypsin and $0.05 \%$ EDTA to the flask and incubating for 5 minutes. When the cells were visibly detached and floating in the media, $5 \mathrm{ml}$ of DMEM was added to inactivate the Trypsin-EDTA. The contents of the flask were transferred to a $15 \mathrm{ml}$ conical tube (BD Falcon, San Jose, CA) and centrifuged for 5 minutes at 1500 RPM. The media was removed via vacuum pipetting and the pellet of cells was resuspended in $10 \mathrm{ml}$ of DMEM. Two $5 \mathrm{ml}$ aliquots of re-suspended cells were then placed in two T-75 flasks each containing $10 \mathrm{ml}$ DMEM and incubated at $37^{\circ} \mathrm{C}$ in a humidified atmosphere of $5 \% \mathrm{CO}_{2}$ and $95 \%$ air.

\section{Specific Aim 1: To determine if periostin is expressed by Dental Pulp Cells in vitro and the effect on TGF- $\beta 1$ on its expression}


We analyzed periostin expression levels of DPSC, DPF and MDPC-23 by qRT-PCR, Western blotting and ELISA. DPSC and DPF are primary cell lines and were used between passages 4 and 7, while MDPC-23 cells are an immortalized cell line. Cells were cultured as previously described until a level of $75 \%$ confluence was reached. At which point the media was removed by vacuum pipetting, the cell layer was washed with $5 \mathrm{ml}$ of sterile PBS, and the cells were passed by adding $1 \mathrm{ml}$ of $0.25 \%$ trypsin and $0.05 \%$ EDTA to the flask and incubating for 5 minutes. When the cells were visibly detached and floating in the media, $5 \mathrm{ml}$ of DMEM was added to inactivate the Trypsin-EDTA. The contents of the flask were transferred to a $15 \mathrm{ml}$ conical tube (BD Falcon, San Jose, CA) and centrifuged for 5 minutes at 1500 RPM. The media was removed via vacuum pipetting and the pellet of cells was re-suspended in 10ml of DMEM. A volume of 15ul of re-suspended cells was removed and placed on a Weber hemocytometer (chamber depth $0.1 \mathrm{~mm} \times 1 / 400 \mathrm{~mm}$ ) and counted. Total cell count was made to ensure at least 100,000 cells were placed in $2 \mathrm{ml}$ of DMEM in each well of a 6-well plate and subcultured with media changes every 48 hours to reach $75 \%$ confluence. At which point, cell cultures were divided into groups defined as Group 1: control, cells in DMEM only (no TGF- $\beta 1$ treatment); Group 2: cells treated with $10 \mathrm{ng} / \mathrm{ml}$ TGF- $\beta 1$ at time point 0 and after 24 hours; and Group 3: cells treated with $10 \mathrm{ng} / \mathrm{ml}$ TGF- $\beta 1$ at time point 0 and after 24 hours. All treatment groups had a total volume of $2 \mathrm{ml} \mathrm{DMEM}$ at the start and changed once at 24 hours. Cell collection occurred at 48 hours. We utilized 10ng/ml and 20ng/ml TGF- $\beta 1$ concentrations due to the reports that periostin expression in PDL cells increases with increasing TGF- $\beta 1$ concentration (23). It is also known that odontoblast cells can be stimulated by TGF- $\beta 1$ (38) and all DPCs express TGF- $\beta 1$ (49). A pilot study was completed using $0 \mathrm{ng} / \mathrm{ml}, 5 \mathrm{ng} / \mathrm{ml}, 10 \mathrm{ng} / \mathrm{ml}$, and $20 \mathrm{ng} / \mathrm{ml}$ TGF- $\beta 1$ concentrations (41) to

determine the effects of TGF- $\beta 1$ on periostin expression. No relevant results were identified for the $5 \mathrm{ng} / \mathrm{ml}$ TGF- $\beta 1$ groups, and were eliminated from the experimental design.

\section{RNA Extraction}

RNA isolation was performed using the PureLink® RNA Mini Kit (Invitrogen). Total RNA was isolated from cells by washing the cells twice with $2 \mathrm{ml}$ of PBS, and collected 
in $500 \mathrm{ml}$ lysis buffer (Trizol@) by scraping the cells into $1.5 \mathrm{~mL}$ microcentrifuge tubes. The cells collected in Trizol ${ }^{\circledR}$ were incubated for 5 minutes, followed by addition of $0.1 \mathrm{ml}$ chloroform to each microcentrifuge tube. The tubes were shaken vigorously by hand for 15 seconds and incubated at room temperature for 2-3 minutes. The tubes were then centrifuged at $12,000 \AA \sim \mathrm{g}$ for 15 minutes at $4^{\circ} \mathrm{C}$. After centrifugation, $400 \mu \mathrm{L}$ of the upper colorless aqueous phase (containing RNA) was transferred to a fresh RNase-free tube. At this point an equal volume $70 \%$ ethanol was added and vortexed to obtain a final ethanol concentration of $35 \%$. The tubes were then inverted to disperse any visible precipitate. A volume of $700 \mu \mathrm{L}$ of each sample was then transferred to a spin cartridge and centrifuged at $12,000 \AA \sim \mathrm{g}$ for 15 seconds at room temperature. The flow-through volume was discarded and the spin cartridge was re-inserted into the same collection tube (this was repeated until the entire sample was collected). Next, $350 \mu \mathrm{L}$ wash buffer I was added to the spin cartridge containing the bound RNA. It was centrifuge at 12,000 $\AA \mathrm{g}$ for 15 seconds at room temperature. The flow-through was discarded and the spin cartridge was inserted into a new collection tube. At this point the DNase step was performed by PureLink ${ }^{\circledR}$ DNase treatment protocol. A total volume of $80 \mu \mathrm{L}$ PureLink ${ }^{\circledR}$ DNase mixture (10X DNase I reaction buffer $(8 \mu \mathrm{L})$, re-suspended DNase $(3 \mathrm{U} / \mu \mathrm{L})$ $(10 \mu \mathrm{L})$, RNase-Free water $(62 \mu \mathrm{L})$ was added directly onto the surface of the spin cartridge membrane and incubated at room temperature for 15 minutes. Following this, $350 \mu \mathrm{L}$ wash buffer I was added to the spin cartridge and centrifuged at 12,000 $\AA$ g for 15 seconds at room temperature. The flow-through was discarded and a new collection tube was inserted into the spin cartridge. A volume of $500 \mu \mathrm{L}$ wash buffer II with ethanol was then added to the spin cartridge. It was centrifuged at $12,000 \AA \sim \mathrm{g}$ for 15 seconds at room temperature. The flow-through was discarded and the spin cartridge was reinserted into the same collection tube (repeated once). The spin cartridge was centrifuged at $12,000 \AA \sim \mathrm{g}$ for 1 minute to dry the membrane with bound RNA. The collection tube was discarded and the spin cartridge was inserted into a recovery tube. At this point, $50 \mu \mathrm{L}$ RNase-Free water was added to the center of the spin cartridge and incubated at room temperature for 1 minute. The spin cartridge and recovery tube were centrifuged for 1 minute at $\geq 12,000 \AA \sim \mathrm{g}$ at room temperature. Samples were stored as purified RNA in RNase-Free water in Eppendorf tubes. To measure the purity of RNA, a 1:25 dilution was 
made using $4 \mu \mathrm{L}$ of RNA and $96 \mu \mathrm{L}$ of RNase-Free water, placed in a cuvette compartment and the absorbance ratio of 260/280 was measured using a DU-640 Spectrophotometer (Beckman Coulter). A total of 81 samples were stored in $-80^{\circ} \mathrm{C}$ freezer until further processing.

\section{Reverse Transcription}

In order to perform qRT-PCR, the RNA samples required reverse transcription (RT) to produce complementary DNA (cDNA). Calculations were performed to allow for reverse transcription reactions to be performed on an equivalent amount of mRNA for each sample (1-2ug). A $50 \mu \mathrm{R}$ R reaction with $1.0 \mu \mathrm{g}$ total RNA was performed using Taqman Reverse Transcription Reagents (Applied Biosystems). The RT reaction was composed of a volume of 30.75ul RT Mix (10x Taqman RT Buffer, 25mM MgCl, dNTPs, Hexamers, RNase Inhibitor, Multiscribe RT (50U/ul) plus a volume of $19.25 \mathrm{ul}$ mix RNase-Free water and sample of RNA. The kit included all the necessary components for the transcription process. The thermal condition for RT was $25^{\circ} \mathrm{C}$ for 10 minutes, $48^{\circ} \mathrm{C}$ for 60 minutes and $95^{\circ} \mathrm{C}$ for 5 minutes and kept at $4^{\circ} \mathrm{C}$ until the samples were removed from the machine. Samples were then stored in $-80^{\circ} \mathrm{C}$ freezer until further processing.

\section{Quantitative Real-Time Polymerase Chain Reaction}

A real-time polymerase chain reaction (qRT-PCR) protocol was performed in triplicate on the cDNA samples from each cell line. The qRT-PCR probes for GAPDH, Periostin, and Collagen I were performed on a DNA sequence detector, using 20ng cDNA per reaction. The conditions for PCR were as follows: 2 minutes at $50^{\circ} \mathrm{C}$ and 10 minutes at $95^{\circ} \mathrm{C}$; then, 40 cycles each of 15 seconds at $95^{\circ} \mathrm{C}$ and 1 minute at $60^{\circ} \mathrm{C}$ on optical $96-w e l l$ plates covered with optical film. Each plate contained triplicates of the test cDNA templates and no-template controls for each reaction mix. The $2^{\Delta \Delta \mathrm{Ct}}$ method was used to calculate gene expression levels relative to GAPDH ( $\underline{50})$. The Taqman Gene Expression Assay IDs (human) are as follow: GAPDH - Hs02758991_g1; POSTN Hs01566748_m1; COL1 - Hs00164004_m1. The Taqman Gene Expression Assay IDs (mouse) are as follows: GAPDH - Mm99999915_g1; POSTN - Mm00450111_m1; COL1 - Mm01302043_g1. 


\section{Baseline Messenger RNA Expression}

Baseline expression was evaluated and normalized to the housekeeping gene glyceraldehyde 3-phosphate dehydrogenase (GAPDH) using qRT-PCR with TaqMan primer/probes.

\section{Western Blot}

Periostin protein expression was analyzed by western blot. Protein isolation and analysis was performed following cell collection. Cells were washed twice with $2 \mathrm{ml}$ of PBS, and collected in $1 \mathrm{ml}$ of PBS by scraping vigorously for 2 minutes into $1.5 \mathrm{ml}$ microcentrifuge tubes. Cells/PBS mixture was centrifuged at 3,000rpm for $10 \mathrm{~min}$ at $4^{\circ} \mathrm{C}$ to form a pellet. The PBS was aspirated by vacuum pipette and the cells were re-suspended in lysis buffer (0.1M Tris $\mathrm{pH} 6.8,2 \% \mathrm{SDS}, 1 \%$ ß-mercaptoethanol, 1:100 protease inhibitor cocktail), homogenized in the bullet blender (Next Advance) for 5 minutes, and incubated on ice for 30 minutes. The lysates were centrifuged again $\left(12,000 \mathrm{rpm}\right.$ for 10 minutes at $\left.4^{\circ} \mathrm{C}\right)$ and protein supernatants collected. Total protein concentration was quantified using the micro assay Bradford method and read using the Multiskan Ascent at a wavelength of $595 \mathrm{~nm}$. Calculations for protein concentration were made and $20 \mu \mathrm{g}$ of each sample was added to the appropriate volume of laemmli sample buffer and 2-mercaptoethanol. After the mix was prepared, each sample was boiled at $95^{\circ} \mathrm{C}$ for 5 minutes and electrophoretically resolved using 10\% SDSPAGE gels (100 V, 2 hours), then electroblotted onto polyvinylidene fluoride membranes (PVDF) (90 V, 90 minutes). Membranes were blocked (5\% milk in TBST pH 7.4, 1 hour), and immuno-probed for periostin $(0.25 \mathrm{ug} / \mathrm{ml}$ in $5 \%$ milk, rabbit polyclonal to periostin overnight; 1:4,000 goat anti-rabbit IgG-HRP, 1 hour $)$ and GAPDH $(0.167 \mathrm{ug} / \mathrm{mL}$, in $5 \%$ milk, antihuman/mouse/rat GAPDH overnight; 1:4,000 donkey anti-goat IgG-HRP, 1 hour). Immunopositive bands were detected by enhanced chemiluminescence (ECL) and autoradiography. Positive controls for periostin included recombinant protein and human periodontal ligament cells (hPDL) on passages 4-7, cell culturing was identical to the methods previously described (느). 


\section{ELISA Protein Analysis}

For periostin protein quantification the DuoSet ELISA Development System using sandwich ELISA was utilized to measure natural and recombinant human Periostin/OSF2 for DPSC and DPF (R\&D Systems, DY3548) and mouse Periostin/OSF-2 for MDPC23 (R\&D Systems, DY2955). Cell culturing was completed as previously described. Protein isolation and analysis was performed following cell collection. Cells were washed twice with $2.0 \mathrm{ml}$ PBS, and collected in $1.0 \mathrm{ml}$ PBS by scraping vigorously for 2 minutes into $1.5 \mathrm{ml}$ microcentrifuge tubes. Cells/PBS mixture was centrifuged at 3,000rpm for 10 minutes at $4^{\circ} \mathrm{C}$ to form a pellet. The PBS was aspirated by vacuum pipette and the cells were re-suspended in an ELISA compatible lysis buffer (Invitrogen, FNN0071), homogenized in the bullet blender for 5 minutes, and incubated on ice for 30 minutes. The lysates were centrifuged again $\left(12,000\right.$ RPM for 10 minutes at $\left.4^{\circ} \mathrm{C}\right)$ and protein supernatants collected. Specific concentration parameters for each kit were identified for the human kit (range: 187 - 12,000pg/ml with no sensitivity listed) and the mouse kit (range: 0.156 - 10ng/m with sensitivity: $0.065 \mathrm{ng} / \mathrm{ml}$ ). A 96-well micro-plate was coated with $100 \mu \mathrm{L}$ per well of the diluted capture antibody. The plate was sealed and incubated overnight at room temperature. After 24 hours, each well was aspirated and forcefully washed with $400 \mu \mathrm{L}$ of wash buffer from a squirt bottle; this process was repeated for a total of three washes. Following the last wash, aspirating the plate and blotting it against clean paper towels to remove all remaining wash buffer. Next, $300 \mu \mathrm{L}$ of blocking buffer was added to each well and incubated at room temperature for 1 hour. Following this, the aspiration/wash protocol was repeated. Next, $100 \mu \mathrm{L}$ of each sample or standards in reagent diluent was added to each well. The micro-plate was covered with an adhesive strip and incubated for 2 hours at room temperature. After incubation, the aspiration/wash step was repeated. Next, $100 \mu \mathrm{L}$ of biotinylated detection antibody diluted in reagent diluent was added to each well. The micro-plate was again covered with a new adhesive strip and incubated for 2 hours at room temperature. The aspiration/wash step was repeated. Next, $100 \mu \mathrm{L}$ of the working dilution of Streptavidin-HRP was added to each well. The micro-plate was again covered and incubated for 20 minutes at room temperature out of direct light. The aspiration/wash step was then repeated. Next, $100 \mu \mathrm{L}$ substrate solution was added to each well and incubated for 20 minutes at room 
temperature out of direct light. Finally, $50 \mu \mathrm{L}$ of stop solution was added to each well and the micro-plate was gently tapped to ensure thorough mixing. A micro-plate reader set to $450 \mathrm{~nm}$ was used to determine the optical density of each well immediately after the stop solution was added.

\section{Statistical Analysis}

All statistical analyses were completed with the support of the University of Michigan's Center for Statistical Consultation and Research (CSCAR). All data for aim 1 was analyzed using one-way ANOVA with Fisher's LSD post-hoc pairwise comparison $(\mathrm{P} \leq 0.05)$. A "lower case letter" will denote statistically significant results between compared groups. The analysis was completed using IBM SPSS 21.0 Software (IBM Corp, Armonk, New York, United States). At least three independent trials of each experiment were done in triplicate to verify reproducibility of results. 
Specific Aim 2: To analyze the influence of biomechanical stimulation on the expression of periostin in different dental pulp cells

Analysis of periostin expression levels in DPSC, DPF and MDPC-23 were evaluated by qRT-PCR, Western blot and ELISA. Cells were cultured as previously described until a level of $75 \%$ confluence was reached. Total cell count was made to ensure $\left(1 \times 10^{5}\right.$ cells/well) were placed in $2 \mathrm{ml}$ of DMEM on flexible-bottomed BioFlex ${ }^{\mathrm{TM}}$ Culture Plates coated with Collagen I (Flexcell International Corp.) until they reached 75\% confluence. Media was changed every 48 hours. At which point, cell cultures were subjected to the application of continuous or intermittent biomechanical stimulation. The experimental groups were run independently, each with a static control (no biomechanical stimulation). Cell collection occurred at 48 hours.

Application of continuous biomechanical stimulation: A cyclic mechanical force was applied to the dental pulp cells using the cell culture-loading station Flexcell® FX$5000^{\mathrm{TM}}$ System (Flexcell International Corp., Hillsborough, NC, USA). Fresh media was added every 48 hours. To apply the biomechanical stimulation to the cells, the flexible bottoms of the plates were deformed to $14 \%$ by a computer-operated vacuum system at six cycles/minute (i.e., 5 seconds on and 5 seconds off) for 48 hours. Non-stimulated cells were used as controls $(\underline{24}, \underline{30}, \underline{40})$. Collection for RNA and total protein were at 48 hours after application of the biomechanical stimulation.

Application of intermittent biomechanical stimulation: A cyclic mechanical force was applied as previously described for continuous biomechanical stimulation. The application parameters were modified as follows: stimulation was applied for 8 hours at six cycles/minute (i.e., 5 seconds on and 5 seconds off) and then allowed to rest (no stimulation) for 16 hours. Two total cycles were completed. Non-stimulated cells were used as controls. RNA and total protein were collected at 48 hours after application of the biomechanical stimulation.

\section{RNA Extraction}


Cells were collected and RNA was purified as previously described.

\section{Reverse Transcription}

Messenger RNA was reverse transcribed to cDNA as previously described using the same Taqman mix/probes for GAPDH, Periostin, and Collagen I as previously described.

\section{Quantitative Real-Time Polymerase Chain Reaction}

qRT-PCR was performed as previously described.

\section{Western Blot}

Protein was collected, lysed, and quantified as previously described. Western blot was performed as previously described for continuous biomechanical stimulation only. Antibodies used were the same as previously described. Western blot for intermittent biomechanical stimulation was not performed since this experimental group was added after western blot and ELISA was completed for continuous biomechanical stimulation. Since, periostin protein expression was found for the continuous biomechanical stimulation group, it was determined to utilize an ELISA technique only for the intermittent group.

\section{ELISA Protein Analysis}

ELISA was performed as previously described and the ELISA kits were used according to manufacturer's protocol.

\section{Statistical Analysis for Specific Aim 2}

All statistical analyses were completed with the support of CSCAR. Messenger RNA data was analyzed using a Student's t-test for pairwise comparison between each control and type of biomechanical stimulation (continuous or intermittent) $(\mathrm{P} \leq 0.05)$. ELISA data was analyzed using ANOVA with Fisher's LSD post-hoc test $(\mathrm{P} \leq 0.05)$. A "lower case letter" will denote statistically significant results between compared groups. The analysis was completed using IBM SPSS 21.0 Software (IBM Corp, Armonk, New York, United States). At least three independent trials of each experiment were done in triplicate to 
verify reproducibility of results.

\section{Specific Aim 3: To analyze the effects of periostin on collagen expression by different dental pulp cells}

Total Collagen Assay was used to evaluate collagen expression levels in DPSC, DPF and MDPC-23 odontoblast-like cells. Cells were cultured as previously described until a level of $75 \%$ confluence was reached. Total cell count was made to ensure $\left(1 \times 10^{5}\right.$ cells/well $)$ were place in $2 \mathrm{ml}$ of DMEM in each well of a 6-well plate and sub-cultured with media changes every 48 hours to reach $75 \%$ confluence. At which point, cell cultures were subjected to supplementation with periostin. Group 1: control, cells in DMEM only (no supplementation); Group 2: treated with $50 \mathrm{ng} / \mathrm{ml}$ periostin at time point 0 and $50 \mathrm{ng} / \mathrm{ml}$ periostin at 24 hours; Group 3: treated with $100 \mathrm{ng} / \mathrm{ml}$ periostin at time point 0 and $100 \mathrm{ng} / \mathrm{ml}$ periostin at 24 hours.

\section{Total Collagen Assay}

Cells were washed twice with $2 \mathrm{ml}$ of PBS, and collected in $1 \mathrm{ml}$ of PBS by scraping vigorously for 2 minutes into $1.5 \mathrm{ml}$ microcentrifuge tubes. Cells/PBS mixture was centrifuged at 3,000rpm for 10 minutes at $4^{\circ} \mathrm{C}$ to form a pellet. The PBS was aspirated by vacuum pipette and the cells were re-suspended and diluted 1:1 (100ul/100ul) with 12M $\mathrm{HCl}$ (final concentration 6M HCl). The QuickZyme Total Collagen Kit (QuickZyme Biosciences) was completed according to the manufacturer's protocol. Briefly, tubes were incubated for 20 hours at $95^{\circ} \mathrm{C}$ in a thermoblock. After incubation, tubes were centrifuged for 10 minutes at $13,000 \mathrm{~g}$ and then $35 \mathrm{ul}$ of hydrolyzed samples were pipetted into appropriate wells of a 96-well micro-plate. Next, 75ul of assay buffer was added to each well, the plate was covered and incubated for 20 minutes at room temperature while shaking. A volume of $75 \mathrm{ul}$ detection agent was then added to each well, the plate was sealed and incubated for 60 minutes in a $60^{\circ} \mathrm{C}$ oven. The micro-plate was then cooled on ice to room temperature and the plate was read at $570 \mathrm{~nm}$.

\section{Statistical Analysis for Specific Aim 3}

All statistical analyses were completed with the support of CSCAR. All data was 
analyzed using one-way ANOVA with a Fisher's LSD post-hoc pairwise comparison $(\mathrm{P} \leq 0.05)$. A "lower case letter" will denote statistically significant results between compared groups. The analysis was completed using IBM SPSS 21.0 Software (IBM Corp, Armonk, New York, United States). Two independent trials of each experiment were done in triplicate to verify reproducibility of results. 


\section{Chapter 3 - Results}

\section{Specific Aim 1: To determine if periostin is expressed by Dental Pulp Cells in vitro and the effect of TGF- $\beta 1$ on its expression.}

The results for aim 1 are presented for each cell line.

\section{DPSC}

Periostin mRNA expression was evaluated by qRT-PCR in DPSC for 3 experimental groups which included the control, $10 \mathrm{ng} / \mathrm{ml}$ TGF- $\beta 1$, and $20 \mathrm{ng} / \mathrm{ml}$ TGF- $\beta 1$. All results were normalized to the housekeeping gene GAPDH. Periostin mRNA was evident in each of the 3 experimental groups as seen in Figure 4. There was a statistically significant increase in periostin mRNA expression after exposure to $10 \mathrm{ng} / \mathrm{ml}$ TGF- $\beta 1$ group $(\mathrm{p}<0.018)$ for 48 hours. Where as there was a trend for increased periostin mRNA from the control group to the $20 \mathrm{ng} / \mathrm{ml}$ TGF- $\beta 1$ group ( $\mathrm{p}=0.218$ ), but at lower expression than in the $10 \mathrm{ng} / \mathrm{ml}$ TGF- $\beta 1$ group $(\mathrm{p}=0.116)$.

To demonstrate if DPSC were capable of expressing periostin protein, western blot was performed. Immunopositive bands for periostin were observed at approximately $90 \mathrm{KDa}$. All samples were normalized to the housekeeping protein GAPDH, which showed immunopositive bands at approximately $37 \mathrm{KDa}$. In DPSC, immunopositive bands were evident in the $10 \mathrm{ng} / \mathrm{ml}$ TGF- $\beta 1$ and $20 \mathrm{ng} / \mathrm{ml}$ TGF- $\beta 1$ groups with dose dependent increased expression as compares to the control group as seen in Figure 5.

To further evaluate and quantify periostin protein expression, an ELISA was utilized. Figure 6 shows periostin protein levels in DPSC at control, $10 \mathrm{ng} / \mathrm{ml}$ TGF- $\beta 1$ and $20 \mathrm{ng} / \mathrm{ml}$ TGF- $\beta 1$ groups. Periostin protein expression in DPSC was evident in all 3 groups. There was an overall trend for increased periostin protein expression with increasing concentrations of TGF- $\beta 1$. There was a statistically significant increase in periostin protein from the control to $20 \mathrm{ng} / \mathrm{ml}$ TGF- $\beta 1 \quad(p<0.032)$. There were no statistically significant differences, when comparing the control to $10 \mathrm{ng} / \mathrm{ml}$ TGF- $\beta 1 \quad(\mathrm{p}=0.097)$, or 
comparing the $10 \mathrm{ng} / \mathrm{ml}$ TGF- $\beta 1$ group to the $20 \mathrm{ng} / \mathrm{ml}$ TGF- $\beta 1$ group $(\mathrm{p}=0.247)$.

In summary, DPSC express periostin mRNA and protein and TGF- $\beta 1$ can be used to induce periostin mRNA and protein expression in DPSC.

\section{DPF}

The qRT-PCR for DPF showed periostin mRNA present in each of the 3 experimental groups. There were no statistically significant difference between any of the experimental groups, but there was a trend for increased periostin mRNA expression as the concentration of TGF- $\beta 1$ increased as seen in Figure 7. Comparing periostin mRNA expression from the control group to the $10 \mathrm{ng} / \mathrm{ml}$ TGF- $\beta 1(\mathrm{p}=0.556)$ and $20 \mathrm{ng} / \mathrm{ml}$ TGF$\beta 1(p=0.255)$ showed no statistically significant differences. Comparing 10ng/ml TGF- $\beta 1$ to $20 \mathrm{ng} / \mathrm{ml}$ TGF- $\beta 1$ ( $\mathrm{p}=0.549)$ was not statistically significant.

To demonstrate if DPF were capable of expressing periostin protein western blotting was performed. Immunopositive bands for periostin were evident in the control, $10 \mathrm{ng} / \mathrm{ml}$ TGF- $\beta 1$ and $20 \mathrm{ng} / \mathrm{ml}$ TGF- $\beta 1$ groups. The band intensity was relatively consistent, as seen in Figure 8.

To evaluate and quantify periostin protein expression, an ELISA was utilized. Figure 9 shows periostin protein levels in DPF at control, $10 \mathrm{ng} / \mathrm{ml}$ TGF- $\beta 1$ and $20 \mathrm{ng} / \mathrm{ml} \mathrm{TGF-} \beta 1$ groups. Periostin protein expression in DPF was evident in all 3 groups. There was an overall trend for decreased periostin protein expression with increasing concentrations of TGF- $\beta 1$. There was a statistically significant decrease in periostin protein from the control group to the $10 \mathrm{ng} / \mathrm{ml}$ TGF- $\beta 1$ group $(\mathrm{p}<0.028)$, as well as from the control to $20 \mathrm{ng} / \mathrm{ml}$ TGF- $\beta 1(\mathrm{p}<0.008)$ group. There was not a statistically significant difference, when comparing $10 \mathrm{ng} / \mathrm{ml}$ TGF- $\beta 1$ to the $20 \mathrm{ng} / \mathrm{ml}$ TGF- $\beta 1(\mathrm{p}=0.095)$.

In summary, DPF express periostin mRNA and protein at control levels. TGF- $\beta 1$ can be used to induce DPF to express increased levels of periostin mRNA but decreased levels of periostin protein. 


\section{$\underline{\text { MDPC-23 }}$}

The qRT-PCR for MDPC-23 shows periostin mRNA present in each of the 3 experimental groups as seen in Figure 10. There were statistically significant increases of periostin mRNA from the control group to $10 \mathrm{ng} / \mathrm{ml}$ TGF- $\beta 1(\mathrm{p}<0.003)$ and to $20 \mathrm{ng} / \mathrm{ml}$ TGF- $\beta 1(p<0.01)$. However, there was not a statistically significant difference when comparing $10 \mathrm{ng} / \mathrm{ml}$ TGF- $\beta 1$ to $20 \mathrm{ng} / \mathrm{ml}$ TGF- $\beta 1$ ( $\mathrm{p}=0.158)$.

To demonstrate if MDPC-23 were capable of expressing periostin protein western blot was performed. Immunopositive bands for periostin were evident in the control, $10 \mathrm{ng} / \mathrm{ml}$ TGF- $\beta 1$ and $20 \mathrm{ng} / \mathrm{ml}$ TGF- $\beta 1$ groups. The band intensity was relatively consistent, as seen in Figure 11.

To evaluate and quantify periostin protein expression, an ELISA protocol was utilized. Figure 12 shows periostin protein levels in MDPC-23 at control, 10ng/ml TGF- $\beta 1$ and $20 \mathrm{ng} / \mathrm{ml}$ TGF- $\beta 1$ groups. Periostin protein expression in MDPC-23 was evident in all 3 groups, but at much lower levels than the other 2 cell lines. There was an overall trend for increased periostin protein expression with increasing concentrations of TGF- $\beta 1$. There were no statistically significant differences between the following groups: control to the $10 \mathrm{ng} / \mathrm{ml}$ TGF- $\beta 1(\mathrm{p}<0.452)$ and $20 \mathrm{ng} / \mathrm{ml}$ TGF- $\beta 1(\mathrm{p}<0.067)$, as well as comparing $10 \mathrm{ng} / \mathrm{ml}$ TGF- $\beta 1$ to $20 \mathrm{ng} / \mathrm{ml}$ TGF- $\beta 1$ ( $\mathrm{p}=0.145)$.

In summary, MDPC-23 express periostin mRNA and protein at control levels. TGF- $\beta 1$ can be used to induce MDPC-23 to express increased levels of periostin mRNA and protein.

Figure 13 shows the relative levels of periostin mRNA between the cell lines, but since the experiments were completed independently the statistical analysis was not completed across cell lines. Figure 14 shows the quantification of periostin protein expression from the ELISA protocol, relative to each cell line. Box 1 shows the ELISA mean values for each experimental group. 


\section{Specific Aim 2: To analyze the influence of biomechanical stimulation on the expression of periostin in different dental pulp cells}

The results for aim 2 are presented for each cell line. Messenger RNA data was analyzed using a Student's t-test for pairwise comparison between each control and type of biomechanical stimulation (continuous or intermittent) $(\mathrm{P} \leq 0.05)$. ELISA data was analyzed using ANOVA with Fisher's LSD post-hoc test $(\mathrm{P} \leq 0.05)$.

\section{DPSC}

Periostin mRNA expression was evaluated by qRT-PCR in DPSC for continuous and intermittent biomechanical stimulation, which each had their own static control. All results were normalized to the housekeeping gene GAPDH. Periostin mRNA was evident in each of the experimental groups. There were no statistically significant differences for either experimental group against their own static control. However, there was a trend for increased periostin mRNA expression from the static control to the continuous biomechanical stimulation group $(\mathrm{p}<0.309)$ as seen in Figure 15. There was also a trend for increased periostin mRNA expression from the static control to the intermittent biomechanical stimulation group $(\mathrm{p}<0.064)$ as seen in Figure 17 .

To demonstrate if DPSC express periostin at the protein level, western blotting was performed for the static control and continuous biomechanical stimulation groups only. Immunopositive bands for periostin were observed at approximately $90 \mathrm{KDa}$. All samples were normalized to the housekeeping protein GAPDH, which showed immunopositive bands at approximately $37 \mathrm{KDa}$. Immunopositive bands were evident for the continuous biomechanical stimulated group, but were not clearly visible in the static control group as seen in Figure 29.

To evaluate and quantify periostin protein expression, ELISA was also utilized. Figure 16 shows periostin protein levels in DPSC at static control and in the continuous biomechanical stimulation group $(\mathrm{p}<0.380)$. Figure 18 shows periostin protein levels at 
static control and in the intermittent biomechanical stimulation group $(\mathrm{p}<0.250)$. There was an overall trend for increased periostin protein expression in both of the biomechanical stimulation groups, but there were no statistically significant differences in any of the results.

In summary, DPSC can be induced by biomechanical stimulation to show a trend for increased periostin mRNA and protein expression.

\section{$\underline{\text { DPF }}$}

Periostin mRNA expression was evaluated by qRT-PCR in DPF for continuous and intermittent biomechanical stimulation, which each had their own static control. All results were normalized to the housekeeping gene GAPDH. Periostin mRNA was evident in each of the experimental groups. There were no statistically significant differences for either experimental group against their own static control. However, there was a trend for increased periostin mRNA expression from the static control to the continuous biomechanical stimulation group $(\mathrm{p}<0.223)$ as seen in Figure 19. There was no change periostin mRNA expression from the static control to the intermittent biomechanical stimulation group $(\mathrm{p}<0.776)$ as seen in Figure 21.

To demonstrate if DPF express periostin at the protein level, western blotting was performed. Immunopositive bands were evident in the static control and continuous biomechanical stimulated groups as seen in Figure 29.

To evaluate and quantify periostin protein expression, ELISA was utilized. Figure 20 shows periostin protein levels at the static control and show a trend for decreased periostin in the continuous biomechanical stimulation group $(p<0.078)$. Figure 22 shows periostin protein levels at static control and a trend to increase periostin in the intermittent biomechanical stimulation group $(\mathrm{p}<0.055)$. There were no statistically significant differences in any of the results.

In summary, DPF can be induced by continuous biomechanical stimulation and show a 
trend for increased periostin mRNA, but decreased periostin protein expression. Whereas DPF shows a trend for increased periostin mRNA and protein expression when intermittently stimulated.

\section{MDPC-23}

Periostin mRNA expression was evaluated by qRT-PCR in MDPC-23 for continuous and intermittent biomechanical stimulation, which each had their own static control. All results were normalized to the housekeeping gene GAPDH. Periostin mRNA was evident in each of the experimental groups. There was a statistically significant decrease in periostin mRNA from the static control group to the continuous biomechanical stimulation group $(\mathrm{p}<0.026)$ as seen in Figure 23. However, there was only a trend for decreased periostin expression from the static control to the intermittent biomechanical stimulation group (0.216) as seen in Figure 25.

To demonstrate if MDPC-23 express periostin at the protein level, western blotting was performed. Immunopositive bands were evident in the static control and continuous biomechanically stimulated groups as seen in Figure 29.

To evaluate and quantify periostin protein expression, ELISA was utilized. There was an overall trend for decreased periostin protein expression in both experimental groups against the static control. Figure 24 shows periostin protein levels at static control and in the continuous biomechanical stimulation group $(\mathrm{p}<0.227)$, whereas in Figure 26 the periostin protein levels are present in the static control and in the intermittent biomechanical stimulation group $(\mathrm{p}<0.078)$.

In summary, MDPC-23 can be induced by biomechanical stimulation to decrease periostin mRNA, and likewise show a trend for decreased periostin protein expression in both experimental groups.

Figure 27 shows the relative levels of periostin mRNA between each of the cell lines, but since the experiments were completed independently the statistical analysis was not 
performed. Figure 28 quantifies periostin protein expression from the ELISA technique, showing the relative levels of protein. Box 2 shows the ELISA mean values for each experimental group. Comparing protein levels across experimental groups the control levels of periostin expression are highest in DPF (Figure 30). When the cells are intermittently biomechanically stimulated there is a change in the behavior of DPF cells. The biomechanical stimulation increases the levels of periostin protein instead of decreasing $(\mathrm{p}<0.005)$.

\section{Specific Aim 3: To analyze the effects of periostin on collagen expression by different dental pulp cell populations}

The results for aim 3 are presented for each cell line. All statistical analysis was completed using ANOVA with Fisher's LSD for comparisons ( $\mathrm{P} \leq 0.05)$.

\section{DPSC}

Collagen Type I mRNA expression was evaluated by qRT-PCR in DPSC for the same 3 experimental groups as in aim 1 and the same 2 experimental groups as in aim 2. All results were normalized to the housekeeping gene GAPDH. Collagen type I mRNA was evident in all 5 experimental groups. There were no statistically significant differences, but all results show that collagen type I mRNA expression increased from the control group to the experimental group. Figure 32 shows the affect of TGF- $\beta 1$ on collagen type I mRNA. There was a trend for increase collagen type I mRNA expression from the control group to $10 \mathrm{ng} / \mathrm{ml}$ TGF- $\beta 1$ ( $\mathrm{p}=0.394)$ and $20 \mathrm{ng} / \mathrm{ml}$ TGF- $\beta 1$ ( $\mathrm{p}=0.183)$. Comparing $10 \mathrm{ng} / \mathrm{ml}$ TGF- $\beta 1$ to $20 \mathrm{ng} / \mathrm{ml}$ TGF- $\beta 1$ ( $\mathrm{p}=0.577$ ) shows an upward trend for collagen type I mRNA expression as well. The experimental groups from aim 2 show a trend for increased collagen type I mRNA expression from static control to continuous biomechanical stimulation $(\mathrm{p}=0.380)$ as seen in Figure 33, as well as from static control to intermittent biomechanical stimulation $(\mathrm{p}=0.250)$ as seen in Figure 34 .

To further evaluate collagen expression, a total collagen assay was utilized. The results from the total collagen assay may not be reliable since many of the experimental data 
values were lower than the most diluted standard value. However, the total collagen assay was completed 2 times in triplicate for each sample and the same results occurred. The total collagen mean values are shown in Box 3. Figure 31 shows the mean total collagen levels in the control $(1.66 \mathrm{ug} / \mathrm{ml})$, in the $50 \mathrm{ng} / \mathrm{ml}$ periostin $(1.42 \mathrm{ug} / \mathrm{ml})$ and in the $100 \mathrm{ng} / \mathrm{ml}$ periostin $(1.36 \mathrm{ug} / \mathrm{ml})$ delivery groups. Overall, there was a downward trend in total collagen expression from exogenous delivery of periostin.

\section{DPF}

Collagen Type I mRNA expression was evaluated by qRT-PCR in DPF for the same 3 experimental groups as in aim 1 and the same 2 experimental groups as in aim 2. All results were normalized to the housekeeping gene GAPDH. Collagen type I mRNA was evident in all 5 experimental groups. There was a statistically significant increase in collagen type 1 from control to $20 \mathrm{ng} / \mathrm{ml}$ TGF- $\beta 1$ ( $\mathrm{p}=0.009)$ and from 10ng/ml TGF- $\beta 1$ to $20 \mathrm{ng} / \mathrm{ml}$ TGF- $\beta 1 \quad(\mathrm{p}=0.027)$ as seen in Figure 36 . There was a trend for increased collagen type I mRNA expression from control to $10 \mathrm{ng} / \mathrm{ml}$ TGF- $\beta 1$ ( $\mathrm{p}<0.383$ ). There were no statistically significant differences in collagen type I expression for aim 2, but collagen type I mRNA expression showed a trend for decreased expression in both biomechanically stimulated groups. Comparing the experimental groups from aim 2, there was a trend for decreased collagen mRNA expression from static control to continuous biomechanical stimulation $(\mathrm{p}=0.660)$ as seen in Figure 37, as well as from static control to intermittent biomechanical stimulation $(\mathrm{p}=0.391)$ as seen in Figure 38 .

To further evaluate collagen expression, a total collagen assay was utilized. The results from the total collagen assay may not be reliable since many of the experimental data values were lower than the most diluted standard value. However, the total collagen assay was completed 2 times in triplicate for each sample and the same results occurred. Figure 35 shows the mean total collagen levels in the control $(1.74 \mathrm{ug} / \mathrm{ml})$, in the $50 \mathrm{ng} / \mathrm{ml}$ periostin $(2.27 \mathrm{ug} / \mathrm{ml})$ and in the $100 \mathrm{ng} / \mathrm{ml}$ periostin $(1.41 \mathrm{ug} / \mathrm{ml})$ groups. There was no change in total collagen expression with increasing concentrations of exogenous periostin delivery. 


\section{MDPC-23}

Collagen Type I mRNA expression was evaluated by qRT-PCR in MDPC-23 for the same 3 experimental groups as in aim 1 and the same 2 experimental groups as in aim 2 . All results were normalized to the housekeeping gene GAPDH. Collagen type I mRNA was evident in all 5 experimental groups. There were no statistically significant differences in any of the experimental groups. In aim 1, control levels to $10 \mathrm{ng} / \mathrm{ml}$ TGF$\beta 1(p=0.154)$ and $20 \mathrm{ng} / \mathrm{ml}$ TGF- $\beta 1(\mathrm{p}=0.177)$ showed trends for increased collagen type I mRNA expression as seen in Figure 40. Comparing 10ng/ml TGF- $\beta 1$ to 20ng/ml TGF- $\beta 1$ $(\mathrm{p}=0.922)$ shows almost no change in collagen type I mRNA expression. Comparing the experimental groups in aim 2 show a trend for decreased collagen type I mRNA expression from static control to the continuous biomechanical stimulation $(\mathrm{p}=0.103)$ as seen in Figure 41, and show a trend for increased collagen type I mRNA expression from static control to intermittent biomechanical stimulation $(\mathrm{p}=0.178)$ as seen in Figure 42.

To further evaluate collagen expression, a total collagen assay was utilized. The results from the total collagen assay may not be reliable since many of the experimental data values were lower than the most diluted standard value. However, the total collagen assay was completed 2 times in triplicate for each sample and the same results occurred. Figure 39 shows the mean total collagen levels in the control $(1.14 \mathrm{ug} / \mathrm{ml})$, in the $50 \mathrm{ng} / \mathrm{ml}$ periostin $(1.72 \mathrm{ug} / \mathrm{ml})$ and in the $100 \mathrm{ng} / \mathrm{ml}$ periostin $(2.71 \mathrm{ug} / \mathrm{ml})$ groups. There was an overall trend for increased total collagen expression with increasing concentrations of exogenous periostin delivery.

Figure 43 represents the effect of TGF- $\beta 1$ on collagen type I mRNA, with relative levels across cell lines. Figure 44, shows the effect from continuous biomechanical stimulation on collagen type I mRNA and Figure 45 shows the effect from intermittent biomechanical stimulation on collagen type I mRNA across all each cell line. 


\section{Chapter 4 - Discussion}

The potential exists to create a clinical protocol in order to achieve a state of dental pulp regeneration. The practicality of this treatment approach would allow for the continued development of the entire tooth through soft and hard tissue formation, but could also lead to possible solutions for artificial tooth implantation. The difficulty lies in correctly identifying the sequence of events that must occur, as well as the appropriate constituents that are needed. There have been different mature and progenitor cell lines studied, as well as unique ECM bioactive molecules (3), 3D scaffolds (ㅁ, $\underline{5})$, and biomaterials ( $(\underline{6})$. However, for the first time, the bioactive molecule, periostin, was explored as to how it relates to the dentin-pulp complex. Historically, there has been ambiguous localization of periostin within dental pulp tissue, and only accurately identified in the periodontal ligament $(22, \underline{23}, \underline{27}, \underline{31})$, as well as other load bearing tissues throughout the body (21). Even though periostin has been acknowledged in the pulp proper, previous studies have lacked to identify which specific cell types are responsible for its expression.

In this study, we set out to identify the dental pulp cell populations responsible for the expression of periostin and suggest a potential role for its expression. Our experimental design allowed for the in vitro investigation of 3 cell types, which are located in the dental pulp. DPSC, DPF, and MDPC-23 odontoblast-like cells were used since these cells compromise the majority of cells present in the heterogenic population of the dental pulp. We first examined the capacity of each cell line's ability to express periostin mRNA and protein at control levels and compared those results to periostin mRNA and protein expression after the cells were treated with different concentrations of TGF- $\beta 1$. We observed that DPSC, DPF, and MDPC-23 cells each express periostin mRNA at control levels and observed significant differences in periostin mRNA in DPSC and MDPC-23 after TGF- $\beta 1$ treatment. Periostin protein expression in DPSC also showed significant increases after TGF- $\beta 1$ treatment, and the western blot supports this by showing an increase in immunopositive band intensity from the control to the TGF- $\beta 1$ treatment groups. In DPF there were no significant differences in periostin mRNA expression, but the ELISA data showed a significant decrease in periostin protein expression in the TGF- 
$\beta 1$ treatment groups. The MDPC-23 cells also showed periostin protein expression at control levels and significant differences when treated with TGF- $\beta 1$, but overall, at much lower levels compared to the DPSC and DPF.

Periostin mRNA and protein were identified in the control groups of DPF and MDPC-23 cells, but the DPSC only expressed periostin after TGF- $\beta 1$ treatment. The DPF and MDPC-23 cell lines are both well characterized and are terminally differentiated cells, whereas DPSC are adult stem cells with the ability to differentiate into cells of odontogenic, osteogenic, adipogenic or chondrogenic pathways (34). It was previously thought that periostin was only expressed during tooth development $(23,27,31)$ and was not expressed in the mature pulp. Our results indicate that DPF and MDPC-23 cells have the capacity to express periostin without any stimulation, whereas DPSC shows induction potential by stimulation with TGF- $\beta 1$ in order to express periostin. Our results also show that the mean values for periostin protein quantification in MDPC-23 were extremely low, compared to DPSC or DPF. Recently, periostin was identified in the pulp proper after mechanical drilling with peak expression at 24 hours, and visibility up to 7 days (32). These results suggested that dental pulp cells express periostin, but did not specify the exact cell type. This leads us to speculate that either DPF cells were stimulated to express periostin, or DPSC were activated, allowed to differentiate and then expressed periostin. Expression was not evident in the odontoblast zone (32). The mechanical drilling model supports our findings, since TGF- $\beta 1$ is expressed as a result from stress to the dental pulp. TGF- $\beta 1$ may also be released during carious demineralization of the dentin matrix and be come available in the mediation of dental repair processes $(\underline{38}, \underline{51})$. Its main function is to regulate cell growth and differentiation $(38, \underline{41)}$. TGF- $\beta 1$ usually has stimulatory effects for cells of mesenchymal origin and inhibitory effects for cells of epithelial or neuroectoderm origin (52). DPSC, DPF and MDPC-23 are all of mesenchymal origin and therefore should have stimulatory effects if the treatment concentrations are appropriate.

In aim 2 of this experiment, each cell line was biomechanically stimulated in either a continuous or intermittent pattern. The continuous group underwent 48 straight hours of 
$14 \%$ strain in 6 cycles per minute using the Flexcell ${ }^{\circledR}$ FX-5000 ${ }^{\mathrm{TM}}$ System. Whereas, the intermittent group was stimulated under the same conditions for 8 hours, allowed to rest for 16 hours, then stimulated for an additional 8 hours and allowed to rest for 16 more hours before collection at 48 hours. The experimental parameters were designed to incorporate ideal conditions for periostin expression in hPDL cells (53), as well as being a suitable stimulus to DPC $(\underline{40}, \underline{44}, \underline{45})$ Biomechanical stimulation has been shown to regulate the expression of periostin and ECM incorporation via TGF- $\beta 1$ modulation (24, $25,27)$, as well as playing an important role in regulating the function of mesenchymal stem cells (54). The type of mechanical stress to dental pulp may vary, but includes fluid shear stress, compression, hydrostatic pressure, and uniaxial vertical and horizontal stretching (55). There are conditions where the dental pulp is stretched vertically, such as during tooth eruption and in orthodontic forces. These forces can also transfer horizontal stretch to DPSCs and PDL tissues (56). Previous studies have also suggested that the mechanical stress of drilling acts in the same way as mechanical stress of mastication to induce periostin expression (32). Continuous biomechanical stimulation was an attempt to mimic clinically relevant situations such as chronic dental trauma, uncontrolled orthodontic movements, iatrogenic trauma and chronic para-functional forces. The intermittent biomechanical stimulation was designed to mimic the nocturnal parafunctional forces of chronic bruxism. Since, biomechanical stimulation is modulated via TGF- $\beta 1$ and we wanted to relate the effects of biomechanical stimulation to that of exogenous TGF- $\beta 1$ delivery. The results from aim 2 show similar trends in periostin mRNA and protein expression, for each cell line, as in aim 1. There were no significant differences in the DPSC, but both periostin mRNA and protein showed trends for increased expression. The DPF cells showed similar results as when treated with TGF- $\beta 1$, but none of the differences were statistically significant. There were trends for increased periostin mRNA in both biomechanical groups and increased periostin protein in the intermittent group. However, there was a trend for decreased periostin protein in the continuous group. The periostin mRNA and protein levels in MDPC-23 cells show an overall trend for decreased periostin expression in both types of biomechanical stimulation. The only statistically significant result was a decrease in periostin mRNA from the static control to continuous biomechanical stimulation group. 
Biomechanical stimulation activates several intracellular signaling pathways through mechanoreceptors $(56,57)$, thus leading to activation of cells. Studies have shown that mechanical stress can regulate the differentiation of DPSC into odontoblasts (40), while other studies claim mechanical stress has no effect on differentiation of DPSC (58). Our results suggest that biomechanical stimulation may be used to induce expression of periostin mRNA and protein. Further evaluation is needed, and potential changes to the experimental parameters may be warranted. The parameters for biomechanical stimulation were $14 \%$ strain in 6 cycles per minute (24). Other investigators have used DPCs subjected to $6 \%, 12 \%$, or $15 \%$ strain in 6 cycles per minute for $3-48$ hours and showed that mechanical stress could stimulate DPCs (45). However, cyclic strain can also cause cellular damage and studies have shown that when $15 \%$ cyclic strain is applied it may lead to cell death (45). Others have shown that a maximum of $15 \%$ cyclic strain in 6 cycles per minute mimics physiological occlusal loading or the effects of moderate orthodontic force inducing stress across a PDL with $40 \mathrm{kPa}$. They found that mechanical stress up-regulates the mRNA levels of encoding key markers for differentiation of DPC to odontoblasts (BSP, OPN, DSPP, DMP-1) (40).

The final aim of this experiment was to identify periostin's affect on collagen. The experimental model included treating each cell line with different concentrations of periostin for 48 hours. Collagen fibrillogenesis is a complex, highly regulated, multistep process involving many proteins. Collagen is the main structural component of the ECM and stabilizes the dental pulp, as well as being the precursor to dentinogenesis. Periostin is co-localized and directly binds to Collagen Type I (29). Therefore if periostin is expressed in the dental pulp, identifying which cells express it will give us clues as to how it affects collagen synthesis and ultimately repair and regeneration. In general, we observed no statistically significant differences in total collagen expression. There were trends for decreased total collagen expression in DPSC, no change in DPF, and increased collagen expression in MDPC-23. TGF- $\beta 1$ has similar mRNA expression patterns as Collagen Type I, and when odontoblasts express TGF- $\beta 1$ it is sequestered within the pulpal ECM where it can participate in repair and homeostasis after pulp injury $(\underline{37}, \underline{41})$. 
TGF- $\beta 1$ has been shown to be an active component of the dental ECM associated with regulation of cell growth, differentiation and matrix biosynthesis (59). Therefore we also evaluated collagen type I after each of the experimental parameters in aim 1 and 2 . Collagen Type I mRNA showed trends for increased expression from static control, after treatment with different concentrations of TGF- $\beta 1$, or when biomechanically stimulated in DPSC. The DPF cells showed a statistically significant increase in collagen type I mRNA after treatment with different concentrations of TGF- $\beta 1$, but showed trends for decreased collagen type I mRNA expression when biomechanically stimulated. The MDPC-23 cells showed a trend for increased collagen type I mRNA after treatment with different concentrations of TGF- $\beta 1$ and intermittent biomechanical stimulation, but a trend for decreased collagen type I after continuous biomechanical stimulation. There were differences in the result from qRT-PCR probing for Collagen Type I and the total collagen assay. It is possible that the total collagen assay is not sensitive enough to identify specific collagen, therefore not showing a difference in active collagen fibrillogenesis. The total collage assay identifies all collagen, including degraded collagen and immature collagen. Additionally, exogenous periostin delivery to the cells, actually have no effect on influencing or activating its expression potential of collagen.

Overall, DPSC are very responsive to TGF- $\beta 1$ and have the ability to induce periostin expression. Interestingly, the western blot data does not show immunopositive bands for the control group in aim 1. In this group, there is no stimulus, so cells may still be in an undifferentiated state and lack the ability to express periostin protein. Whereas, when DPSC are treated with TGF- $\beta 1$, the cell may be activated and differentiate into a mature cell type that is capable of expressing periostin. DPSC are readily induced to express periostin by TGF- $\beta 1$. The question remains what cell type has the DPSC differentiated into, since they have the ability to differentiate into cells of odontogenic, osteogenic, adipogenic or chondrogenic pathways (34), Unfortunately, we were not able to identify this cell type and there is no way to verify this since no additional evaluations were completed. In an active state of differentiation the cells would have to under go 1 full cell cycle, which is about 12-16 hours to complete. This would allow enough time for maturation of the cellular processes, stimulation to have an affect, and periostin to be 
expressed at the 48-hour collection. However, if the confluence levels during cell culture have already caused differentiation of the DPSC, we may observe that periostin expression would be completely dependent on TGF- $\beta 1$ concentration and activation of the cells. TGF- $\beta 1$ mRNA has been expressed by preodontoblasts and odontoblasts, and is also implicated in odontoblast differentiation and dentin formation (41). Therefore, these cells could be influenced to take an odontogenic differentiation pathway. (41). Other studies have suggested DPSCs physiologically receive mechanical stress by mastication and swallowing, thus our results suggest that mechanical stretch may have an essential role in the maintenance of DPSCs through increasing the proliferation, while suppressing osteogenic differentiation (44). The total collagen assay showed little change in collagen expression of DPSC after exogenous periostin delivery. This is an interesting finding, since DPSC have been a very responsive cell. It is possible that periostin does not regulate or activate DPSC to differentiate, and therefore collagen expression is unchanged or even decreased. These cells are not being stimulated or induced, and therefore in a stable state, so there is no need for ECM stabilization or collagen formation. It would be interesting to see how the cells would respond to biomechanical stimulation and then exogenous periostin delivery.

In general, DPF show similar results comparing aim 1 to aim 2. There is a general trend for increased periostin mRNA, and decreased periostin protein, except when observing the intermittent biomechanical stimulation group for periostin protein which shows increased expression. There is much speculation as to why there would be increases in mRNA and decreases in protein for both aim 1 and 2. There are several possible explanations for this observation. One possibility is that there is a problem posttranslational, not allowing periostin protein to be transcribed. Another possibility is that 48 hours may be too long of an evaluation period to assess periostin protein expression. If the pulp proper expresses periostin that peaks at 24 hours following stimulation (32), we can speculate that these cells may have expressed more periostin at 24 hours in order to achieve homeostasis, and then periostin expression decreased as time went on. There is no doubt that DPF express periostin, as is evident in the control, but the cells may be extremely sensitive to TGF- $\beta 1$ concentrations or biomechanical stimulation. The TGF- $\beta 1$ 
concentrations and the parameters for $14 \%$ strain for a total of 48 hours may be too long to stimulate these cells and may be causing damage to the cells. These stimulations to DPF may initially be stimulatory as the cells react, but may change to inhibitory after some time. By overloading DPF with TGF- $\beta 1$ it may inhibit and down regulate any periostin expression and the homeostatic effects of periostin. These effects may only affect periostin post-translational, inhibiting its transcription into protein, and inhibiting its secretion extracellular. As TGF- $\beta 1$ stimulated DPSC to migrate, differentiate and proliferate, it may also act to inhibit DPF, allowing the progenitor cells to be activated. Interestingly, when the DPF are intermittently biomechanically stimulated, there are no changes in periostin mRNA, but a trend for increased periostin protein. The intermittent stimulation, may allow the DPF cells to rest and rebound, in order for intracellular processes to take place and lead to the expression of periostin protein. The affects on total collagen following exogenous periostin delivery to DPF show no change in total collagen. The qRT-PCR data from aim 1 shows that collagen type I is significantly upregulated following increasing concentrations with TGF- $\beta 1$, however, collagen type I is down-regulated following biomechanical stimulation in both groups.

The MDPC-23 shows periostin protein expression is at much lower levels than the DPSC and DPF at control, after treatment from TGF- $\beta 1$ and biomechanical stimulation. These results suggest that MDPC-23 has the ability to express periostin at controls levels, and those levels can be influenced when stimulated. However, the levels of periostin expression may be at insignificant levels and may not have a clinical application. The MDPC-23 cells are odontoblast-like cells and are a terminally differentiated cell line. Odontoblasts typically have a more specialized function than the other 2 cell lines in this study. The primary function of odontoblasts, regulated by TGF- $\beta 1$, is dentinogenesis. TGF- $\beta 1$ has been shown to induce secretion of dentin extracellular matrix components associated with primary dentinogenesis and to play a role in tertiary or reparative dentinogenesis (41). This process includes the synthesis of procollagen fibrils in the odontoblasts' cell bodies, where it aggregates and increases its fibril diameter. The procollagen then migrates through the predentin where is will undergo mineralization at the mineralization front. This procollagen matures during this migration and will be 
mineralized there after and incorporated into dentin as tertiary dentin. The majority of collagen biosynthesis takes about 2 hours to reach the predentin (33). Simulations to MDPC-23 cells react by initiating dentinogenesis and not by regulating ECM stability or soft tissue homeostasis. Recent experiments show that during cavity preparation, periostin expression is identified in the pulp proper, but not in the odontoblast layer (32). This supports our results, and suggests that even though odontoblasts possess the ability to express periostin, the in vivo application may be inappropriate since odontoblast extracellular secretions are into pre-dentin that ultimately become mineralized. The role of periostin to control ECM stability and soft tissue homeostasis during stress may be regulated through the expression of a different cell type. Biomechanical stimulation to the MDPC-23 cells resulted in down-regulation of periostin expression. It is possible that under the influence of mechanical stress, odontoblasts do not express periostin, since they function to in hard tissue stabilization. Another explanation is that the biomechanical stimulation was too strong and caused the MDPC-23 cells to die. The exogenous periostin delivery model shows a trend for increased total collagen expression. This result is in line, since periostin is closely related to collagen production and MDPC-23 cells primary function is to make collagen as a pre-cursor to mineralization. The influence of TGF- $\beta 1$ to increase collagen type I mRNA is supported since; TGF- $\beta 1$ is a known regulator of dentinogenesis as well.

\section{Proposed Hypothesis}

We hypothesize that biomechanical stimulation of the dental pulp causes localized inflammation leading to the release of local mediators, such as TGF- $\beta 1$. This growth factor regulates intracellular and extracellular pathways of dental pulp cells. Periostin is expressed by dental pulp fibroblasts throughout the pulp to stabilize the ECM and maintain pulpal homeostasis. TGF- $\beta 1$ also aids in migration, differentiation and proliferation of progenitor cells to the area of repair, which also express periostin for ECM stabilization prior to collagen formation. Biomechanical stimulation may also activate existing odontoblast cells to express periostin at low levels prior to collagen formation. Periostin will bind to the collagen fibers in the ECM to increase tissue strength and structural stability. It is suggested that periostin expression regulates soft tissue 
stabilization, and if periostin is down regulated it leads to increased mineralization of the pulp space (32). Therefore, this may further confirm that periostin expression by DPSC and DPF stabilizes soft tissue formation during the healing phase and prevents soft tissue mineralization from occurring. Therefore, periostin's role is extremely important in maintaining the pulp's homeostasis and structural stability through supporting a competent collagen fibrillar system and avoiding complete pulp mineralization due to biomechanical forces.

It is speculated that mineralization of dental pulp tissue is feasible, but resisted by a negative regulation system. The expression of periostin has been shown to be upregulated by cavity preparation, suggesting that the mechanical stress of drilling acts in the same manner as other mechanical stressors such as mastication as to induce periostin expression (32). Periostin expression was distributed throughout the pulp tissue, and seemed to localize between cells rather than inside them. Suggesting that periostin is secreted from dental pulp cells and stored in the ECM. Periostin expression is highly up regulated during early events of repair in several tissues. Whereas, when faced with particularly intense stimuli, such as replantation, this mechanism fails to keep the structure of dental pulp tissue intact, leading to canal space obliteration ( $\underline{60})$. After mastication, the incisors of periostin-null mice show massive increase in dentin formation and reduction in pulp space compared to age-matched controls. It has also been shown that over expression of TGF- $\beta 1$ has a significant reduction in tooth mineralization and defective dentin formation ( $\underline{61})$. Findings in developing mouse mandibles have suggested that periostin serves as adhesive equipment at the sites of cell-to matrix interaction and aids against potentially harmful mechanical forces that include occlusal forces and tooth eruption $(\underline{31})$.

\section{Limitations and Future Directions}

The findings derived from this study contribute to the ongoing effort of describing the basic elements involved in pulpal pathogenesis. Current clinical reality reflects the lack of a comprehensive understanding of the molecular and cellular events that lead to pulp disease, often times limiting treatment only when symptoms appear and normal tissue 
function is altered or lost. Insights into pulpal pathogenesis incorporate gene, protein, and metabolite data into dynamic biologic networks that include disease-initiating and progression mechanisms. New evidence is emerging that periostin may play a greater role in regulating pulpal homeostasis and preventing complete mineralization of the pulp space $(32,41)$. Ultimately, the data generated may have significant implications to aid in the understanding of pulpal biology relevant to cell-matrix dynamics and homeostasis. This data adds supporting scientific information that will help capture the dynamic nature of extracellular biochemical events involved in the transition between pulpal health, disease and the ability to repair and/or regenerate.

The realization is that there are several limitations to extrapolate any findings using an in vitro culture methodology to the clinical treatment in humans. These methods are challenging, with multiple variables such as cellular behavior, culturing techniques and operator error influencing the ability to generate consistent and reproducible results. However, in vitro testing is key for understanding and predicting what might happen in vivo. It is also an irreplaceable process in order to test different conditions that might influence the final in vivo outcomes. Furthermore, future transitions from in vitro to in vivo experiments will be looking at effects that are the result of complex systemic, local, and environmental interactions. Therefore, understanding the in vitro and in vivo experiences is key in order to propose specific ways or concentrations for a possible exogenous delivery of periostin. Furthermore, in vivo animal studies could be proposed in the future based on the results.

\section{Conclusion}

To conclude, Dental Pulp Cells (DPCs) such as: Stem cells, Fibroblasts and Odontoblastlike cells are capable of expressing periostin. We have successfully demonstrated that periostin mRNA and protein are expressed by all these dental cell populations in vitro. We have also confirmed that the expression of periostin is regulated by TGF- $\beta 1$. In addition, biomechanical stimulation may be used as a model to stimulate DPCs in vitro with either stimulatory or inhibitory effects. Lastly, exogenous delivery of periostin to DPCs yields inconclusive effects on total collagen expression. Overall, DPSCs show the 
most responsiveness and predictable behavior to stimulus. We propose that activation of DPCs through TGF- $\beta 1$ and biomechanical stimulation may regulate the potential therapeutic effects of these cells. Beyond the limits of this study, periostin may have a potential therapeutic effect; in order to stabilize the ECM during dentinogenesis, while pulpal repair and regeneration is occurring. 


\section{Tables and Figures}

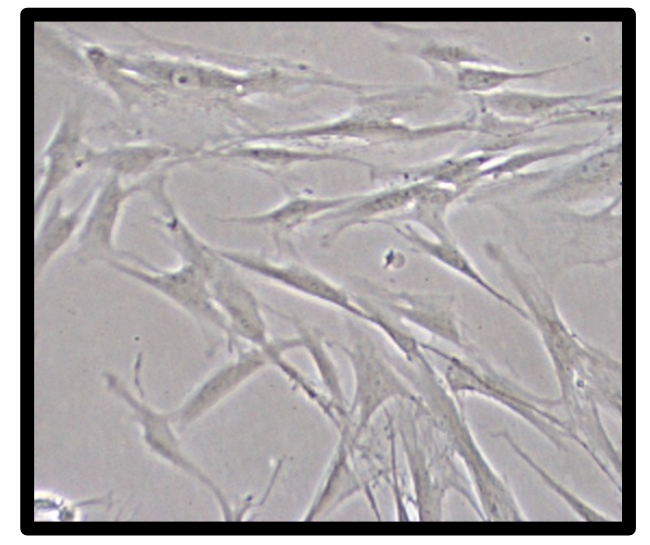

Figure 1: Phase contrast image of human dental pulp stem cells (DPSC) at 100x magnification. Cells were grown in Dulbecco's Modified Eagle's medium supplemented with heat inactivated 10\% FBS, 1\% penicillin/streptomycin and 1:1000 fungizone. Cultures were maintained at $37^{\circ} \mathrm{C}$ in a humidified atmosphere of 5\% CO2 and 95\% air.

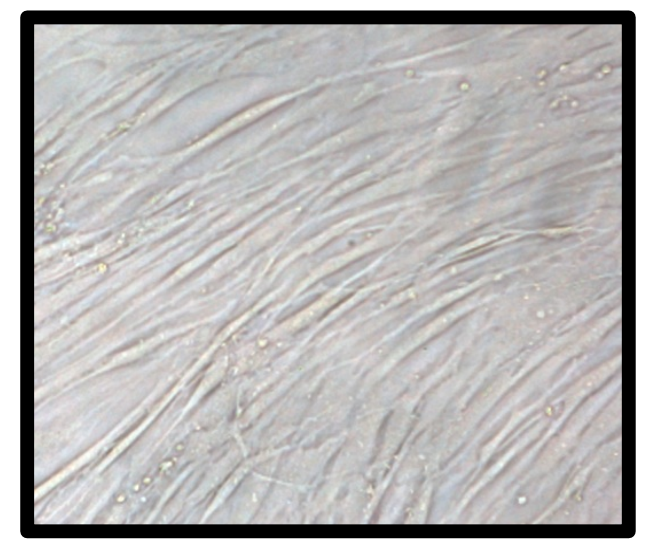

Figure 2: Phase contrast image of human dental pulp fibroblast cells (DPF) at 100x magnification. Cells were grown in Dulbecco's Modified Eagle's medium supplemented with heat inactivated 10\% FBS, 1\% penicillin/streptomycin and 1:1000 fungizone. Cultures were maintained at $37^{\circ} \mathrm{C}$ in a humidified atmosphere of 5\% CO2 and 95\% air.

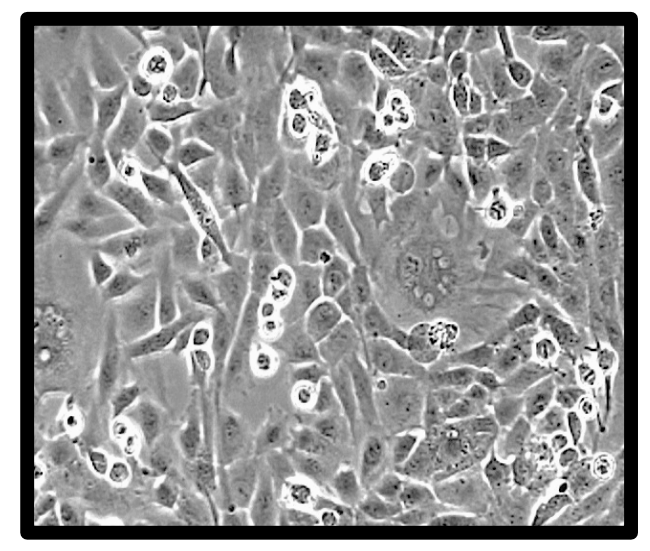

Figure 3: Phase contrast image of MDPC-23 odontoblast-like cells at 100x magnification. Cells were grown in Dulbecco's Modified Eagle's medium supplemented with heat inactivated $10 \%$ FBS, 1\% penicillin/streptomycin and 1:1000 fungizone. Cultures were maintained at $37^{\circ} \mathrm{C}$ in a humidified atmosphere of 5\% CO2 and 95\% air. 


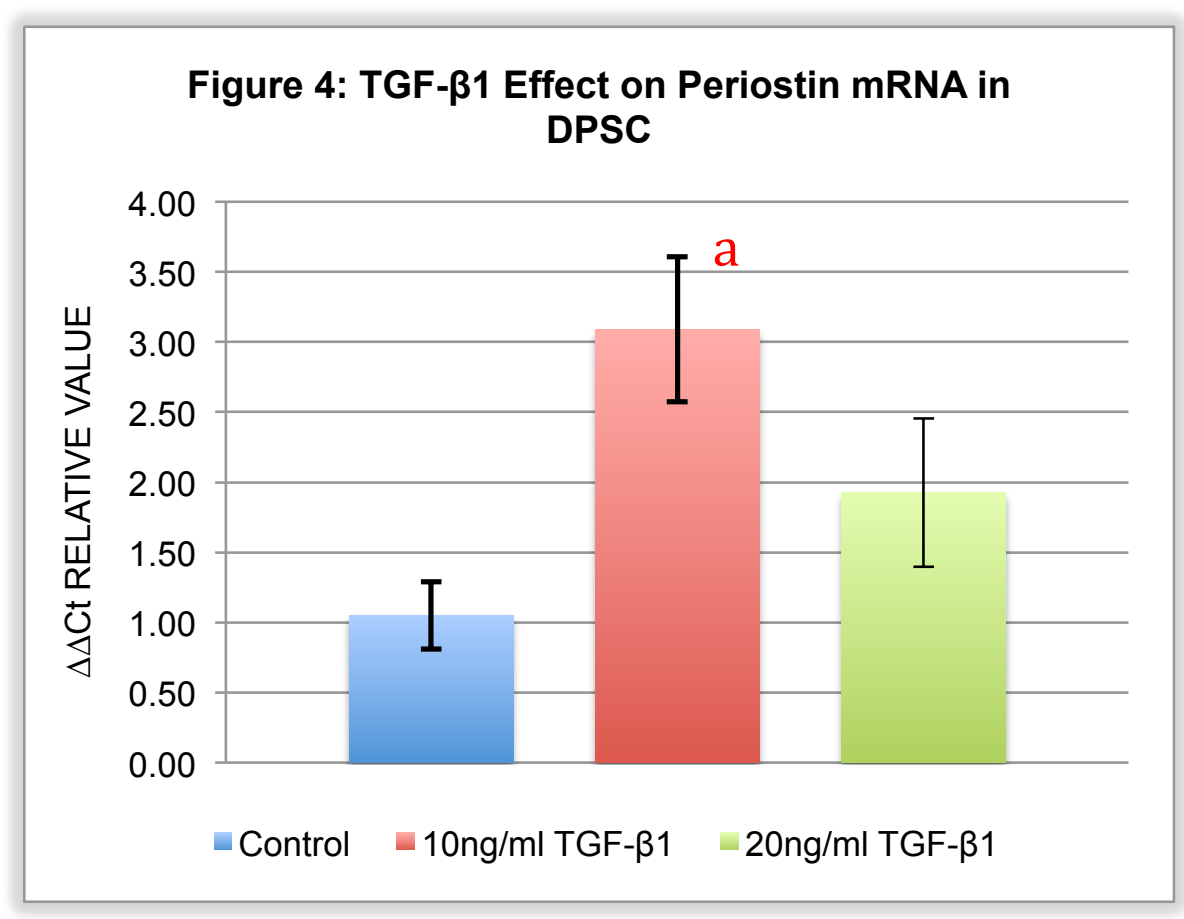

Figure 4: TGF- $\beta 1$ Effect on Periostin mRNA in DPSC after 48 hours. Statistically significant difference from control to $10 \mathrm{ng} / \mathrm{ml}$ TGF- $\beta 1$ [a: $(\mathrm{P}=0.018)$ Fisher's LSD]

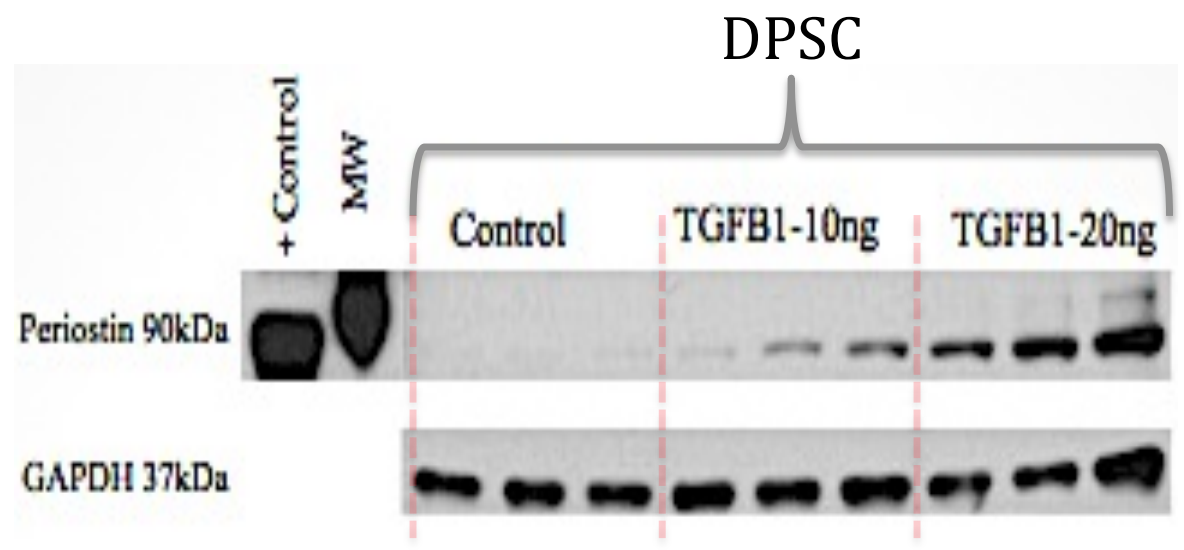

Figure 5: Western Blot for periostin protein in DPSC; GAPDH as housekeeping protein; comparing control to treatment with TGF- $\beta 1$ after 48 hours. Molecular Weight (MW) and hPDL cells used for positive control. 


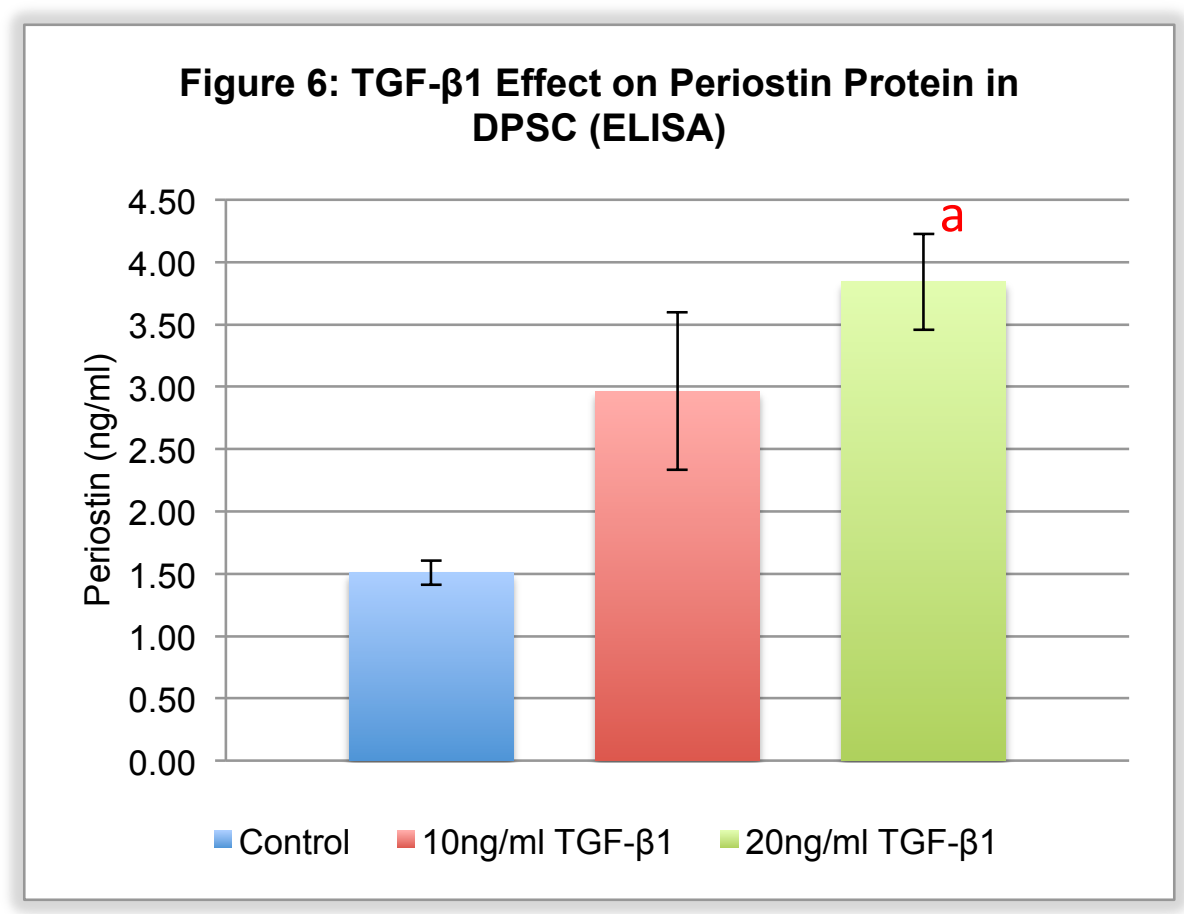

Figure 6: TGF-ß1 Effect on Periostin Protein in DPSC after 48 hours. Statistically significant difference from control to $20 \mathrm{ng} / \mathrm{ml}$ TGF- $\beta 1$ [a: $(\mathrm{P}=0.032)$ Fisher's LSD] 


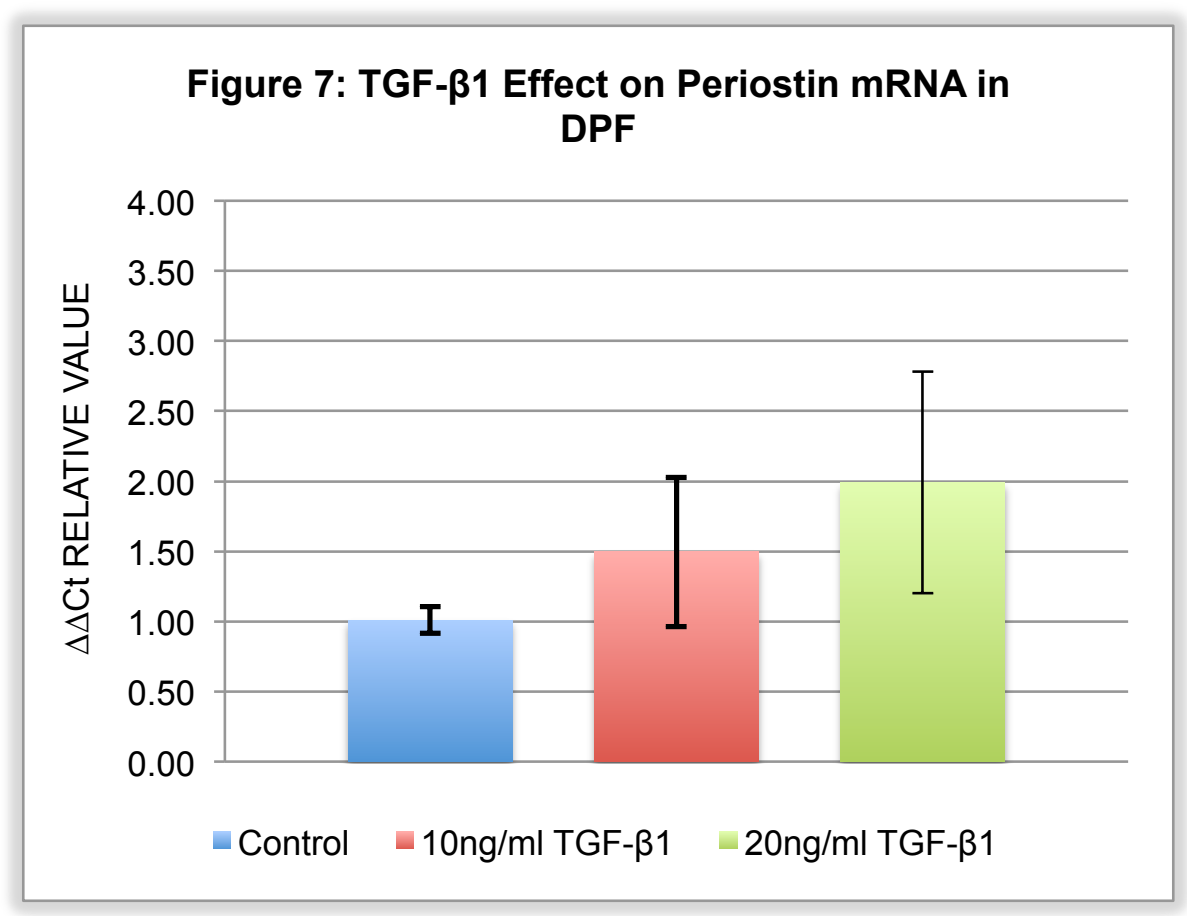

Figure 7: TGF-ß1 Effect on Periostin mRNA in DPF after 48 hours. No statistically significant differences between groups [(P>0.05) Fisher's LSD]

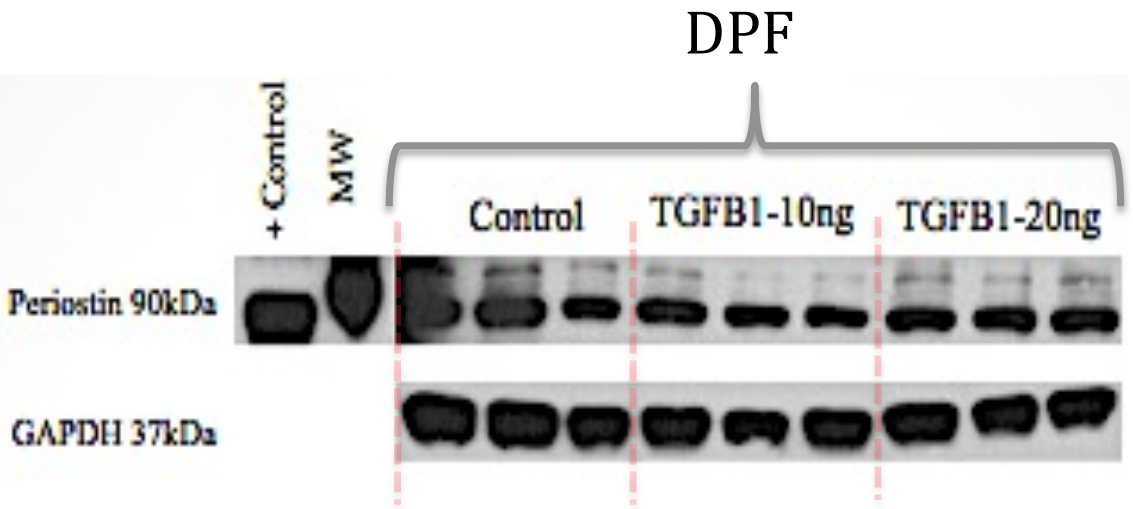

Figure 8: Western Blot for periostin protein in DPF; GAPDH as housekeeping protein; comparing control to treatment with TGF- $\beta 1$ after 48 hours. Molecular Weight (MW) and hPDL cells used for positive control. 


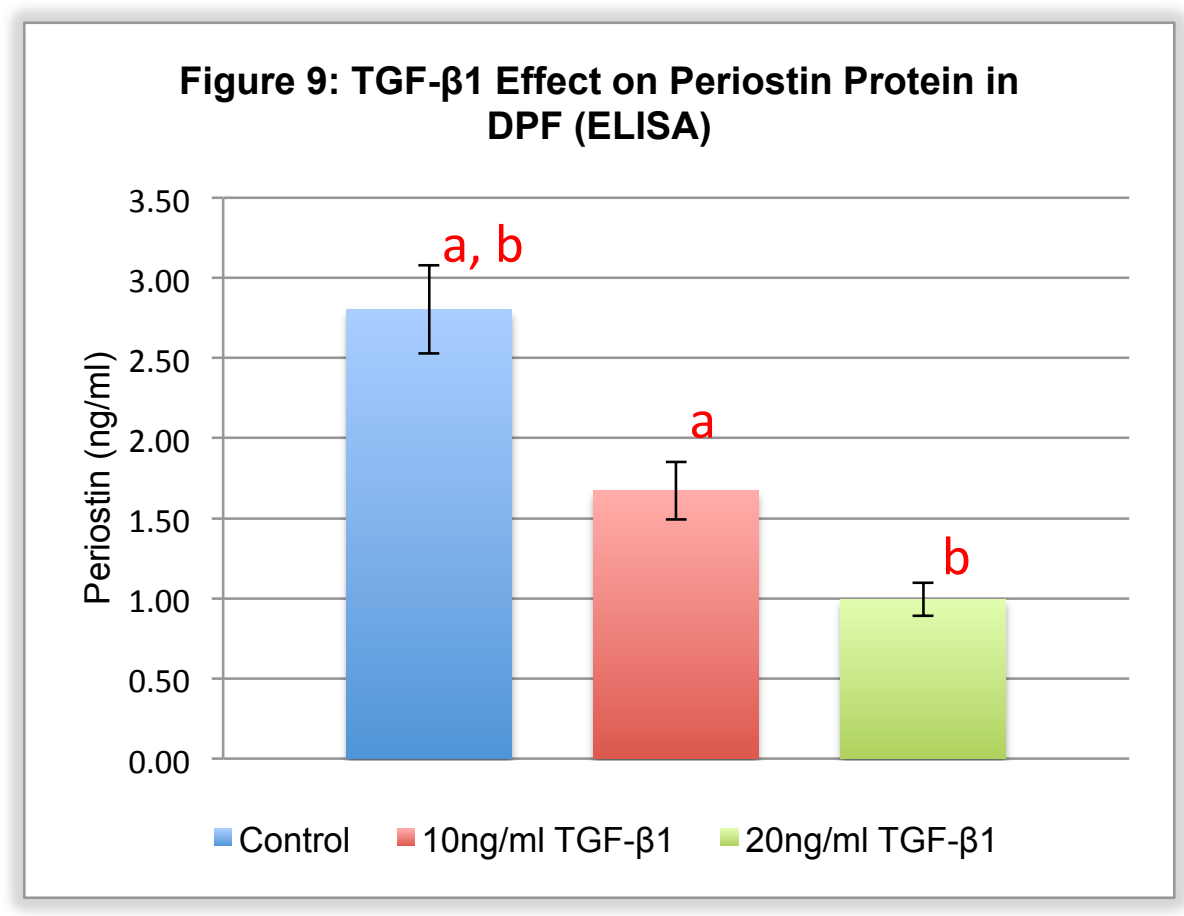

Figure 9: TGF-ß1 Effect on Periostin Protein in DPF after 48 hours. Statistically significant difference from control to $10 \mathrm{ng} / \mathrm{ml}$ TGF- $\beta 1$ and $20 \mathrm{ng} / \mathrm{ml}$ TGF- $\beta 1$ $[\mathrm{a}:(\mathrm{P}=0.028), \mathrm{b}:(\mathrm{P}=0.008)$ Fisher's LSD $]$ 


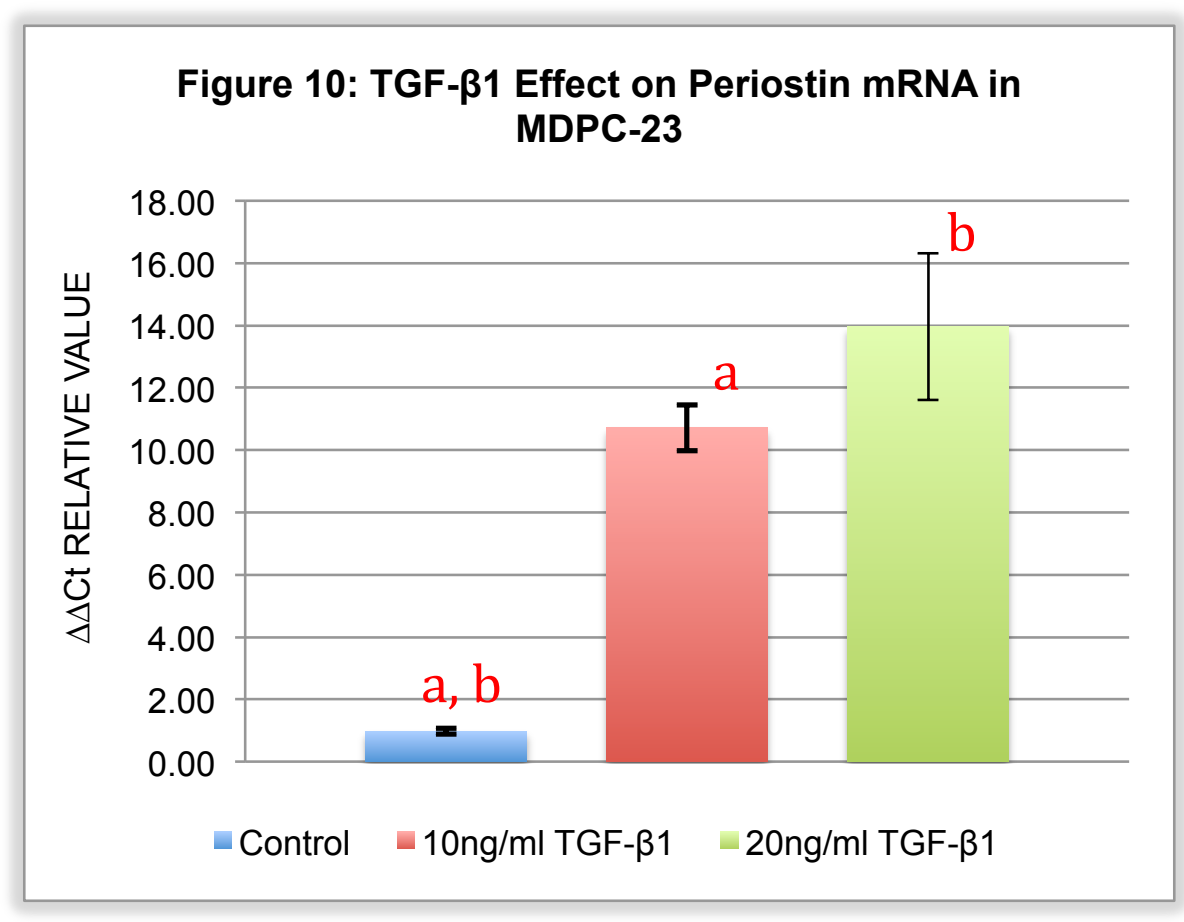

Figure 10: TGF- $\beta 1$ Effect on Periostin mRNA in MDPC-23 after 48 hours. Statistically significant difference from control to $10 \mathrm{ng} / \mathrm{ml}$ TGF- $\beta 1$ and $20 \mathrm{ng} / \mathrm{ml}$ TGF- $\beta 1$ [a: $(\mathrm{P}=0.003), \mathrm{b}:(\mathrm{P}=0.001)$ Fisher's LSD]

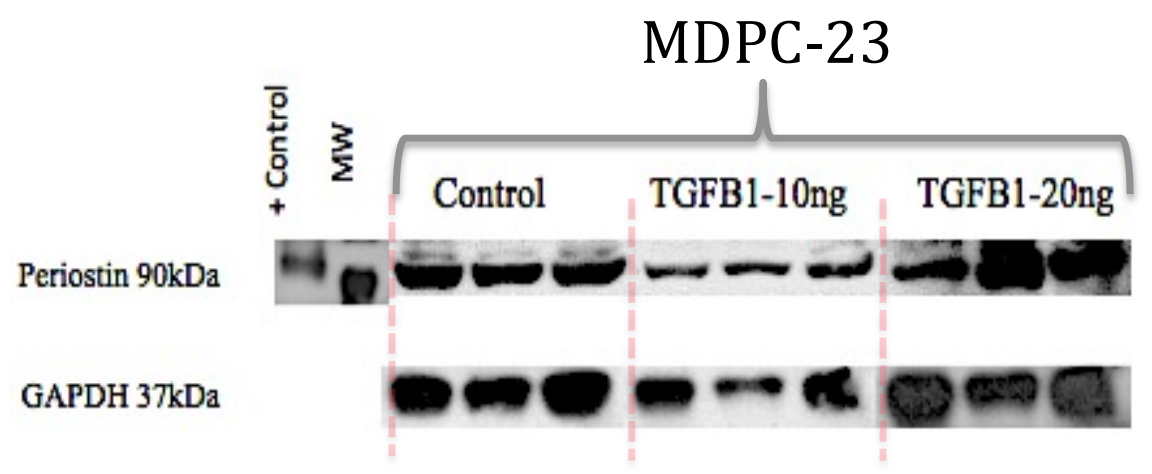

Figure 11: Western Blot for periostin protein in MDPC-23; GAPDH as housekeeping protein; comparing control to treatment with TGF- $\beta 1$ after 48 hours. Molecular Weight (MW) and hPDL cells used for positive control. 


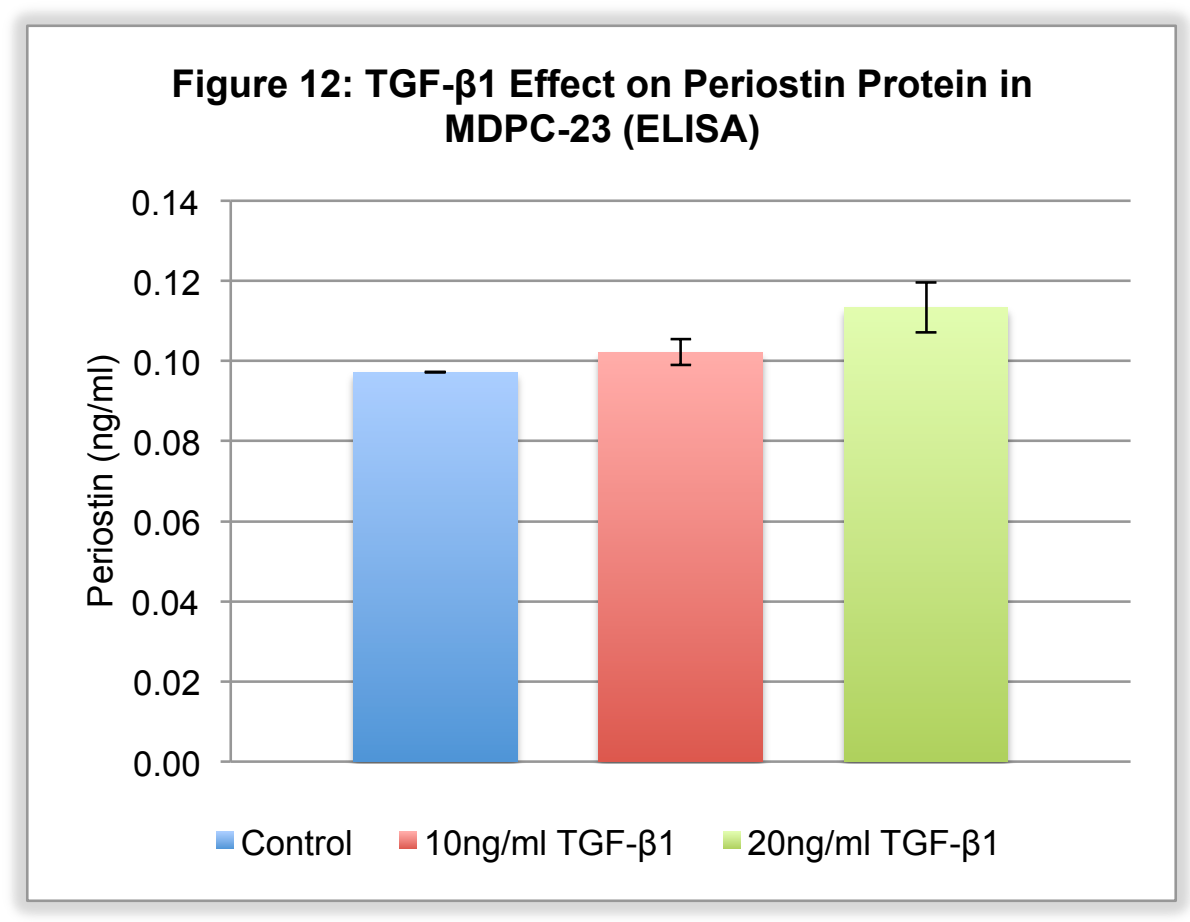

Figure 12: TGF- $\beta 1$ Effect on Periostin Protein in MDPC-23 after 48 hours. No statistically significant differences between groups $[(\mathrm{P}>0.05)$ Fisher's LSD]

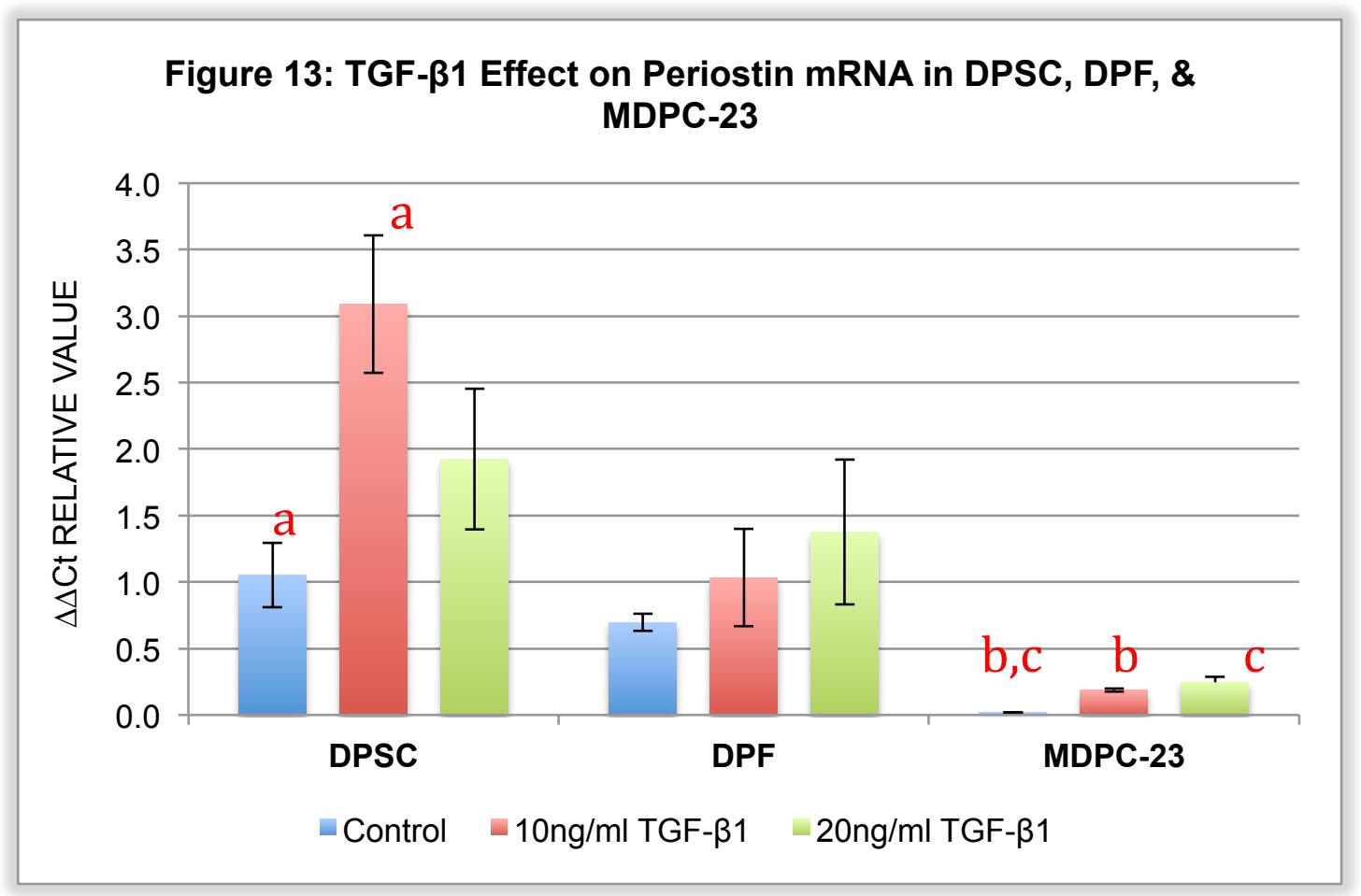

Figure 13: TGF- $\beta 1$ Effect on Periostin mRNA in DPSC, DPF, \& MDPC-23 after 48 hours. Statistically significant differences $[\mathrm{a}:(\mathrm{P}=0.018) ; \mathrm{b}:(\mathrm{P}=0.003) ; \mathrm{c}:(\mathrm{P}=0.001)$ Fisher's LSD] 


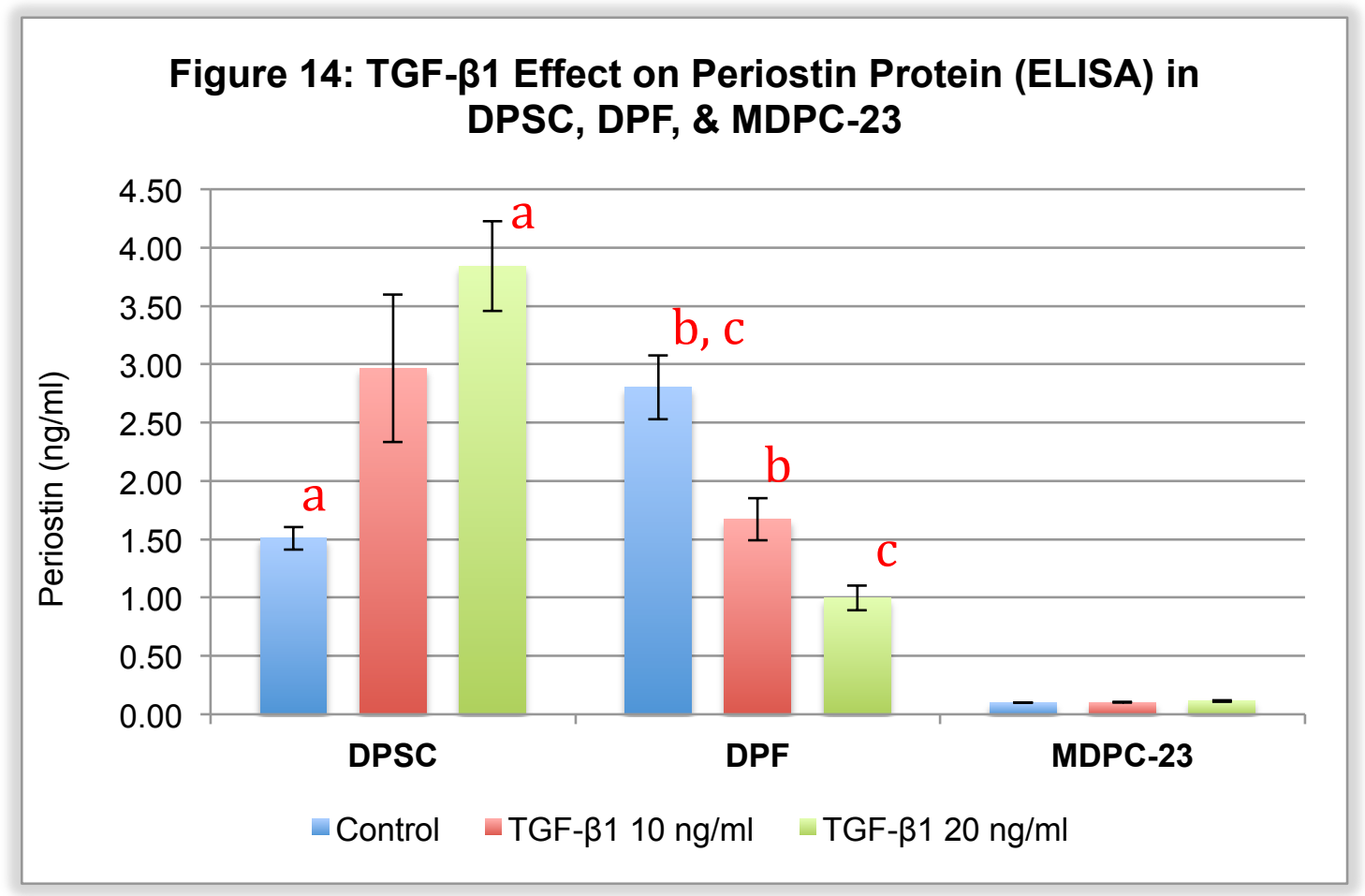

Figure 14: TGF- $\beta 1$ Effect on Periostin Protein (ELISA) in DPSC, DPF, \& MDPC-23 after 48 hours. Statistically significant differences [a: $(\mathrm{P}=0.032) ; \mathrm{b}:(\mathrm{P}=0.028)$; $\mathrm{c}:(\mathrm{P}=0.008)$ Fisher's LSD]

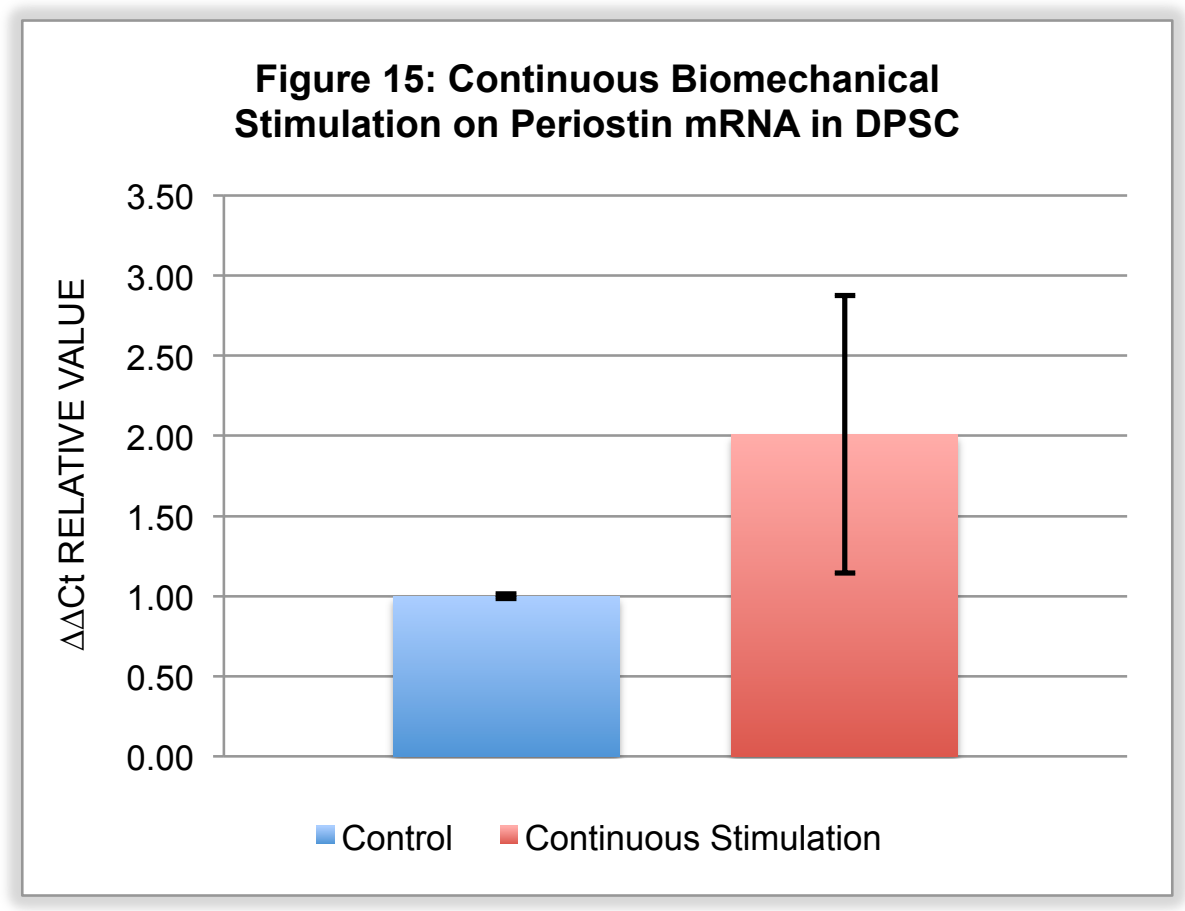

Figure 15: Continuous Biomechanical Stimulation on Periostin mRNA in DPSC after 48 hours. No statistically significant differences between groups $[(\mathrm{P}>0.05)$ Student's t-test] 


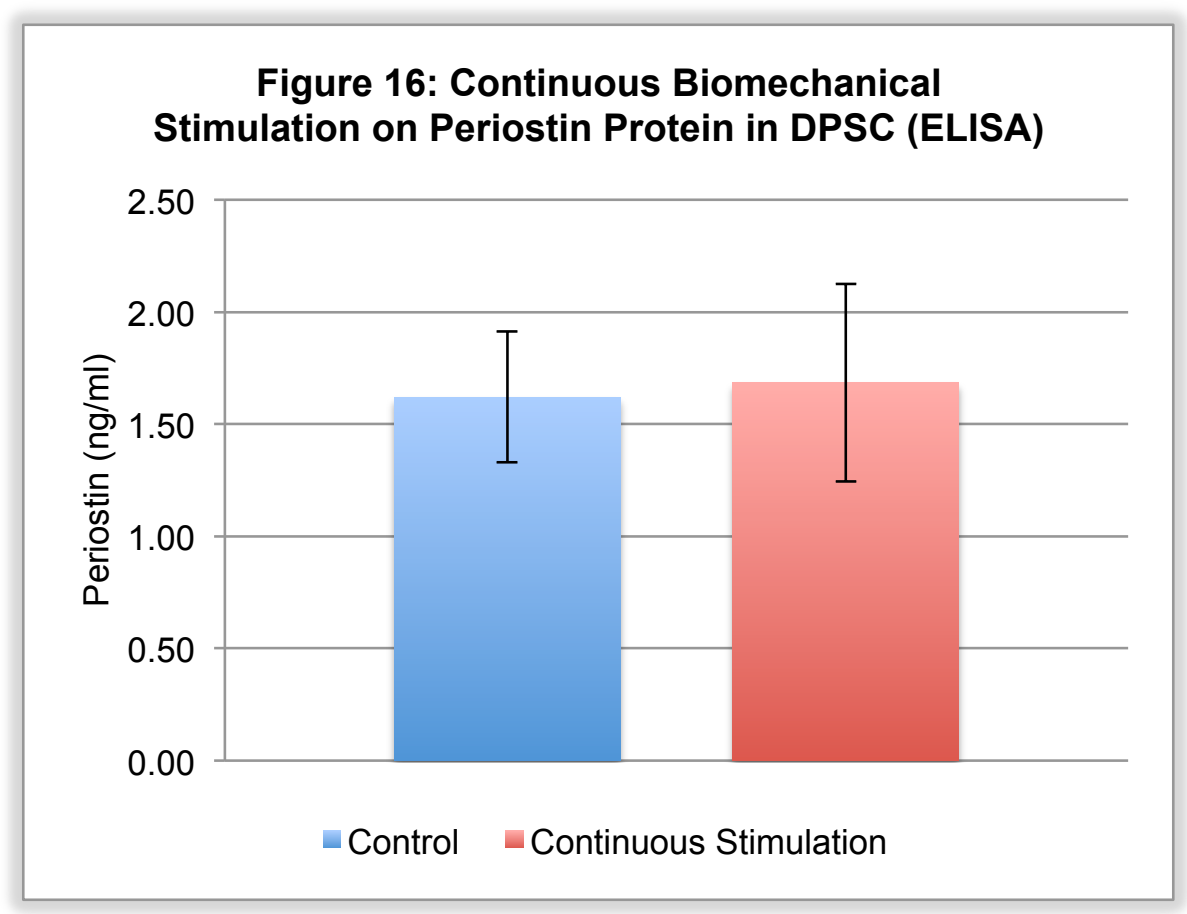

Figure 16: Continuous Biomechanical Stimulation on Periostin Protein in DPSC after 48 hours. No statistically significant differences between groups [ $(\mathrm{P}>0.05)$ Fisher's LSD]

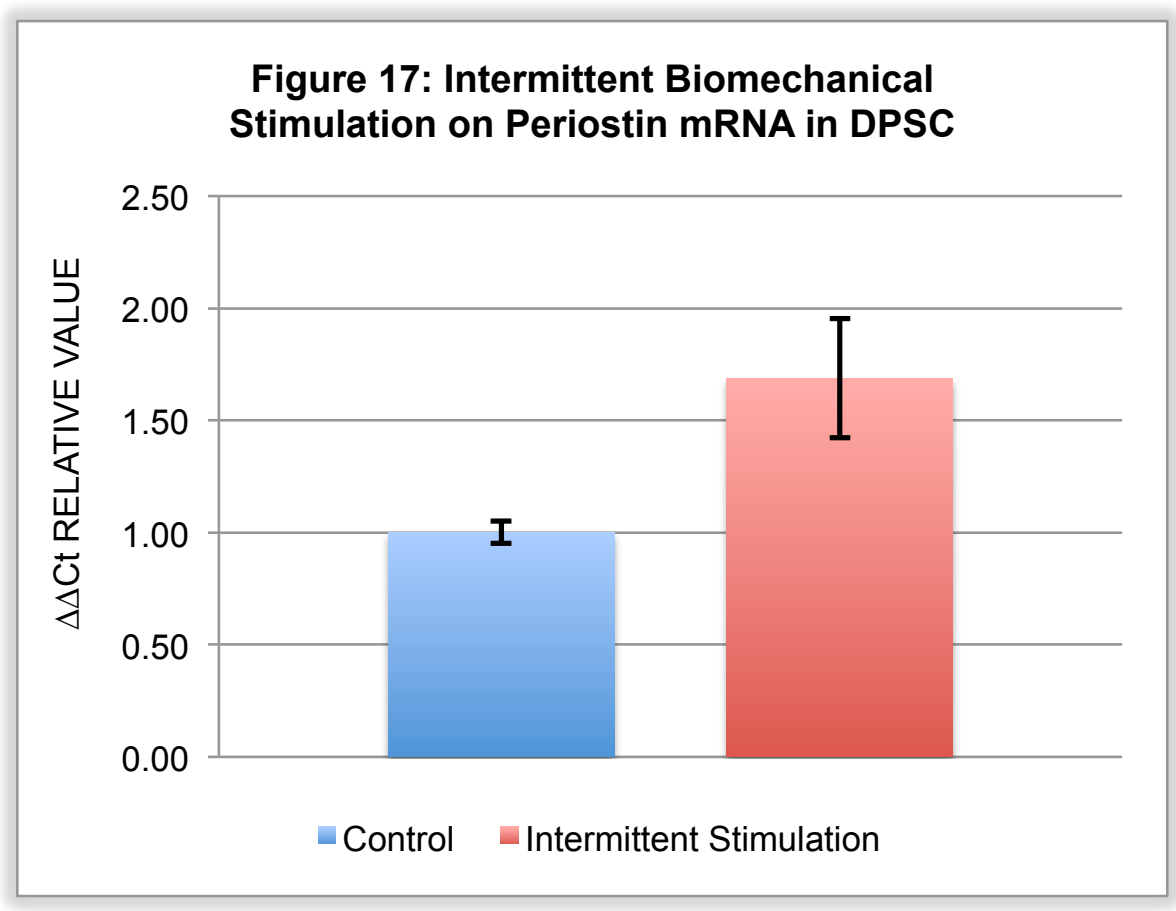

Figure 17: Intermittent Biomechanical Stimulation on Periostin mRNA in DPSC after 48 hours. No statistically significant differences between groups $[(\mathrm{P}>0.05)$ Student's t-test] 


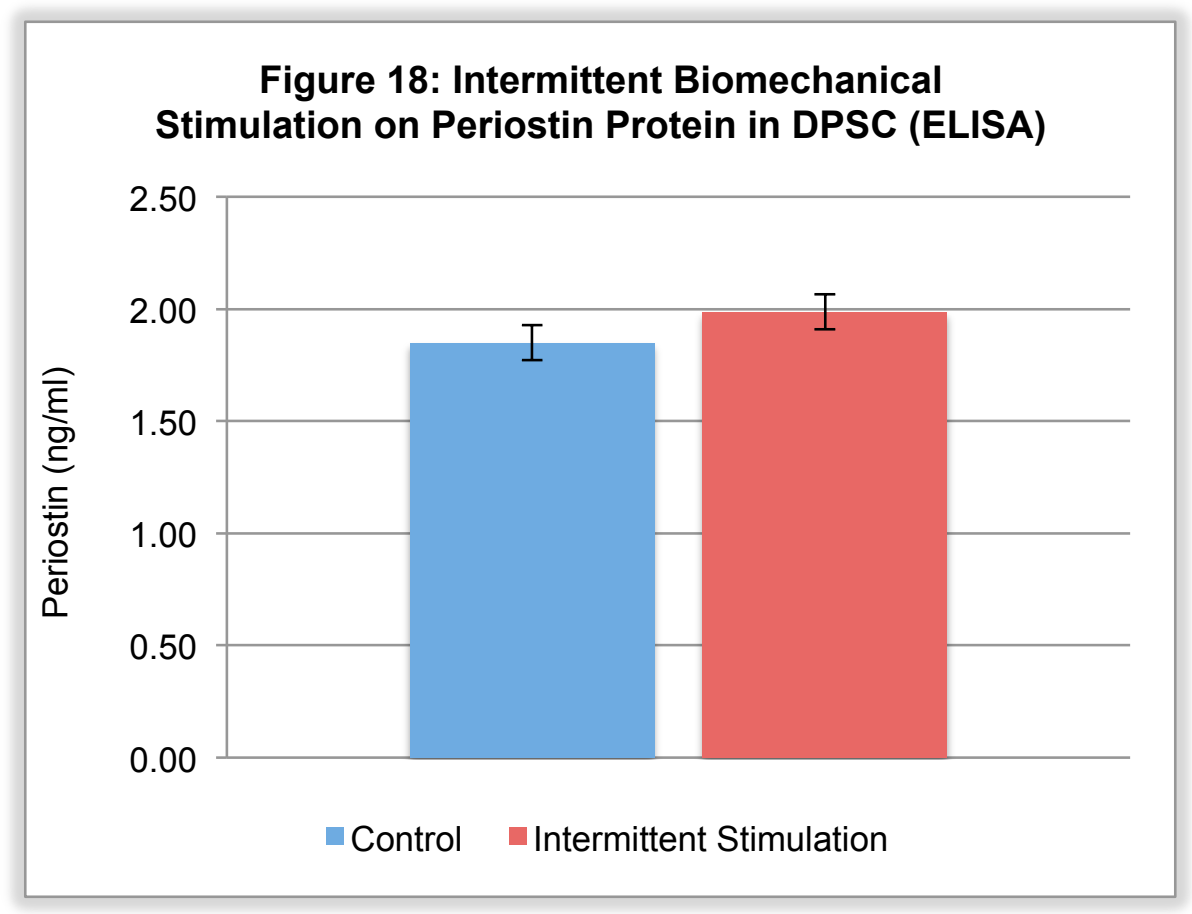

Figure 18: Intermittent Biomechanical Stimulation on Periostin Protein in DPSC after 48 hours. No statistically significant differences between groups [ $(\mathrm{P}>0.05)$ Fisher's LSD]

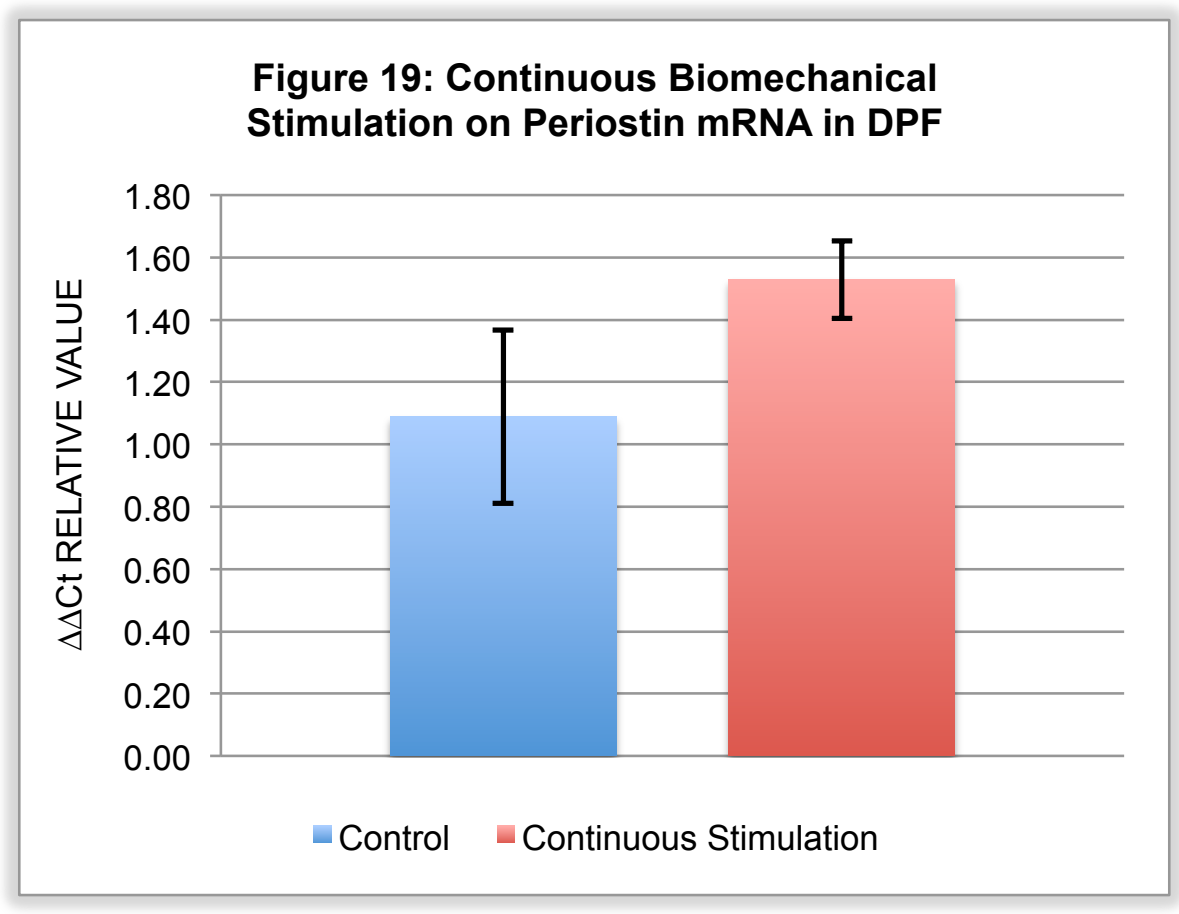

Figure 19: Continuous Biomechanical Stimulation on Periostin mRNA in DPF after 48 hours. No statistically significant differences between groups [ $(\mathrm{P}>0.05)$ Student's ttest] 


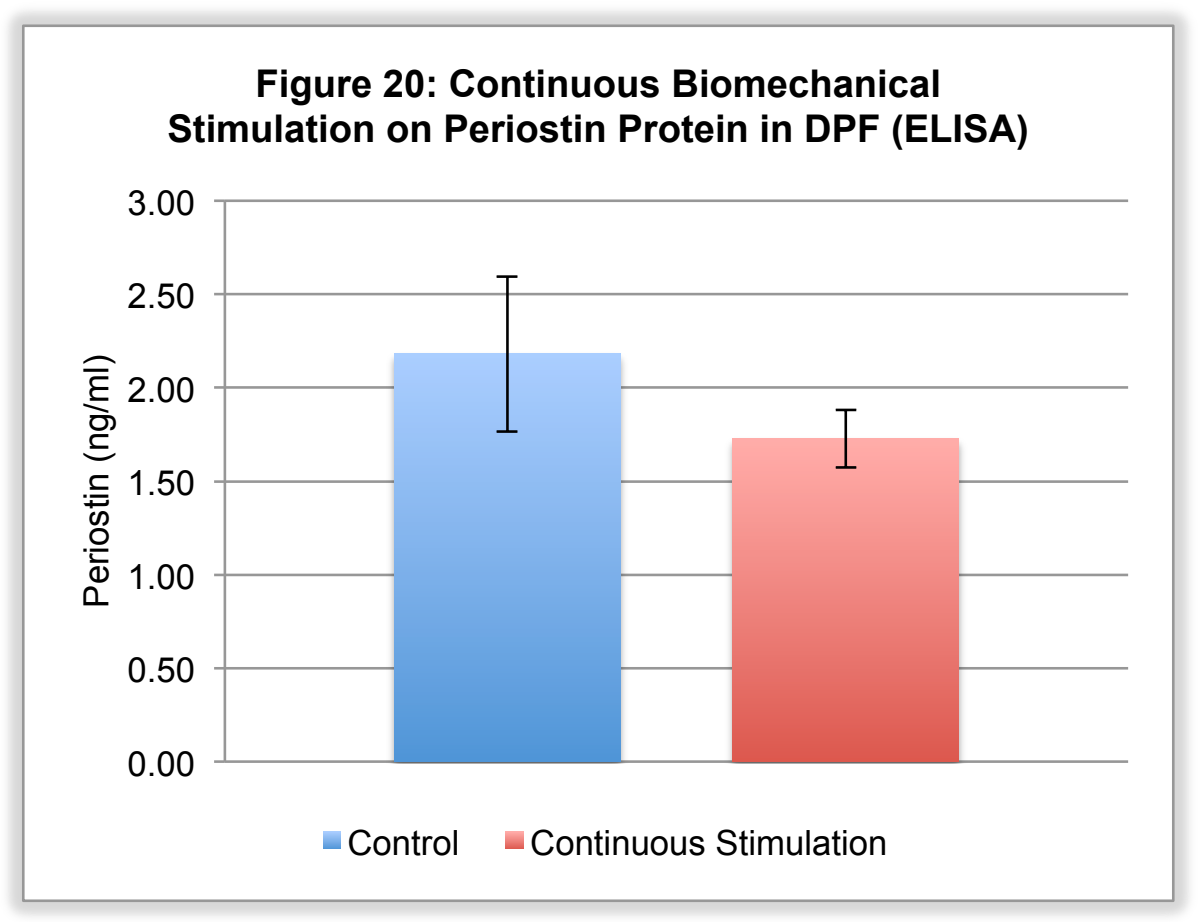

Figure 20: Continuous Biomechanical Stimulation on Periostin Protein in DPF after 48 hours. No statistically significant differences between groups [(P>0.05) Fisher's LSD]

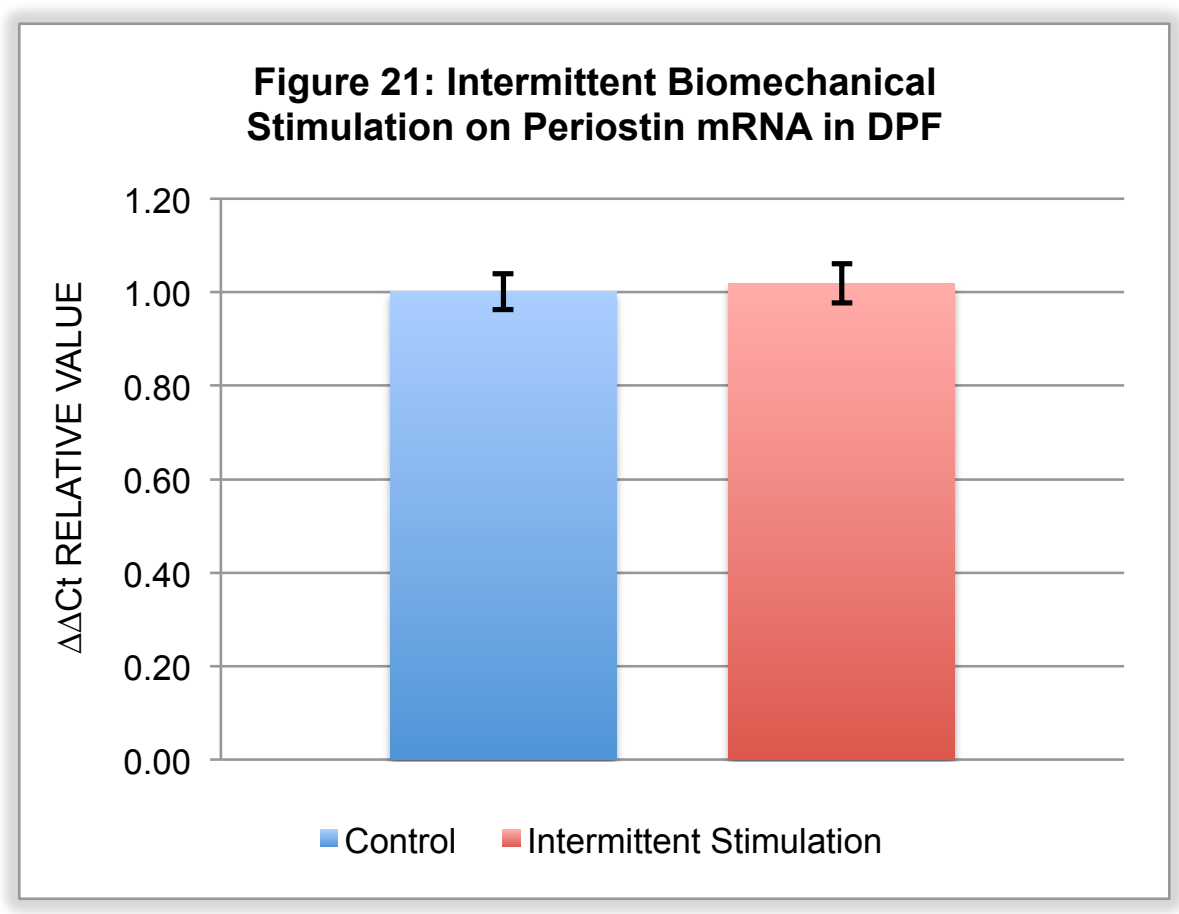

Figure 21: Intermittent Biomechanical Stimulation on Periostin mRNA in DPF after 48 hours. No statistically significant differences between groups [ $(\mathrm{P}>0.05)$ Student's ttest] 


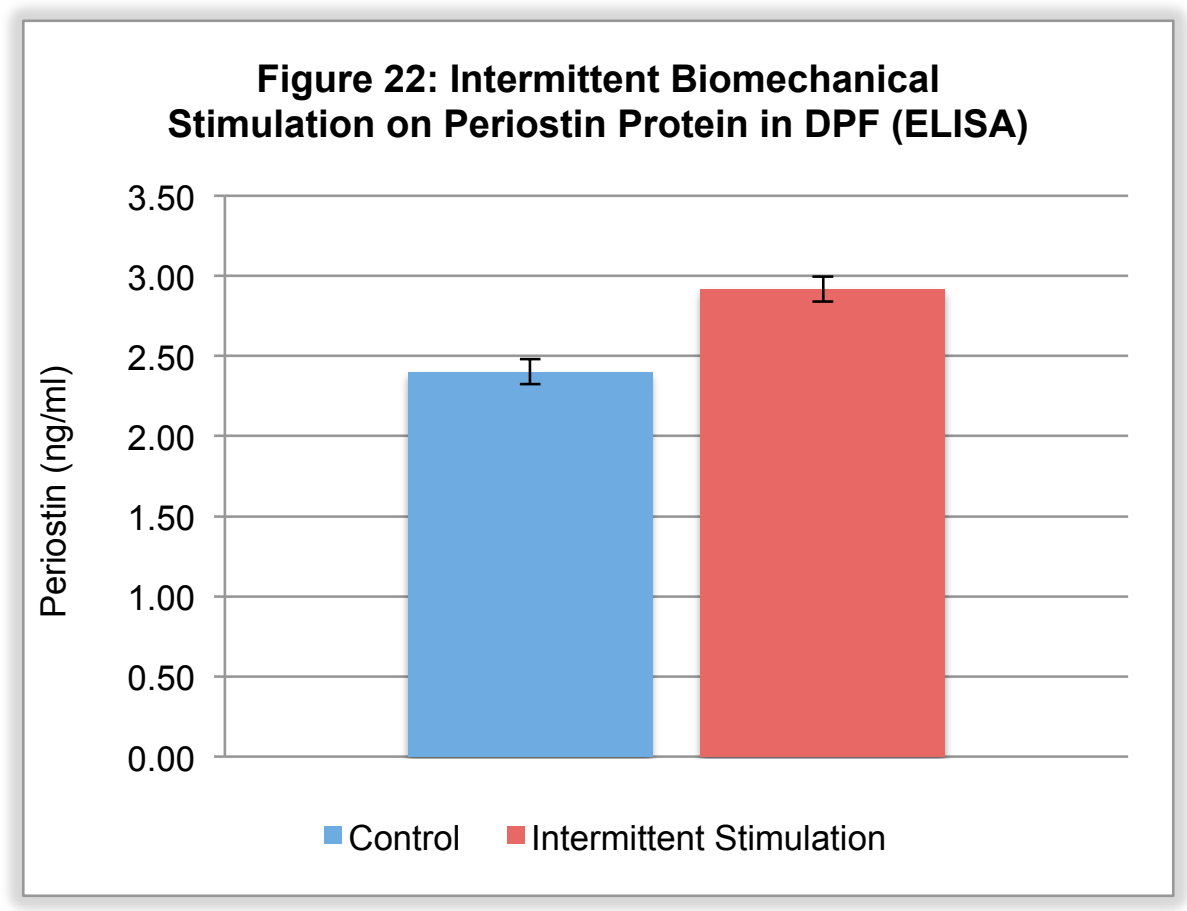

Figure 22: Intermittent Biomechanical Stimulation on Periostin Protein in DPF after 48 hours. No statistically significant differences between groups [( $P>0.05)$ Fisher's LSD]

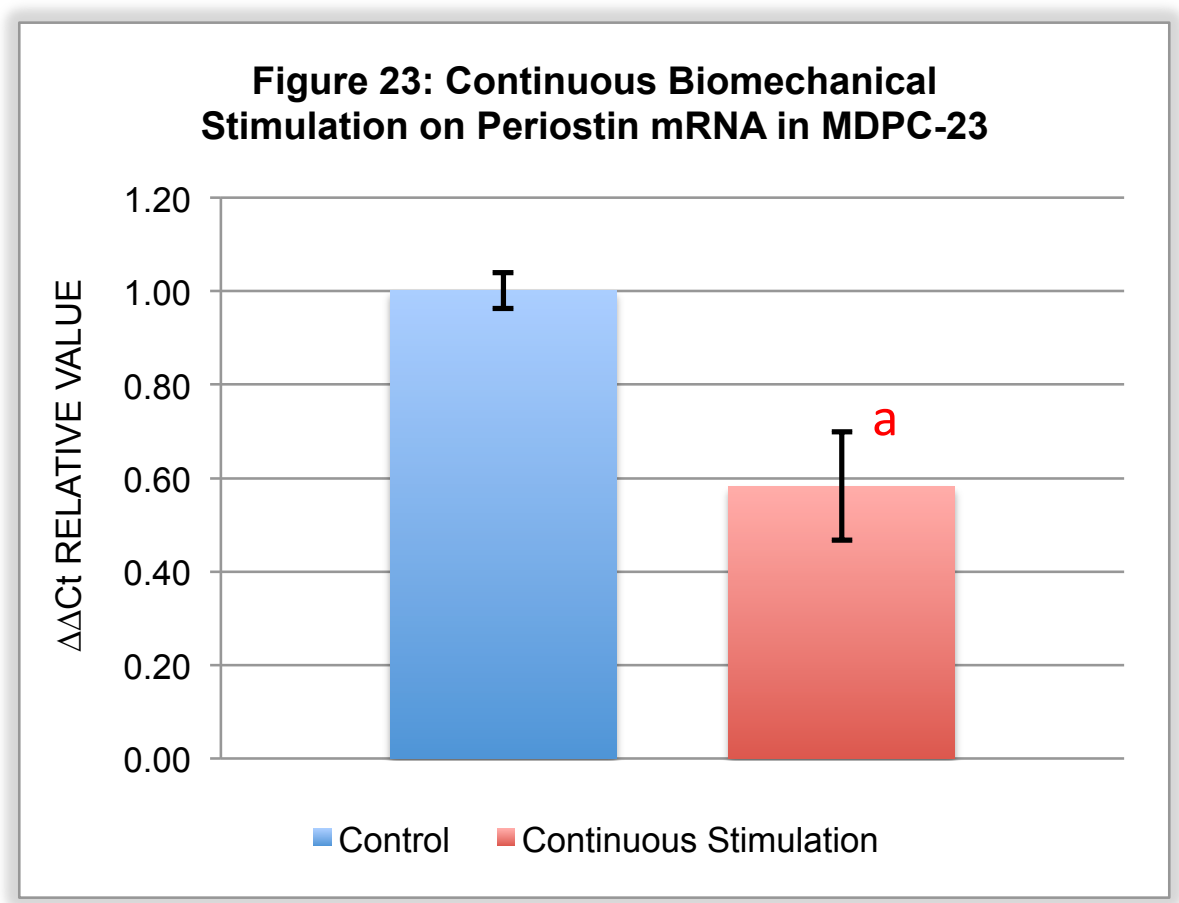

Figure 23: Continuous Biomechanical Stimulation on Periostin mRNA in MDPC-23 after 48 hours. Statistically significant differences between groups [a: $(\mathrm{P}=0.026)$ Student's t-test] 


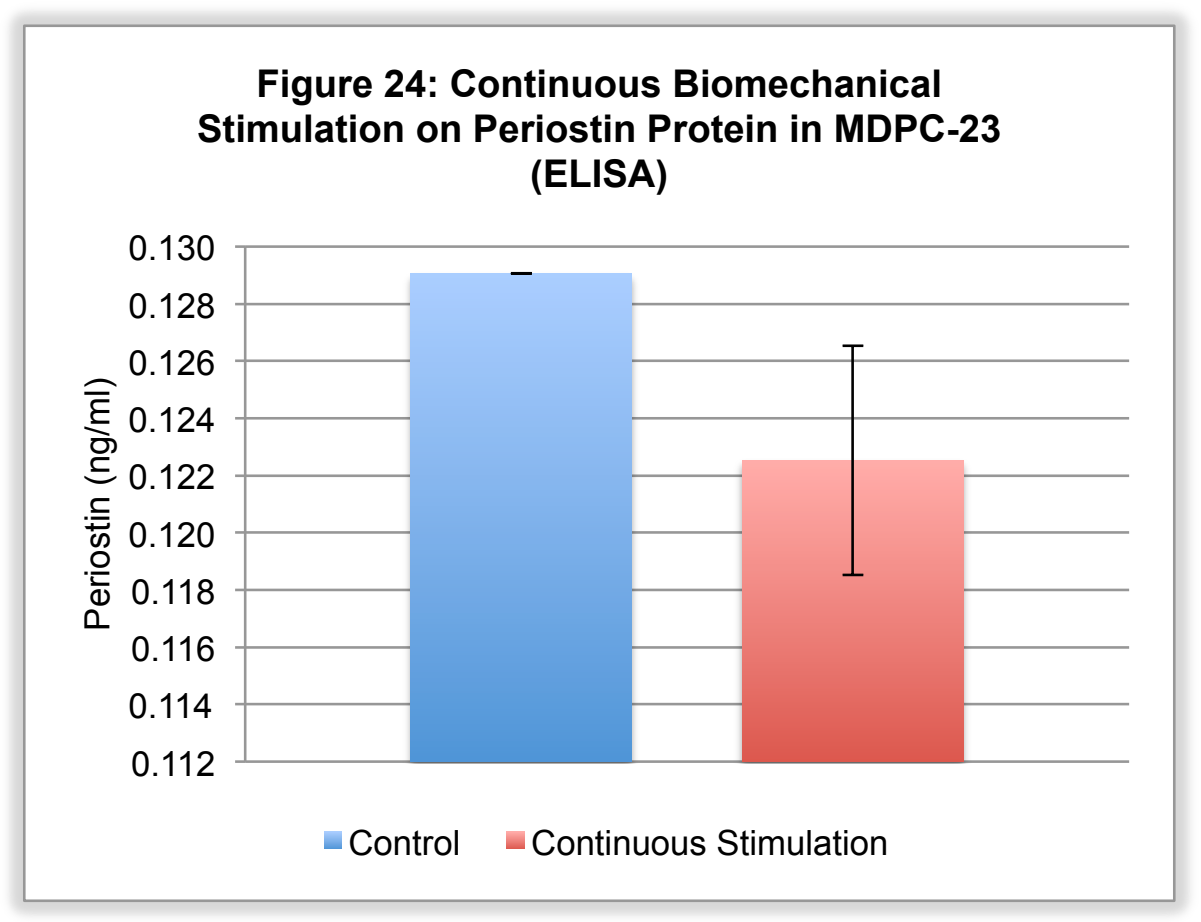

Figure 24: Continuous Biomechanical Stimulation on Periostin Protein in MDPC-23 after 48 hours. No statistically significant differences between groups [( $\mathrm{P}>0.05)$ Fisher's LSD]

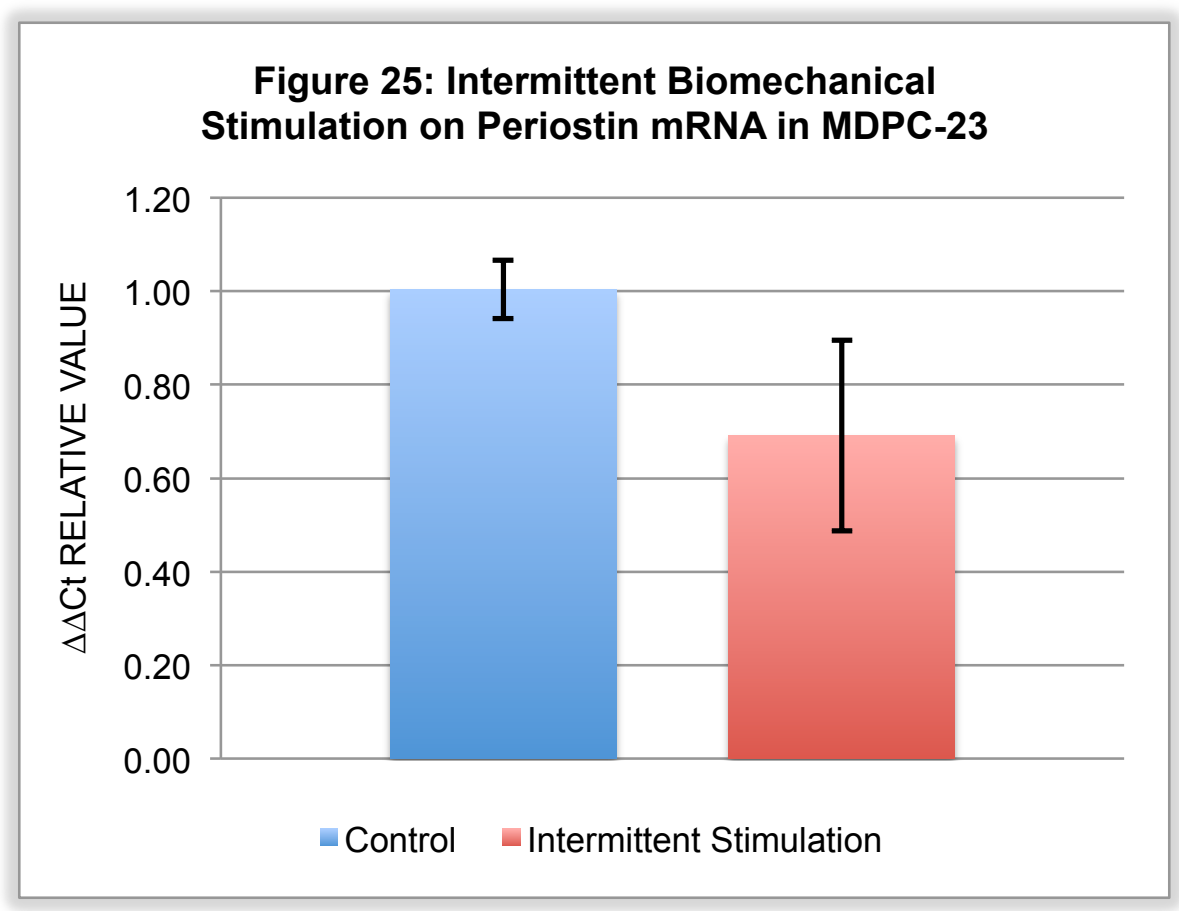

Figure 25: Intermittent Biomechanical Stimulation on Periostin mRNA in MDPC23 after 48 hours. No statistically significant differences between groups $[(\mathrm{P}>0.05)$ Student's t-test] 


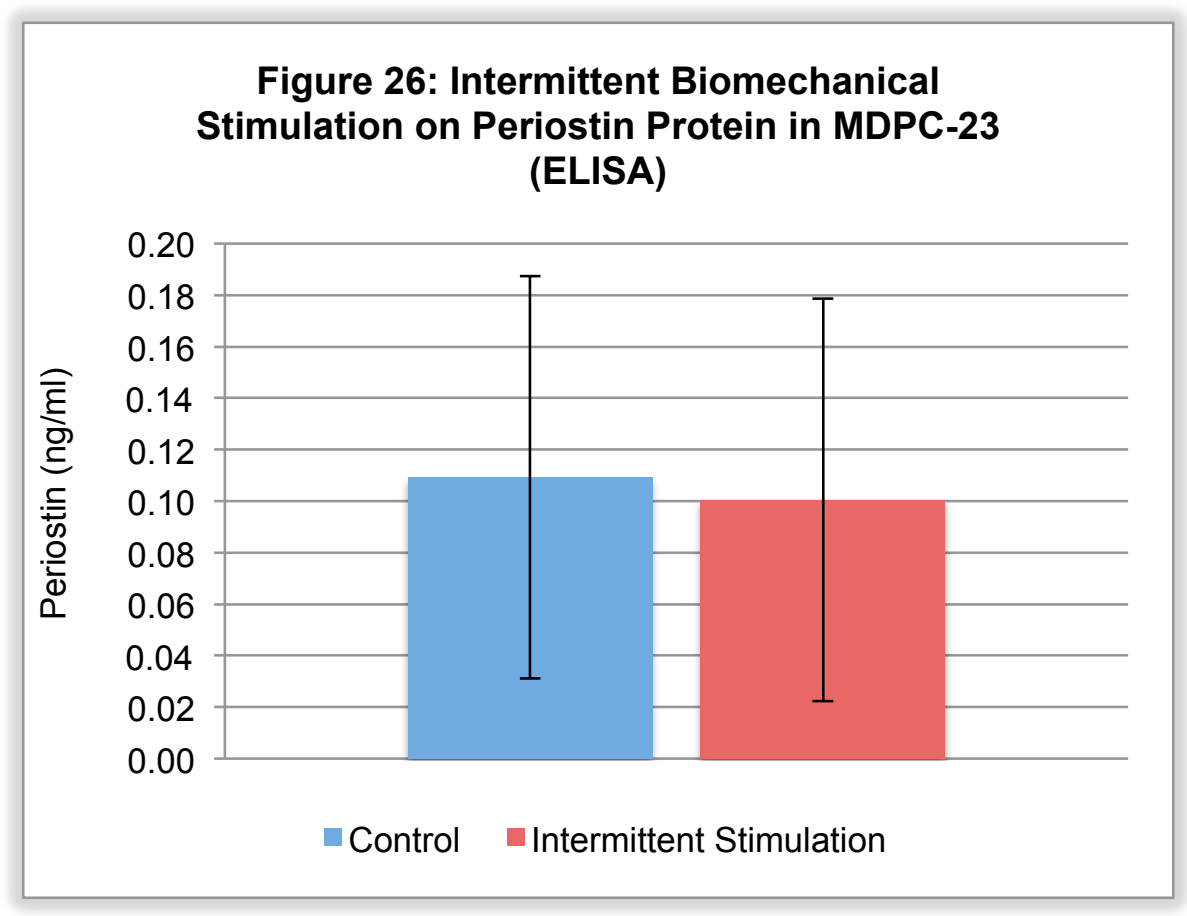

Figure 26: Intermittent Biomechanical Stimulation on Periostin Protein in MDPC23 after 48 hours. No statistically significant differences between groups $[(\mathrm{P}>0.05)$ Fisher's LSD]

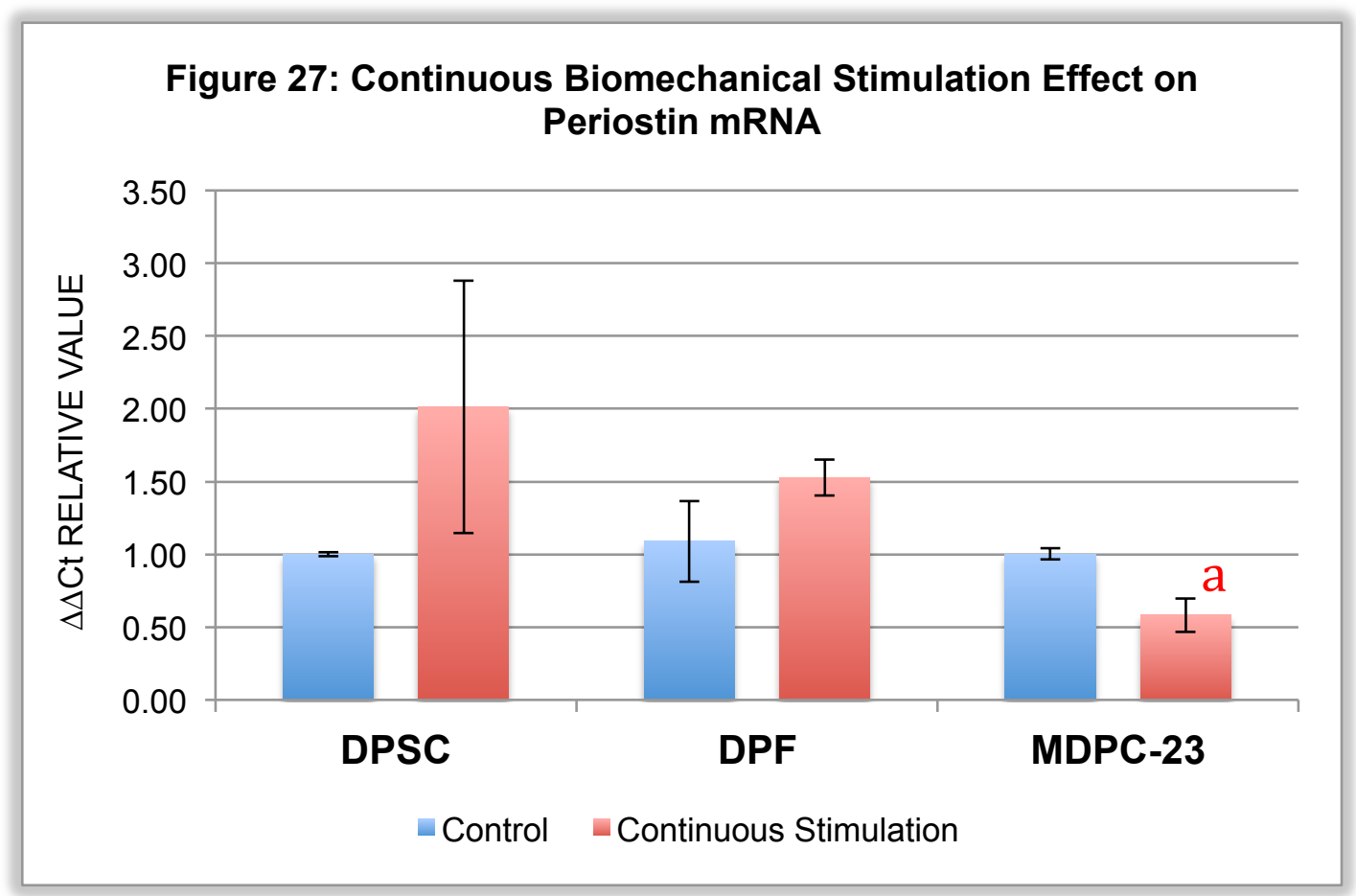

Figure 27: Continuous Biomechanical Stimulation Effect on Periostin mRNA in DPSC, DPF, \& MDPC-23 after 48 hours. Statistically significant difference [a: $(\mathrm{P}=0.026)$ Student's t-test] 


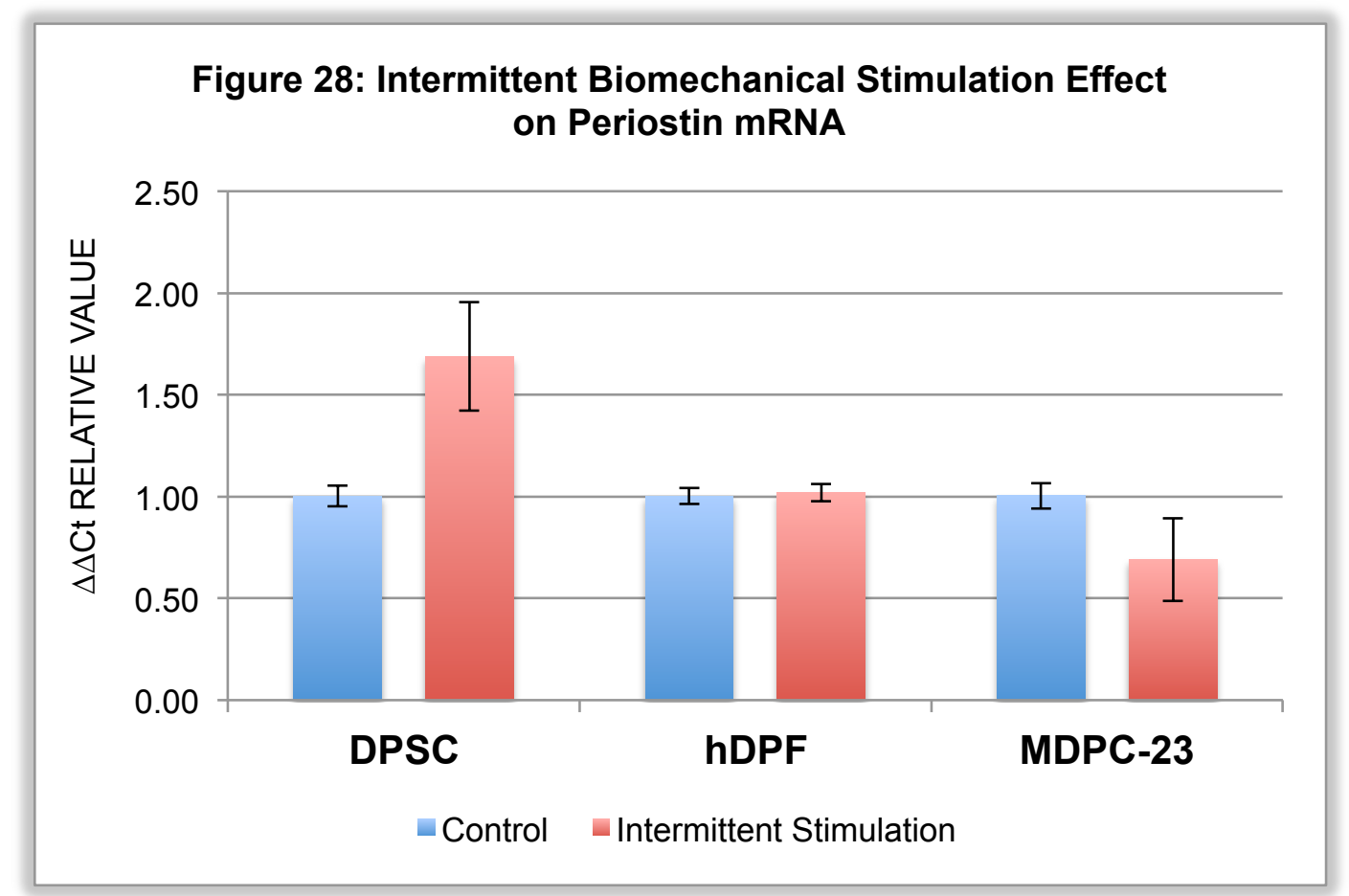

Figure 28: Intermittent Biomechanical Stimulation Effect on Periostin mRNA in DPSC, DPF, \& MDPC-23 after 48 hours. No statistically significant findings between groups $[(\mathrm{P}>0.05)$ Student's t-test $]$ 

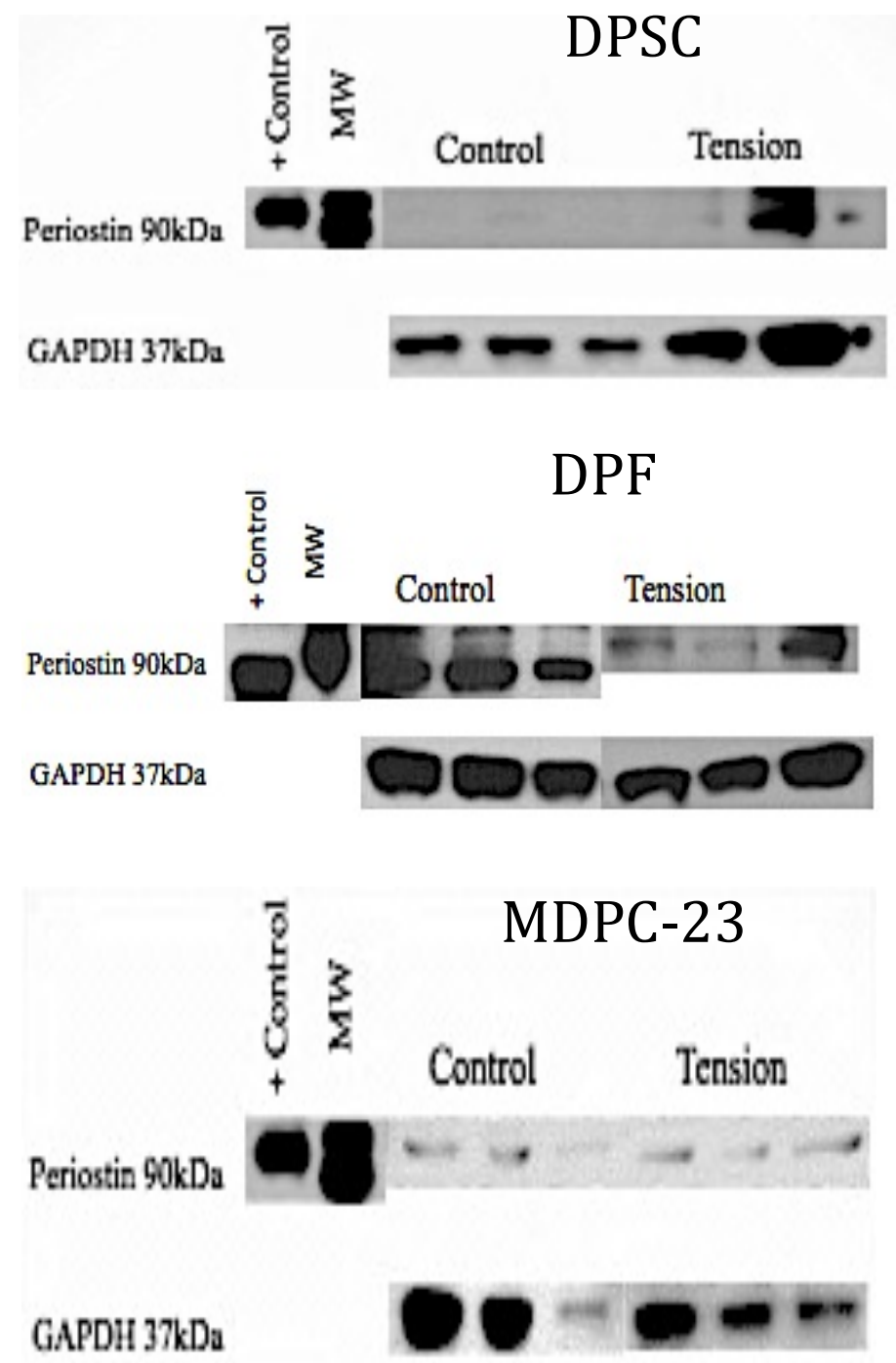

Figure 29: Western Blot for DPSC, DPF, \& MDPC-23 probing for periostin, GAPDH as housekeeping protein; comparing at baseline levels to biomechanical stimulation after 48 hours. Molecular Weight (MW) and hPDL cells used for positive control. 


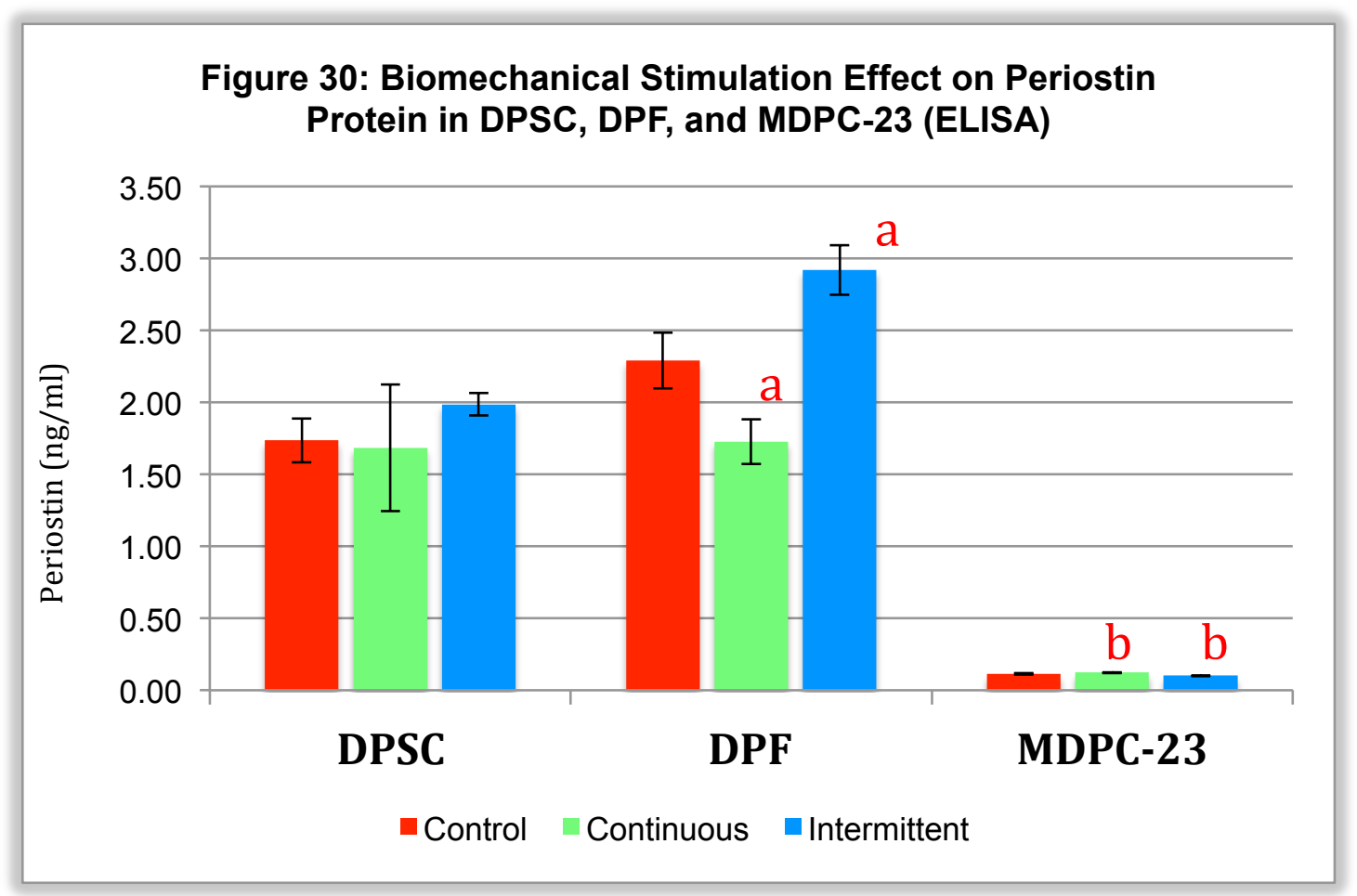

Figure 30: Biomechanical Stimulation Effect on Periostin Protein in DPSC, DPF, and MDPC-23 (ELISA) after 48 hours. Statistically significant differences [a: $(\mathrm{P}=0.005) ; \mathrm{b}:(\mathrm{P}=0.012)$ Fisher's LSD] 


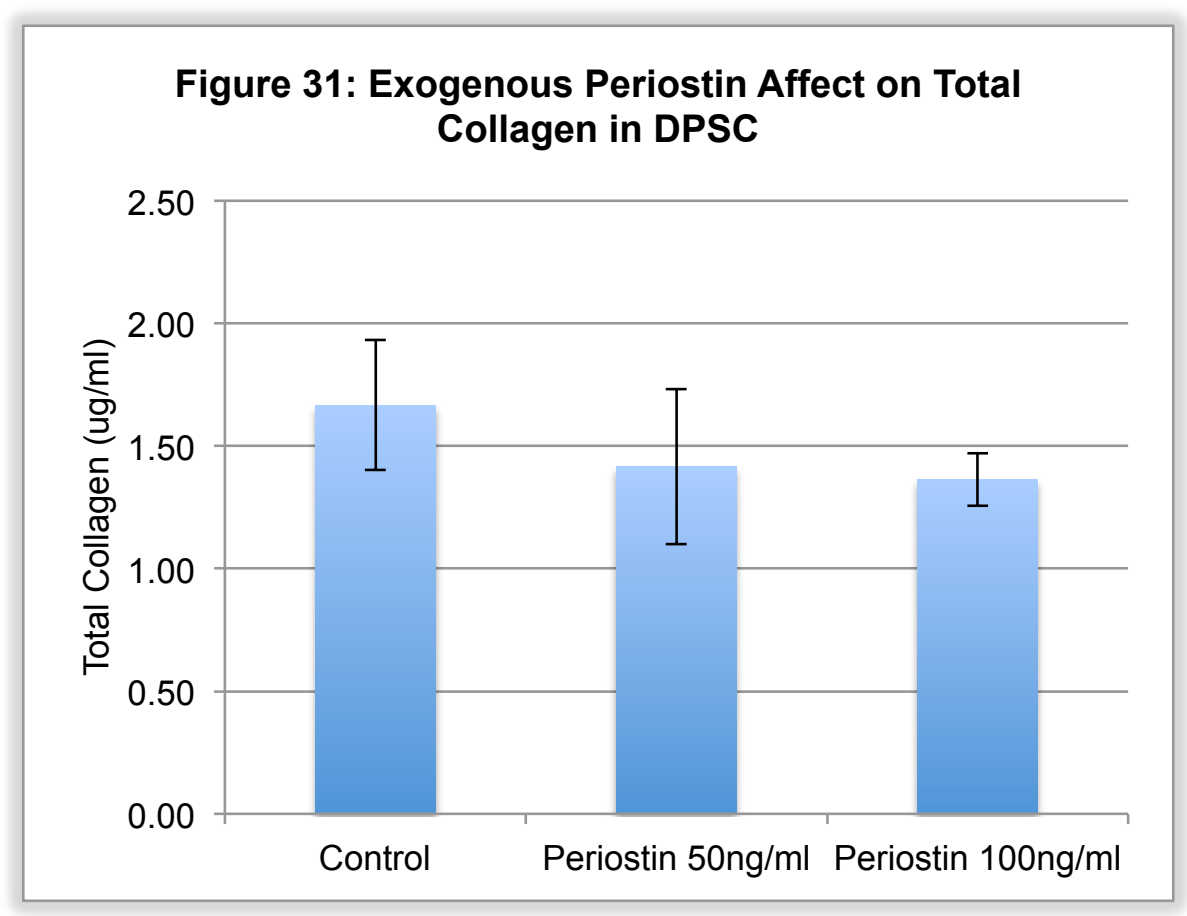

Figure 31: Exogenous Periostin Affect on Total Collagen in DPSC after 48 hours. No statistically significant differences between groups [(P>0.05) Fisher's LSD]

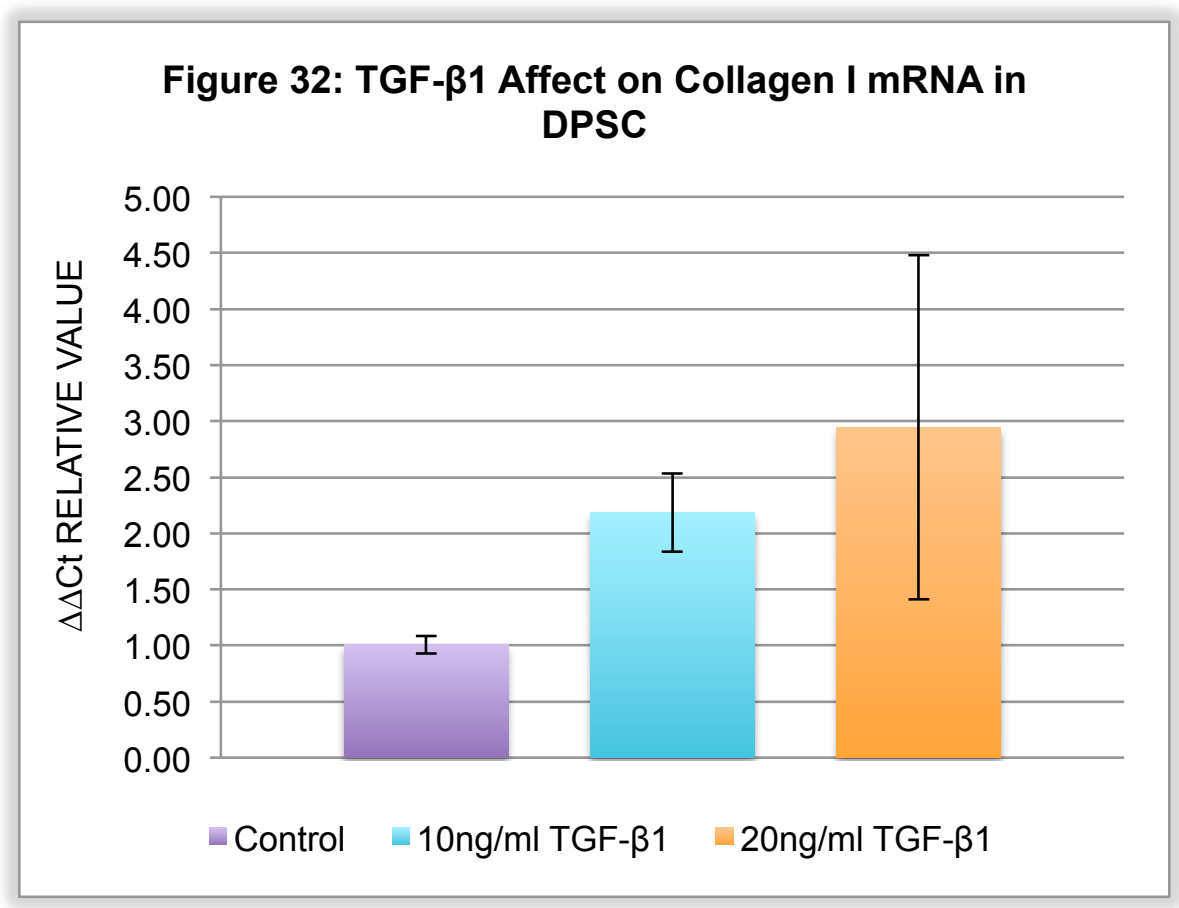

Figure 32: TGF- $\beta 1$ Affect on Collagen I mRNA in DPSC after 48 hours. No statistically significant differences between groups [( $\mathrm{P}>0.05)$ Fisher's LSD] 


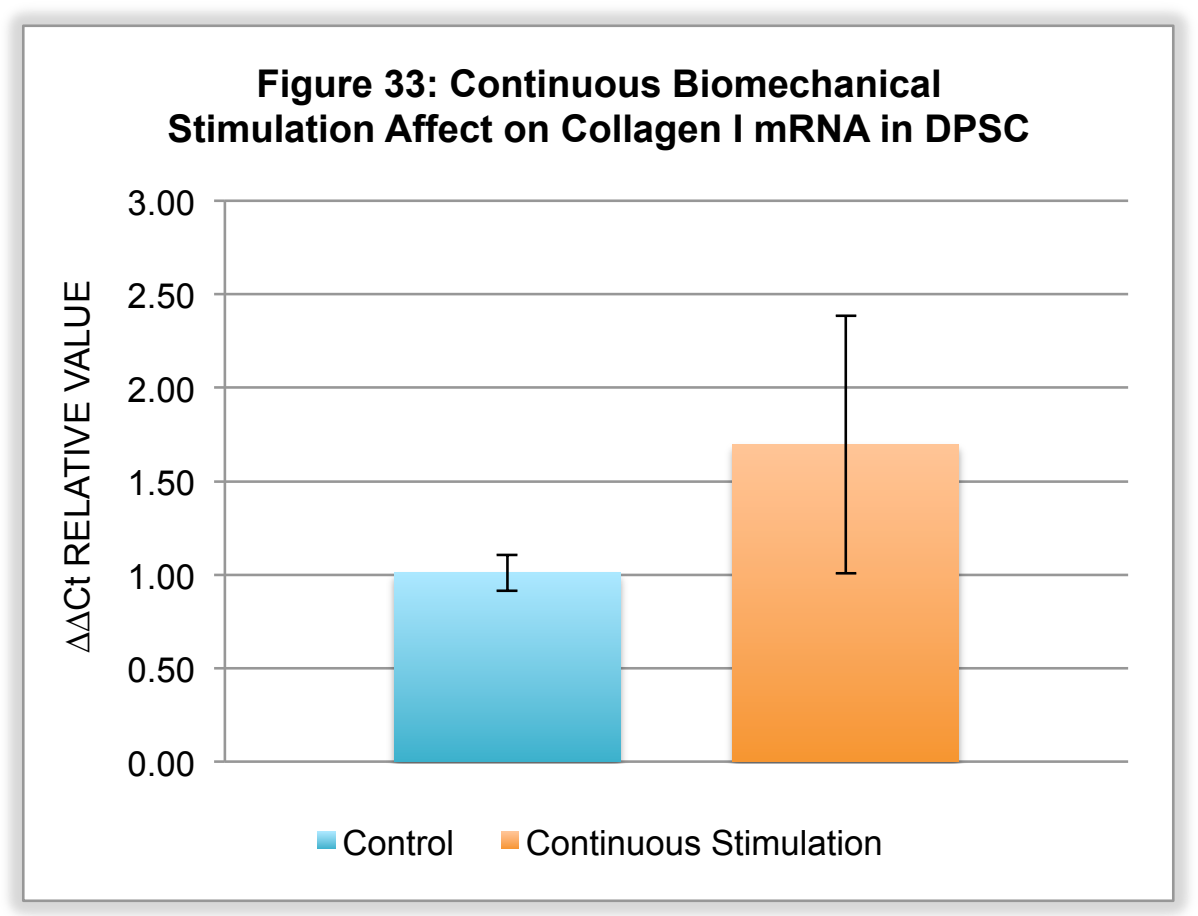

Figure 33: Continuous Biomechanical Stimulation Affect on Collagen I mRNA in DPSC after 48 hours. No statistically significant differences between groups [ $(\mathrm{P}>0.05)$ Student T-test]

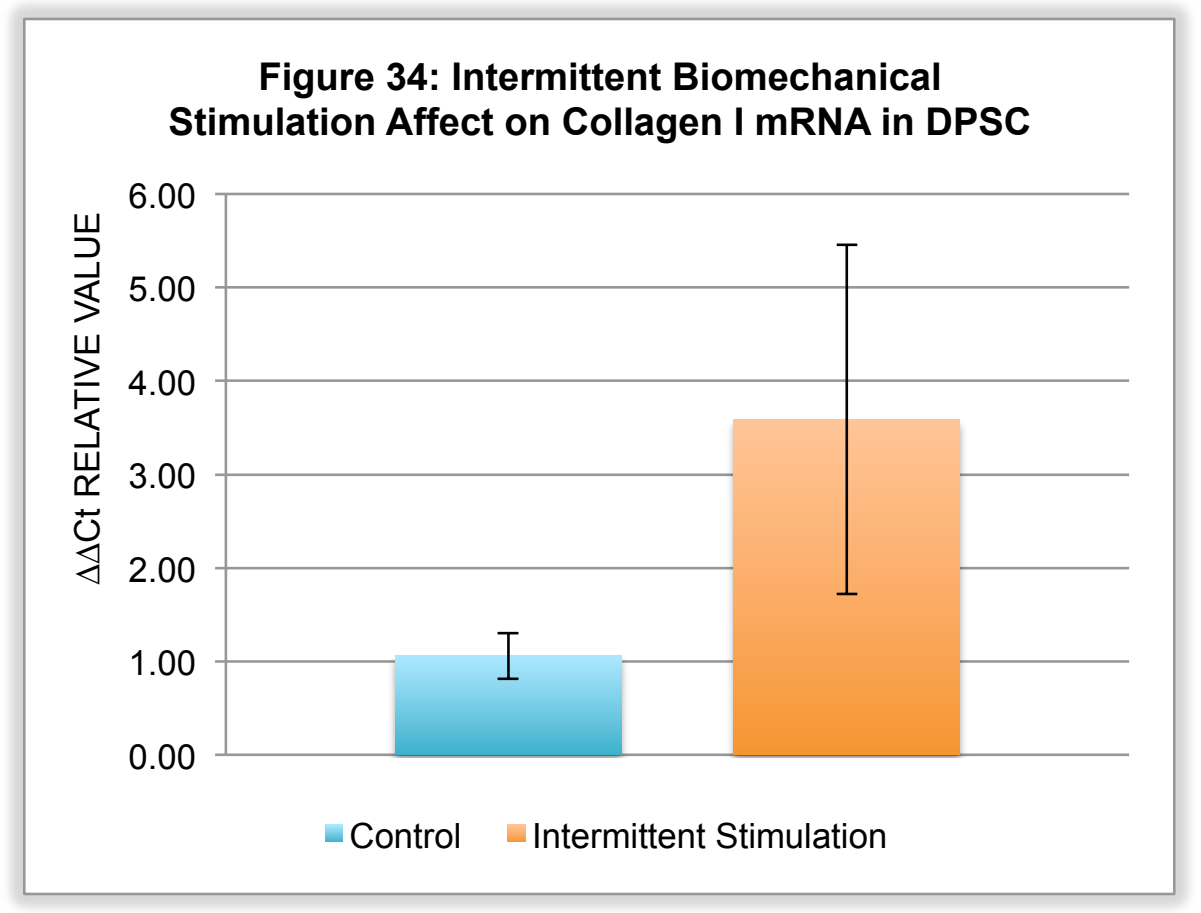

Figure 34: Intermittent Biomechanical Stimulation Affect on Collagen I mRNA in DPSC after 48 hours. No statistically significant differences between groups $[(\mathrm{P}>0.05)$ Student T-test] 


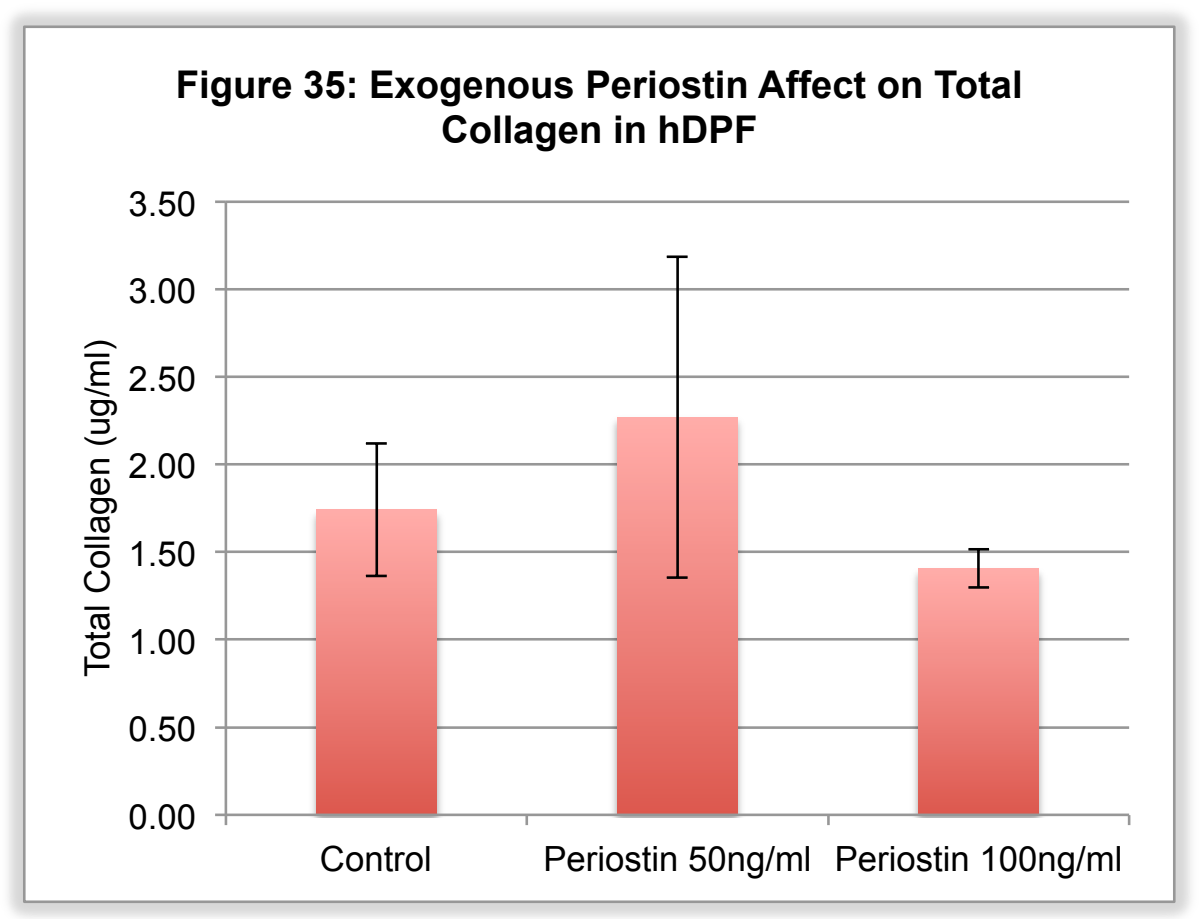

Figure 35: Exogenous Periostin Affect on Total Collagen in DPF after 48 hours. No statistically significant differences between groups [(P>0.05) Fisher's LSD]

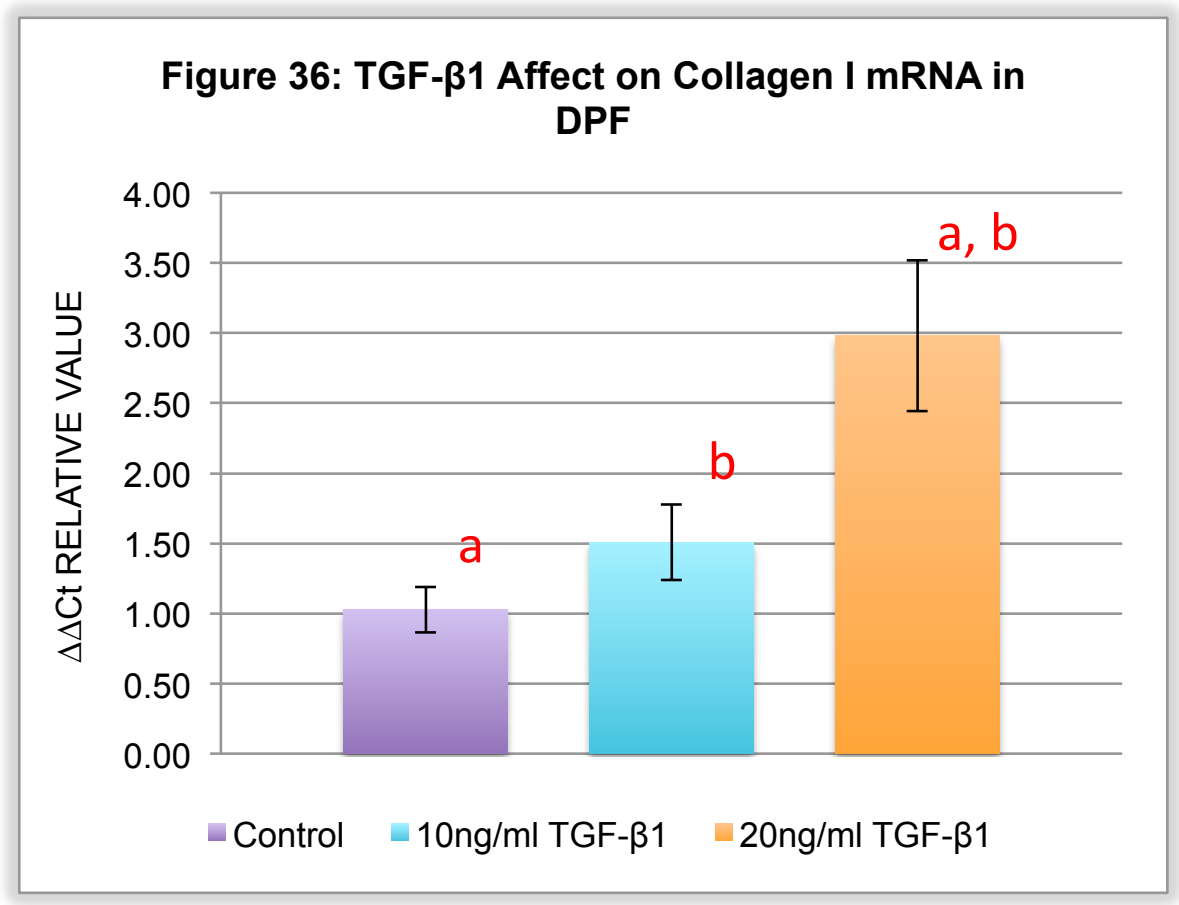

Figure 36: TGF- $\beta 1$ Affect on Collagen I mRNA in DPF after 48 hours. Statistically significant differences [a: $(\mathrm{P}=0.009), \mathrm{b}:(\mathrm{P}=0.027)$; ANOVA LSD] 


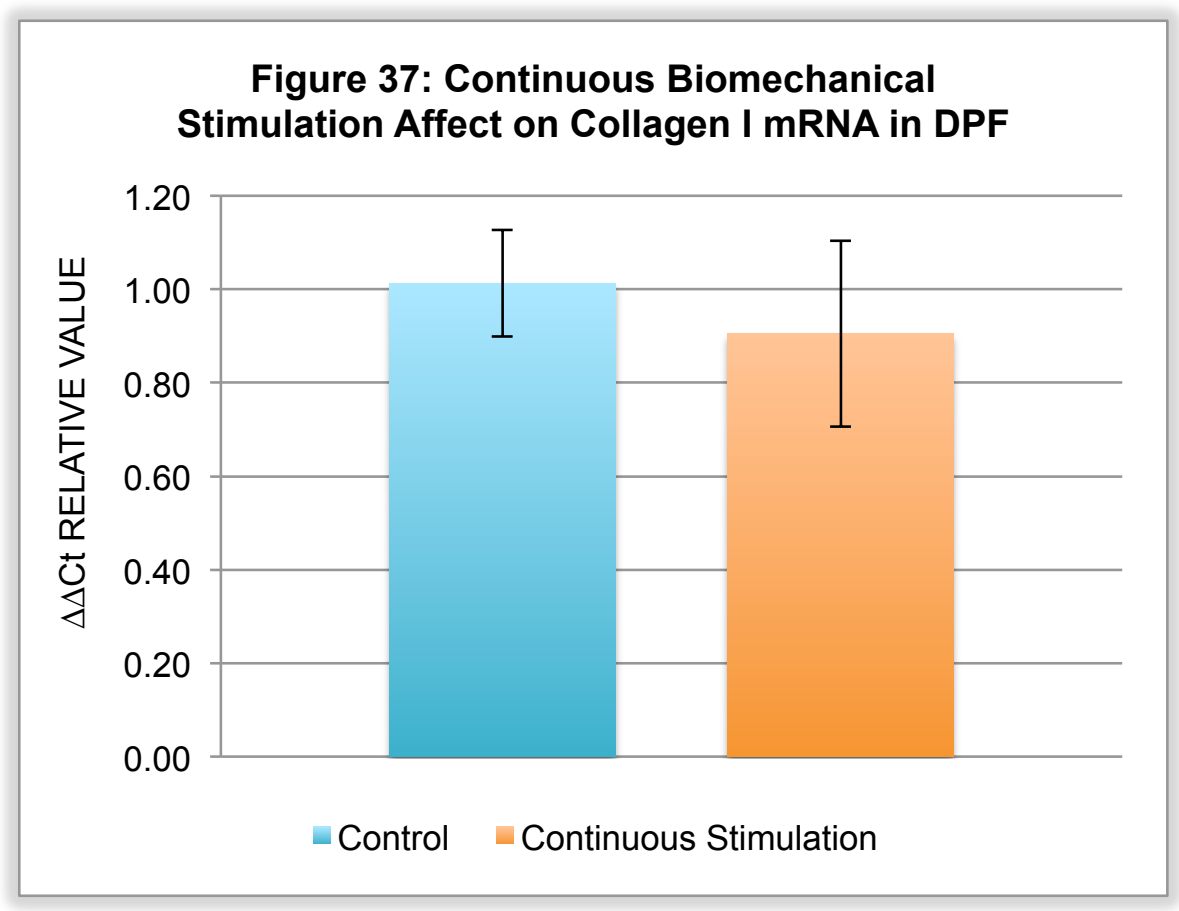

Figure 37: Continuous Biomechanical Stimulation Affect on Collagen I mRNA in DPF after 48 hours. No statistically significant differences between groups $[(\mathrm{P}>0.05)$ Student T-test]

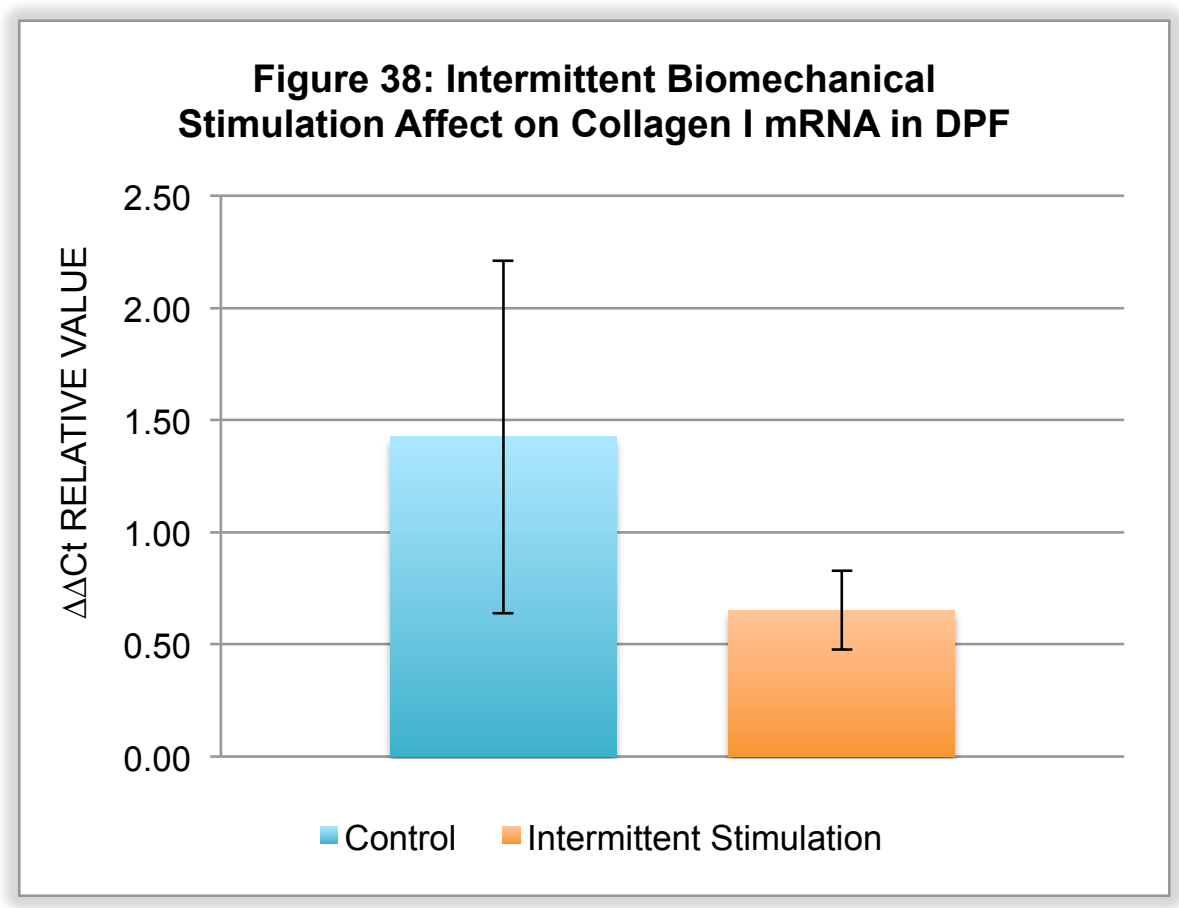

Figure 38: Intermittent Biomechanical Stimulation Affect on Collagen I mRNA in DPF after 48 hours. No statistically significant differences between groups $[(\mathrm{P}>0.05)$ Student T-test] 


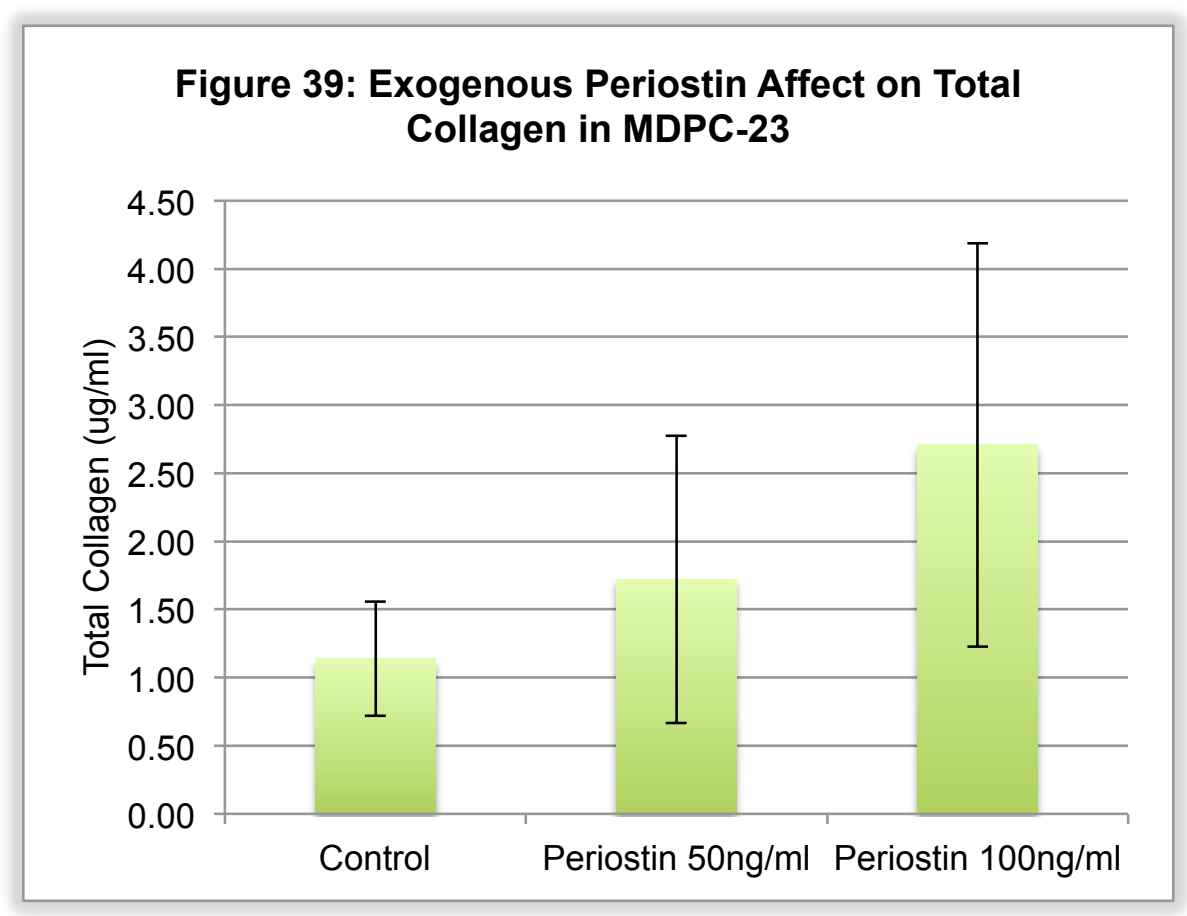

Figure 39: Exogenous Periostin Affect on Total Collagen in MDPC-23 after 48 hours. No statistically significant differences between groups [(P $>0.05)$ Fisher's LSD]

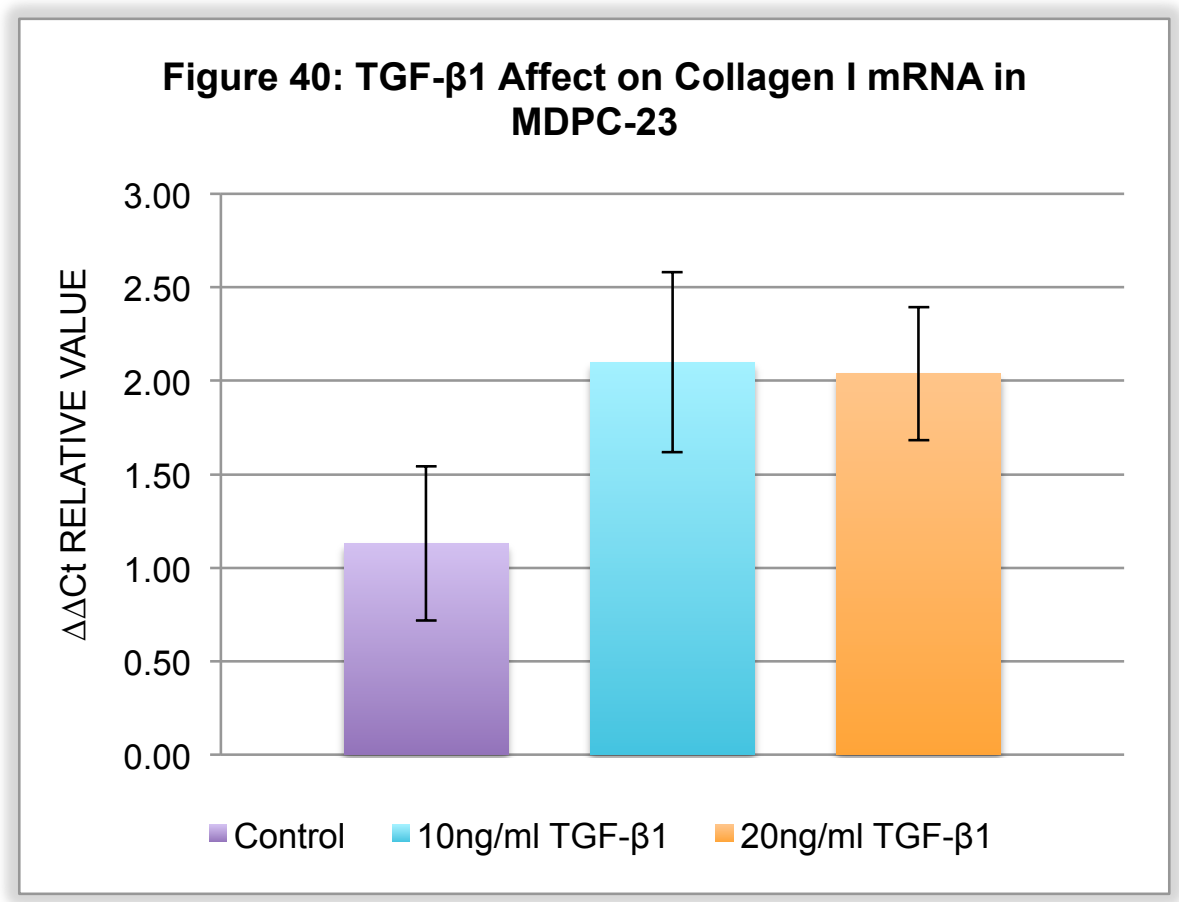

Figure 40: TGF- $\beta 1$ Affect on Collagen I mRNA in MDPC-23 after 48 hours. No statistically significant differences between groups [( $\mathrm{P}>0.05)$ Fisher's LSD] 


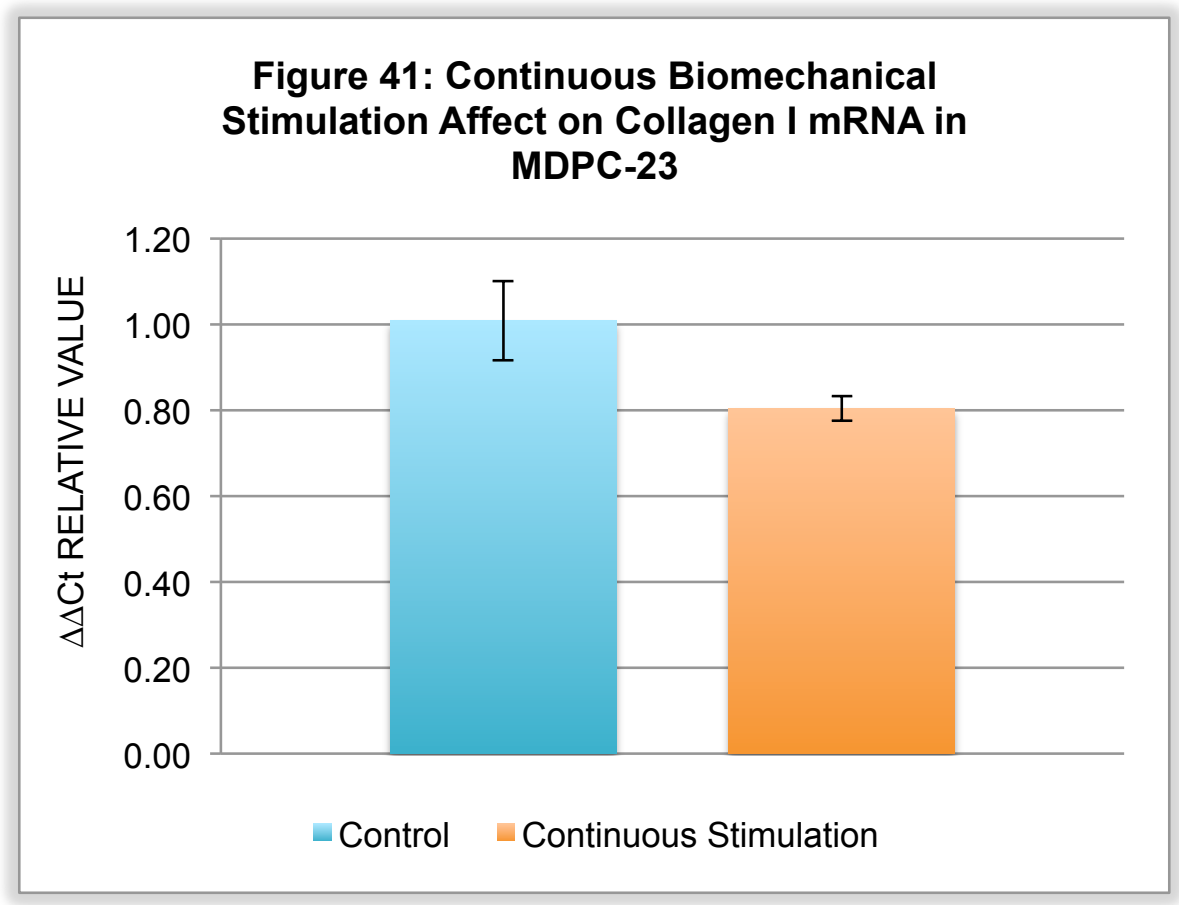

Figure 41: Continuous Biomechanical Stimulation Affect on Collagen I mRNA in MDPC-23 after 48 hours. No statistically significant differences between groups $[(\mathrm{P}>0.05)$ Student T-test $]$

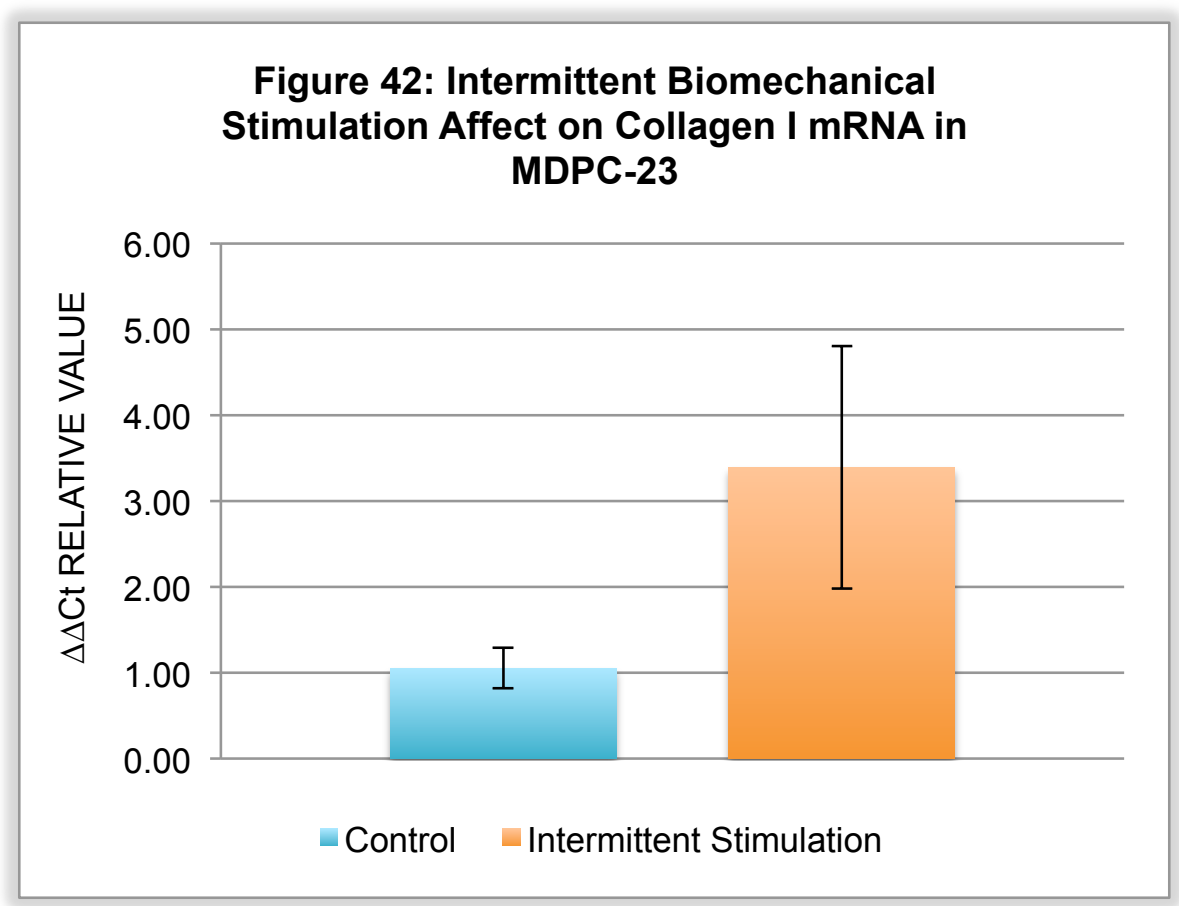

Figure 42: Intermittent Biomechanical Stimulation Affect on Collagen I mRNA in MDPC-23 after 48 hours. No statistically significant differences between groups $[(\mathrm{P}>0.05)$ Student T-test $]$ 


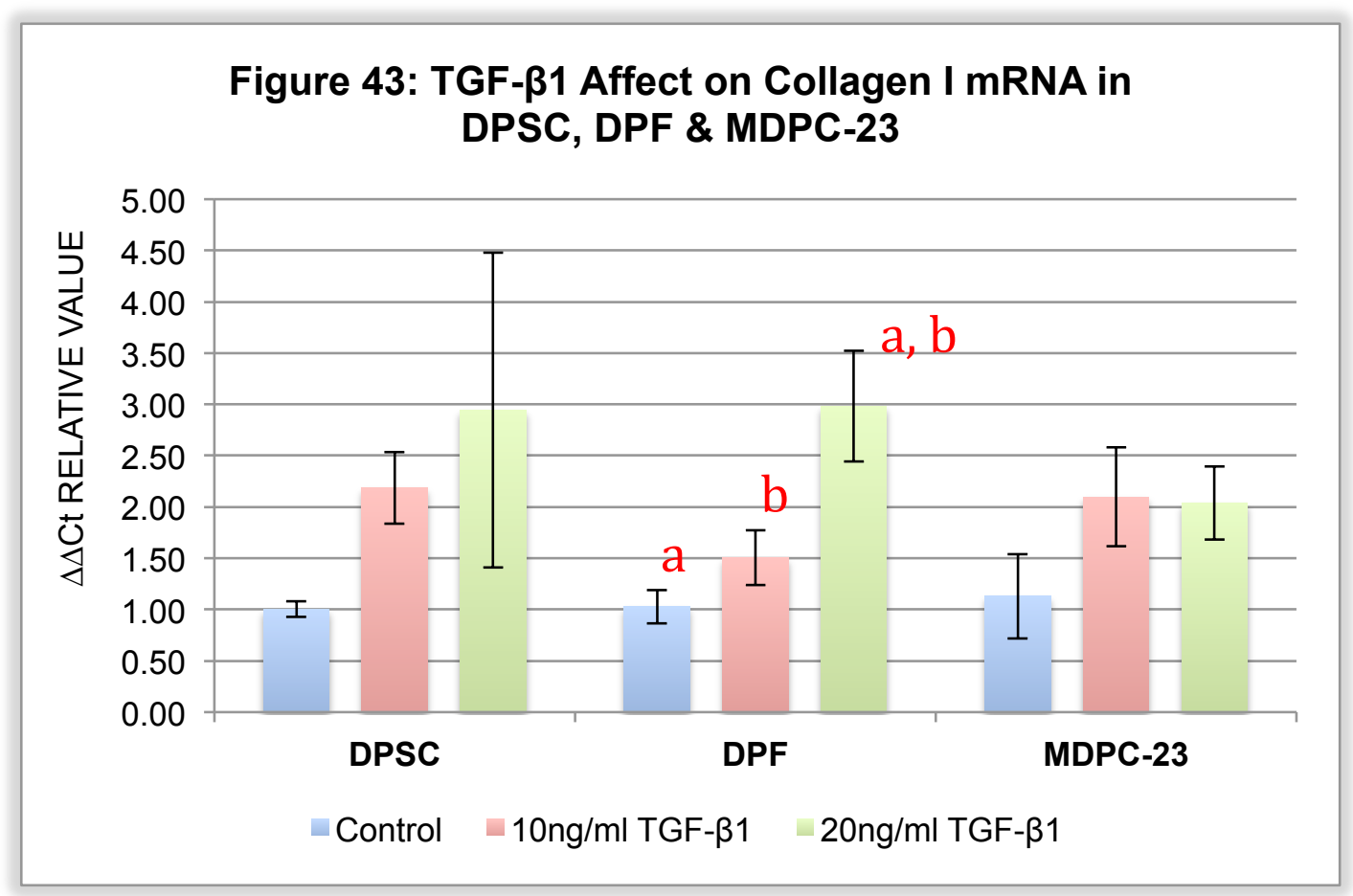

Figure 43: TGF- 11 Affect on Collagen I mRNA in DPSC, DPF \& MDPC-23 after 48 hours. Statistically significant differences [a:( $\mathrm{P}=0.009), \mathrm{b}:(\mathrm{P}=0.027)$; ANOVA LSD]

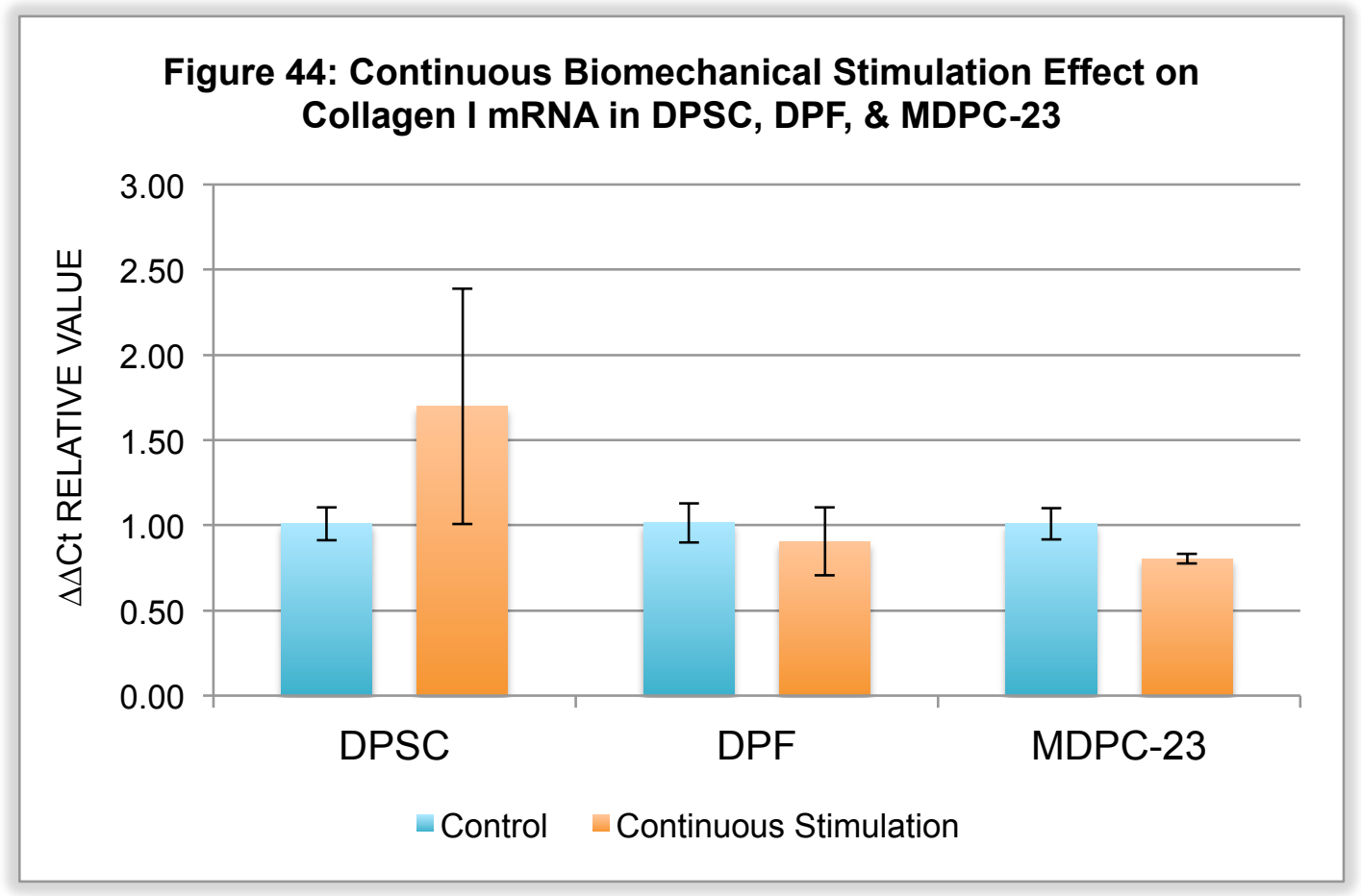

Figure 44: Continuous Biomechanical Stimulation Effect on Collagen I mRNA in DPSC, DPF, \& MDPC-23 after 48 hours. No statistically significant differences between groups $[(\mathrm{P}>0.05)$ Student T-test $]$ 


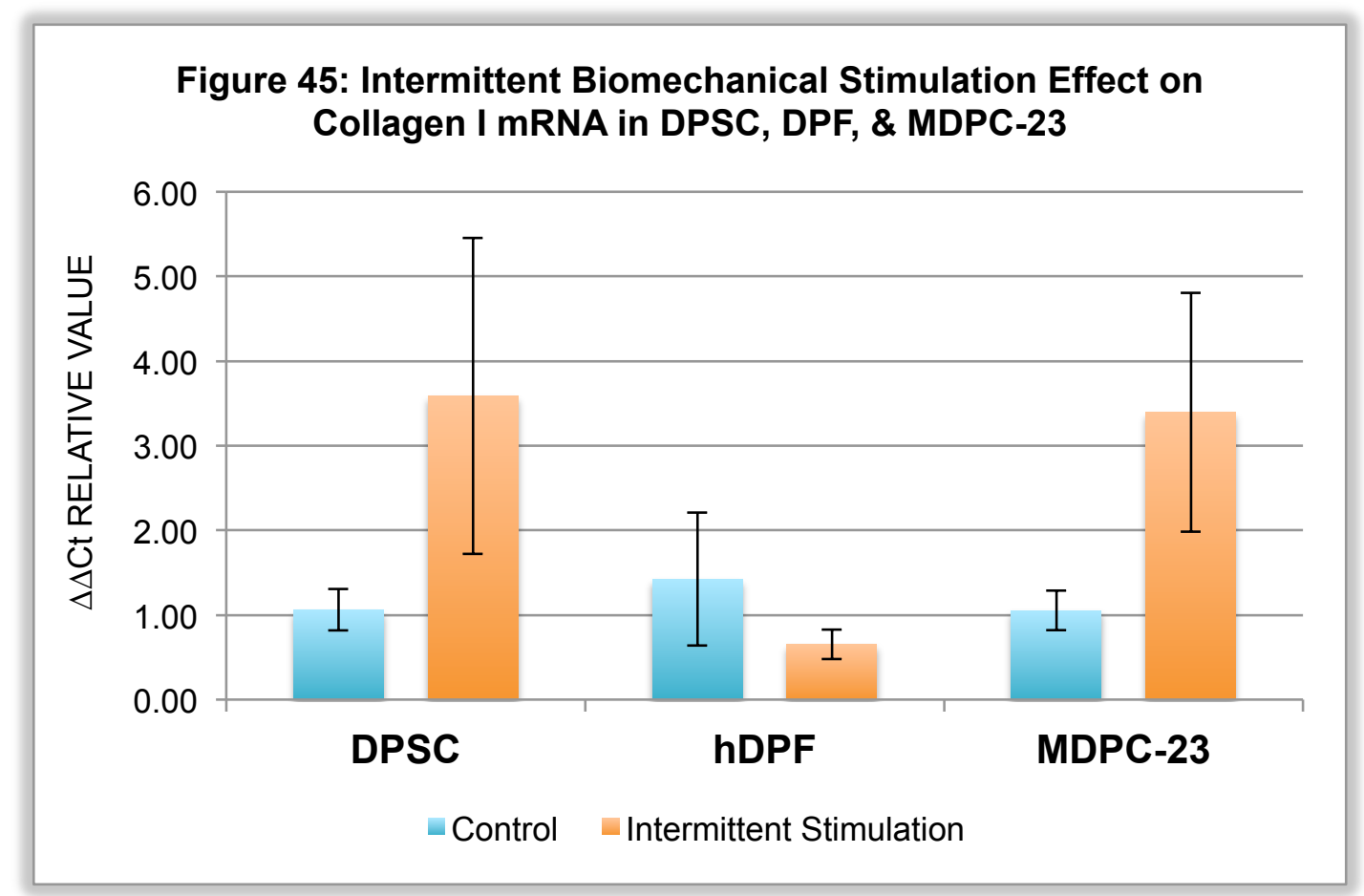

Figure 45: Intermittent Biomechanical Stimulation Effect on Collagen I mRNA in DPSC, DPF, \& MDPC-23 after 48 hours. No statistically significant differences between groups $[(\mathrm{P}>0.05)$ Student $T$-test $]$ 


\begin{tabular}{|c|c|c|c|c|c|c|}
\hline \multicolumn{7}{|c|}{ Box 1: ELISA Mean Values - TGF- $\beta 1$ Effect on Periostin Protein $(\mathrm{ng} / \mathrm{ml})$} \\
\hline & \multicolumn{2}{|c|}{ DPSC } & \multicolumn{2}{|c|}{ DPF } & \multicolumn{2}{|c|}{ MDPC-23 } \\
\hline & MEAN & SEM & MEAN & SEM & MEAN & SEM \\
\hline Control & 1.5081 & 0.0965 & 2.8027 & 0.2739 & 0.0972 & 0.0000 \\
\hline 10ng/ml TGF- $\beta 1$ & 2.9647 & 0.6324 & 1.6725 & 0.1811 & 0.1022 & 0.0032 \\
\hline 20ng/ml TGF- $\beta 1$ & 3.8412 & 0.3871 & 0.9958 & 0.1041 & 0.1134 & 0.0063 \\
\hline
\end{tabular}

Box 2: ELISA Mean Values - Biomechanical Stimulation Effect on Periostin Protein (ng/ml)

\begin{tabular}{|c|c|c|c|c|c|c|}
\hline & \multicolumn{2}{|c|}{ DPSC } & \multicolumn{2}{|c|}{ DPF } & \multicolumn{2}{|c|}{ MDPC-23 } \\
\hline & MEAN & SEM & MEAN & SEM & MEAN & SEM \\
\hline Control & 1.7352 & 0.1519 & 2.2912 & 0.1944 & 0.1143 & 0.0055 \\
\hline Continuous Stimulation & 1.6848 & 0.4402 & 1.7261 & 0.1542 & 0.1225 & 0.0040 \\
\hline Intermittent Stimulation & 1.9864 & 0.0782 & 2.9182 & 0.1729 & 0.1005 & 0.0037 \\
\hline
\end{tabular}

Box 3: Total Collagen Assay Mean Values - Periostin Affect on Total Collagen (ug/ml)

\begin{tabular}{|c|c|c|c|c|c|c|}
\hline & \multicolumn{2}{|c|}{ DPSC } & \multicolumn{2}{|c|}{ DPF } & \multicolumn{2}{|c|}{ MDPC-23 } \\
\hline & MEAN & SEM & MEAN & SEM & MEAN & SEM \\
\hline Control & 1.6665 & 0.2649 & 1.7414 & 0.3782 & 1.1368 & 0.4190 \\
\hline 50ng/ml Periostin & 1.4163 & 0.3163 & 2.2708 & 0.9169 & 1.7216 & 1.0546 \\
\hline 100ng/ml Periostin & 1.3629 & 0.1065 & 1.4069 & 0.1085 & 2.7082 & 1.4826 \\
\hline
\end{tabular}




\section{References Cited}

1. Murray PE, Garcia-Godoy F, Hargreaves KM. Regenerative endodontics: a review of current status and a call for action. J Endod 2007;33(4):377-390.

2. Hargreaves KM, Giesler T, Henry M, Wang Y. Regeneration potential of the young permanent tooth: what does the future hold? J Endod 2008;34(7 Suppl):S51-56.

3. Goldberg M, Six N, Chaussain C, DenBesten P, Veis A, Poliard A. Dentin extracellular matrix molecules implanted into exposed pulps generate reparative dentin: a novel strategy in regenerative dentistry. Journal of dental research 2009;88(5):396-399.

4. Nakao K, Morita R, Saji Y, Ishida K, Tomita Y, Ogawa M, et al. The development of a bioengineered organ germ method. Nat Methods 2007;4(3):227-230. 5. Park CH, Rios HF, Jin Q, Sugai JV, Padial-Molina M, Taut AD, et al. Tissue engineering bone-ligament complexes using fiber-guiding scaffolds. Biomaterials 2012;33(1):137-145.

6. Ajay Sharma L, Sharma A, Dias GJ. Advances in regeneration of dental pulp - a literature review. Journal of Investigative and Clinical Dentistry 2013:n/a-n/a.

7. Goldberg M. Pulp healing and regeneration: more questions than answers. Adv Dent Res 2011;23(3):270-274.

8. Goldberg M, Smith AJ. Cells and Extracellular Matrices of Dentin and Pulp: A Biological Basis for Repair and Tissue Engineering. Crit Rev Oral Biol Med 2004;15(1):13-27.

9. Linde A, Goldberg M. Dentinogenesis. Crit Rev Oral Biol Med 1993;4(5):679728.

10. Linde A, Lundgren T. From serum to the mineral phase. The role of the odontoblast in calcium transport and mineral formation. Int J Dev Biol 1995;39(1):213222.

11. Roberts-Clark DJ, Smith AJ. Angiogenic growth factors in human dentine matrix. Arch Oral Biol 2000;45(11):1013-1016.

12. Ruch JV, Lesot H, Begue-Kirn C. Odontoblast differentiation. Int J Dev Biol 1995;39(1):51-68.

13. Tziafas D, Papadimitriou S. Role of exogenous TGF-beta in induction of reparative dentinogenesis in vivo. Eur J Oral Sci 1998;106 Suppl 1:192-196.

14. Smith AJ, Tobias RS, Plant CG, Browne RM, Lesot H, Ruch JV. In vivo morphogenetic activity of dentine matrix proteins. J Biol Buccale 1990;18(2):123-129.

15. Cooper PR, Takahashi Y, Graham LW, Simon S, Imazato S, Smith AJ. Inflammation-regeneration interplay in the dentine-pulp complex. Journal of dentistry 2010;38(9):687-697.

16. Fitzgerald M, Chiego DJ, Jr., Heys DR. Autoradiographic analysis of odontoblast replacement following pulp exposure in primate teeth. Arch Oral Biol 1990;35(9):707715 .

17. Nair PN, Duncan HF, Pitt Ford TR, Luder HU. Histological, ultrastructural and quantitative investigations on the response of healthy human pulps to experimental capping with mineral trioxide aggregate: a randomized controlled trial. Int Endod J 2008;41(2):128-150.

18. Pereira JC, Stanley HR. Pulp capping: influence of the exposure site on pulp healing--histologic and radiographic study in dogs' pulp. J Endod 1981;7(5):213-223. 
19. Sayegh FS. The dentinal bridge in pulp-involved teeth. I. Oral Surg Oral Med Oral Pathol 1969;28(4):579-586.

20. Smith AJ, Cassidy N, Perry H, Begue-Kirn C, Ruch JV, Lesot H. Reactionary Dentinogenesis. Int J Dev Biol 1995;39(1):273-280.

21. Hamilton DW. Functional role of periostin in development and wound repair: implications for connective tissue disease. J Cell Commun Signal 2008;2(1-2):9-17.

22. Takeshita S. Osteoblast-specific factor 2 cloning of a putative bone adhesion protein with homology with the insect protein fasciclin I. Biochem. J. 1993(294):271278.

23. Horiuchi K, Amizuka N, Takeshita S, Takamatsu H, Katsuura M, Ozawa H, et al. Identification and characterization of a novel protein, periostin, with restricted expression to periosteum and periodontal ligament and increased expression by transforming growth factor beta. J Bone Miner Res 1999;14(7):1239-1249.

24. Rios HF, Ma D, Xie Y, Giannobile WV, Bonewald LF, Conway SJ, et al. Periostin is essential for the integrity and function of the periodontal ligament during occlusal loading in mice. Journal of periodontology 2008;79(8):1480-1490.

25. Rios H, Koushik SV, Wang H, Wang J, Zhou HM, Lindsley A, et al. periostin null mice exhibit dwarfism, incisor enamel defects, and an early-onset periodontal disease-like phenotype. Mol Cell Biol 2005;25(24):11131-11144.

26. Oka K, Honda MJ, Tsuruga E, Hatakeyama Y, Isokawa K, Sawa Y. Roles of Collagen and Periostin Expression by Cranial Neural Crest Cells during Soft Palate Development. Journal of Histochemistry \& Cytochemistry 2011;60(1):57-68.

27. Ma D, Zhang R, Sun Y, Rios HF, Haruyama N, Han X, et al. A novel role of periostin in postnatal tooth formation and mineralization. J Biol Chem 2011;286(6):43024309.

28. Bao S, Ouyang G, Bai X, Huang Z, Ma C, Liu M, et al. Periostin potently promotes metastatic growth of colon cancer by augmenting cell survival via the Akt/PKB pathway. Cancer Cell 2004;5(4):329-339.

29. Norris RA, Damon B, Mironov V, Kasyanov V, Ramamurthi A, MorenoRodriguez R, et al. Periostin regulates collagen fibrillogenesis and the biomechanical properties of connective tissues. J Cell Biochem 2007;101(3):695-711.

30. Wen W, Chau E, Jackson-Boeters L, Elliott C, Daley TD, Hamilton DW. TGF- 1 and FAK Regulate Periostin Expression in PDL Fibroblasts. Journal of dental research 2010;89(12):1439-1443.

31. Suzuki H, N A, Kil I, Maeda T. Immunohistochemical Localization of Periosint in Tooth and Its Surrounding Tissues in Mouse Mandibles During Development. The Anatomical Record Part A 2004;281A:1264-1275.

32. Zhou M, Kawashima N, Suzuk N, Yamamoto M, Ohnishi K, Katsube K, et al. Periostin is a negative regulator of mineralization in the dental pulp tissue. Odontology 2014.

33. Goldberg M, Kulkami A, Young M, Boskey A. Dentin; structure, composition and mineralization. Frontiers in bioscience 2011;3:711-735.

34. Gronthos S, Mankani M, Brahim J, Robey PG, Shi S. Postnatal human dental pulp stem cells (DPSCs) in vitro and in vivo. Proceedings of the National Academy of Sciences of the United States of America 2000;97(25):13625-13630. 
35. Heyeraas KJ, Berggreen E. Interstitial fluid pressure in normal and inflamed pulp. Crit Rev Oral Biol Med 1999;10(3):328-336.

36. Bakland L, Andreasen JO. Dental traumatology: essential diagnosis and treatment planning. Endodontic Topics 2004;7:14-34.

37. Cassidy N, Fahey M, Prime SS, Smith AJ. Comparative Analysis of Transforming Growth Factor-B Isoforms 1-3 in Human and Rabbit Dentine Matrices. Arch Oral Biol 1997;42(3):219-223.

38. Sloan AJ, Smith AJ. Stimulation of the dentine \pm pulp complex of rat incisor teeth by transforming growth factor-b isoforms $1 \pm 3$ in vitro. Arch Oral Biol 1999;44:149-156. 39. Mjör. Pulp-dentin biology in restorative dentistry: part 5-clinical management and tissue changes associated with wear and trauma. Quintessence Int 2001(32):771778 .

40. Lee S-K, Lee C-Y, Kook Y-A, Lee S-K, Kim E-C. Mechanical stress promotes odontoblastic differentiation via the heme oxygenase-1 pathway in human dental pulp cell line. Life Sciences 2010;86(3-4):107-114.

41. Unterbrink A, O'Sullivan M, Chen S, MacDougall M. TGF $\beta$-1 Downregulates DMP-1 and DSPP in Odontoblasts. Connect Tissue Res 2002;43(2-3):354-358.

42. Berue-Kirn C, Smith AJ, Ruch JV, Wozney JM, Purchio A, Hartmann D, et al. Effects of dentin proteins, transforming growth factor beta 1 (TGFbeta1) and bone morphogenetic protein 2 (BMP2) on the differentiation of odontoblast in vitro. Int. J. Dev. Biol. 1992;36:491-503.

43. Padial-Molina M, Volk SL, Rodriguez JC, Marchesan JT, Galindo-Moreno P, Rios HF. TNF-Alpha and P. gingivalis Lipopolysaccharides Decrease Periostin in Human PDL Fibroblasts. Journal of periodontology 2012.

44. Hata M, Naruse K, Ozawa S, Kobayashi Y, Nakamura N, Kojima N, et al. Mechanical Stretch Increases the Proliferation While Inhibiting the Osteogenic Differentiation in Dental Pulp Stem Cells. Tissue Engineering Part A 2013;19(5-6):625633.

45. Lee S-K, Min K-S, Kim Y, Jeong G-S, Lee S-H, Lee H-J, et al. Mechanical Stress Activates Proinflammatory Cytokines and Antioxidant Defense Enzymes in Human Dental Pulp Cells. J Endod 2008;34(11):1364-1369.

46. Butler WT, Ritchie $\mathrm{H}$. The nature and functional significane of dentin extracellular matrix proteins. Int. J. Dev. Biol. 1995;39:169-179.

47. Botero TM, Son JS, Vodopyanov D, Hasegawa M, Shelburne CE, Nor JE. MAPK signaling is required for LPS-induced VEGF in pulp stem cells. Journal of dental research 2010;89(3):264-269.

48. Hanks CT, Sun ZL, Fang DN, Edwards CA, Wataha JC, Ritchie HH, et al. Cloned $3 \mathrm{~T} 6$ cell line from CD-1 mouse fetal molar dental papillae. Connect Tissue Res 1998;37(3-4):233-249.

49. Sloan AJ PH, Matthews JB, Smith AJ. . Transforming growth factor-B isoform expression in mature human healthy and carious molar teeth. Histochem J 2000(32):247252.

50. Livak K. Analysis of Relative Gene Expression Data Using Real-Time Quantitative PCR and the 2- $\Delta \Delta$ CT Method. Methods 2001;25(4):402-408. 
51. Sloan AJ, Couble ML, Bleicher F, Magloire H, Smith AJ, Farges JC. Expression of TGF- Receptors I and II in the Human Dental Pulp by in situ Hybridization. Adv Dent Res 2001;15(1):63-67.

52. Massague J. The transforming growth factor-beta family. Annu. Rev. Cell. Biol. 1990;6:597-641.

53. Padial-Molina M, Volk SL, Taut AD, Giannobile WV, Rios HF. Periostin is Down-regulated during Periodontal Inflammation. Journal of dental research 2012;91(11):1078-1084.

54. Weyts FAA, Bosmans B, Niesing R, Leeuwen JPTM, Weinans H. Mechanical Control of Human Osteoblast Apoptosis and Proliferation in Relation to Differentiation. Calcified Tissue International 2003;72(4):505-512.

55. Yu V, Damek-Poprawa M, Nicoll SB, Akintoye SO. Dynamic hydrostatic pressure promotes differentiation of human dental pulp stem cells. Biochemical and Biophysical Research Communications 2009;386(4):661-665.

56. Yu, YJ X, D X, Zhao S-L. Effect of cyclic strain on cell morphology, viability and proliferation of human dental pulp cells in vitro. Shanghai Kou Qiang Yi Xue 2009;18(6):599-603.

57. Cook B, Hardy RW, McConnaughey WB, Zuker CS. Preserving cell shape under environmental stress. Nature 2008;452(7185):361-364.

58. Subay R, Kaya H, Tarim B, Subay A, Cox C. Response of Human Pulpal Tissue to Orthodontic Extrusive Applications. J Endod 2001;27(8):508-511.

59. Begue-Kirn C, Smith AJ, Ruch JV, Wozney JM, Purchio A, Hartmann D, et al. Effects of dentin proteins, transforming growth factor beta 1 (TGFbeta1) and bone morphogenetic protein 2 (BMP2) on the differentiation of odontoblast in vitro. Int. J. Dev. Biol. 1992;36:491-503.

60. Takamori Y SH, Nakakura-Ohshima K, Cai J, Cho SW, Jung HS OH. Capacity of dental pulp differentiation in mouse molars as demonstrated by allogenic tooth transplantation. J Histochem Cytochem. 2008(56):1075-1086.

61. Thyagarajan T, Sreenath T, Cho A, Wright JT, AB. K. Reduced expression of dentin sialophosphoprotein is associated with dysplastic dentin in mice overexpressing transforming growth factor-beta 1 in teeth. J Biol Chem 2001;276(14):11016-11020. 